\title{
Ordered Adlayers of a Combined Lateral Switch and Rotor
}

Talina R. Rusch ${ }^{\dagger}$ Alexander Schlimm, ${ }^{\ddagger}$ Nicolai R. Krekiehn, ${ }^{\dagger}$ Benedikt M. Flöser, ${ }^{\ddagger}$

Fynn Röhricht, "Melanie Hammerich, "Irene Lautenschläger, $\ddagger$ Thomas

Strunskus, ${ }^{\S}$ Rainer Herges, ${ }^{*}$. Felix Tuczek, ${ }^{*,+}$ and Olaf M. Magnussen ${ }^{*, \dagger}$

$\dagger$ Institute of Experimental and Applied Physics, Christian Albrechts University Kiel, Germany

$\ddagger$ Institute of Inorganic Chemistry, Christian Albrechts University Kiel, Germany

\Otto Diels Institute of Organic Chemistry, Christian Albrechts University Kiel, Germany

$\S$ Institute for Materials Science, Christian Albrechts University Kiel, Germany

E-mail: rherges@oc.uni-kiel.de; ftuczek@ac.uni-kiel.de; magnussen@physik.uni-kiel.de 


\section{Supporting Information}

Table S1: Surface coverage of samples prepared after (c) determined by STM, UV/Vis spectroscopy, XPS and theoretically calculated.

\begin{tabular}{l|l|l} 
Method & Source & $\theta$ in $\mathrm{nm}^{-2}$ \\
\hline STM & Counted molecules & $0.36 \pm 0.02$ \\
$\mathrm{UV} /$ Vis & Absolut spectrum & $0.79 \pm 0.03$ \\
$\mathrm{UV} /$ Vis & Difference $\pi-\pi^{*}$ band & $0.37 \pm 0.04$ \\
$\mathrm{XPS}$ & $\mathrm{N}$ 1s signal & $0.45 \pm 0.03$ \\
$\mathrm{XPS}$ & $\mathrm{C}$ 1s signal & $0.32 \pm 0.05$ \\
Theoretical & calculated from ideal $(\sqrt{31} \times \sqrt{31}) R 8.9^{\circ}$ superstructure & \\
Theoretical & $(1$ molecule per unit cell $)$ & 0.45 \\
& $\begin{array}{l}\text { calculated from ideal }(\sqrt{31} \times \sqrt{31}) R 8.9^{\circ} \text { superstructure } \\
(0.5 \text { molecules per unit cell })\end{array}$ & 0.23
\end{tabular}


STM

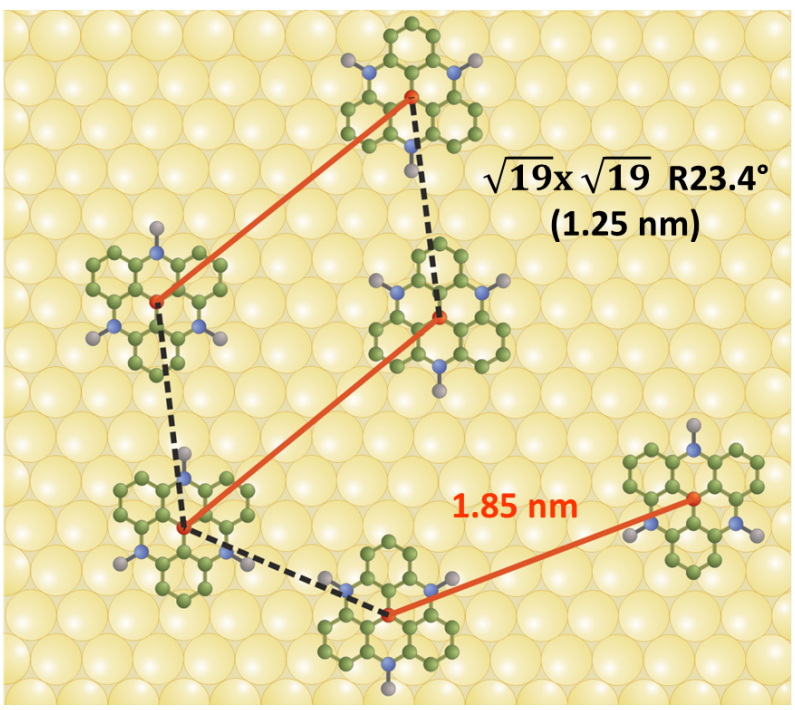

Figure S1: Model of the adsorbed molecules $\mathbf{1}$ in disordered areas (samples of type I). The red lines represent the vertical phenyl-azobenzene-phenyl units between the TATA platforms with an intramolecular distance of $1.85 \mathrm{~nm}$. The dashed black lines indicate the distance corresponding to a $\sqrt{19} \times \sqrt{19}) R 23.4^{\circ}$ with an intermolecular distance of $1.25 \mathrm{~nm}$ 


\section{XPS}

Table S2: Results obtained from quantitative XPS measurements.

\begin{tabular}{l|l|l|l|l|l|l} 
Compound & Transition & Excitation energy & Scans & Intensity & IPS & ratio \\
\hline $\mathbf{1}$ & N 1s & $500 \mathrm{eV}$ & 16 & 64000 & 4000 & 0.00079 \\
$\mathbf{1}$ & $\mathrm{Au} \mathrm{4f}$ & $500 \mathrm{eV}$ & 3 & 15253000 & 5084333 & 0.00079 \\
$\mathbf{1}$ & $\mathrm{C} \mathrm{1s}$ & $350 \mathrm{eV}$ & 5 & 1771000 & 354200 & 0.16877 \\
$\mathbf{1}$ & $\mathrm{Au} \mathrm{4f}$ & $350 \mathrm{eV}$ & 3 & 6296000 & 2098667 & 0.16877 \\
$\mathbf{2}$ & $\mathrm{N} 1 \mathrm{~s}$ & $500 \mathrm{eV}$ & 10 & 63000 & 6300 & 0.00080 \\
$\mathbf{2}$ & $\mathrm{Au} \mathrm{4f}$ & $500 \mathrm{eV}$ & 3 & 23740000 & 7913333 & 0.00080 \\
$\mathbf{2}$ & $\mathrm{C} \mathrm{1s}$ & $350 \mathrm{eV}$ & 5 & 2007000 & 401400 & 0.11931 \\
$\mathbf{2}$ & $\mathrm{Au} \mathrm{4f}$ & $350 \mathrm{eV}$ & 3 & 10092000 & 3364333 & 0.11931
\end{tabular}

Table S3: Comparison of theoretical and experimental N 1s/ Au $4 \mathrm{f}$ and $\mathrm{C}$ 1s/ $\mathrm{Au} 4 \mathrm{f}$ ratios.

\begin{tabular}{l|l|l|l|l} 
Type & $\begin{array}{l}\text { Measured Ra- } \\
\text { tio 2 }\end{array}$ & $\begin{array}{l}\text { Theoretical Ra- } \\
\text { tio for } \mathbf{1} \text { with } \\
1 \text { mol. per unit } \\
\text { cell }\end{array}$ & $\begin{array}{l}\text { Theoretical Ra- } \\
\text { tio for } \mathbf{1} \text { with } \\
1 / 2 \text { mol. per } \\
\text { unit cell }\end{array}$ & $\begin{array}{l}\text { Measured Ra- } \\
\text { tio } \mathbf{1}\end{array}$ \\
\hline $\mathrm{N} \mathrm{1s/Au} \mathrm{4f}$ & 0.00080 & 0.00079 & 0.00039 & 0.00079 \\
$\mathrm{C} \mathrm{1s} / \mathrm{Au} \mathrm{4f}$ & 0.11931 & 0.14650 & 0.07320 & 0.16879
\end{tabular}

Table S4: Fitting parameters for XPS data

\begin{tabular}{l|l|l|l|l} 
Component & Signal & Binding Energy $(\mathrm{eV})$ & Area $(\%)$ & fwhm \\
\hline TATA & N 1s & 399.4 & 72.6 & 1.1 \\
Azo & N 1s & 399.9 & 27.4 & 1.1 \\
Major Comp. & C 1s & 284.6 & 82.8 & 1.3 \\
Minor Comp. & C 1s & 285.7 & 17.2 & 1.5
\end{tabular}




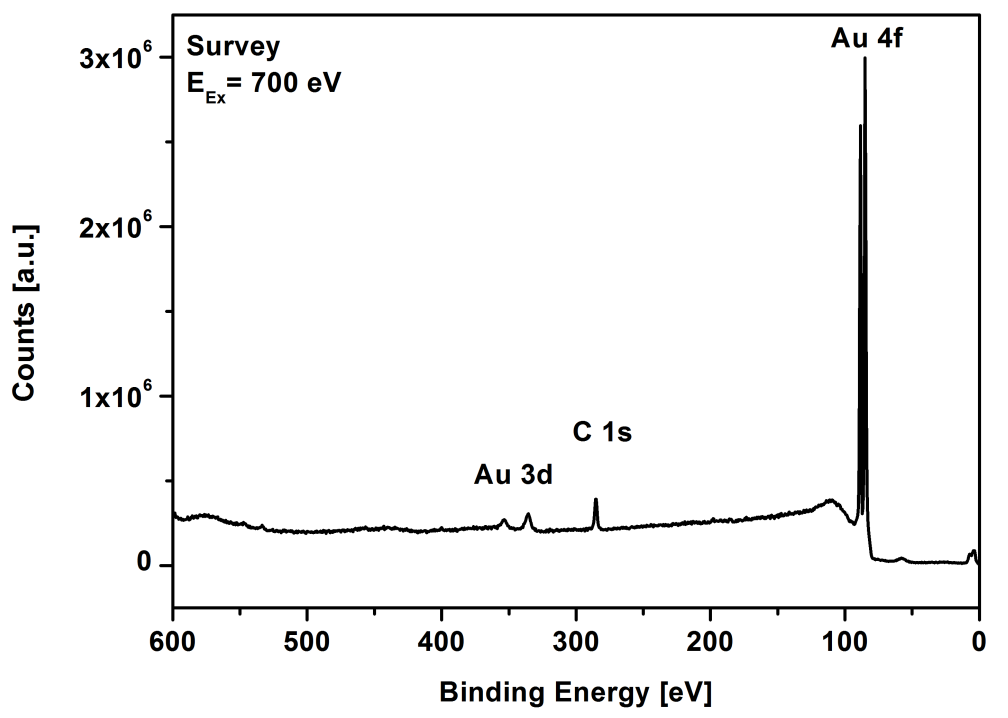

Figure S2: XP spectra of the $\mathbf{1}$ monolayer on $\mathrm{Au}(111)$ showing the survey recorded at a photon energy of $\mathrm{h} \nu=700 \mathrm{eV}$. 


\section{NEXAFS}

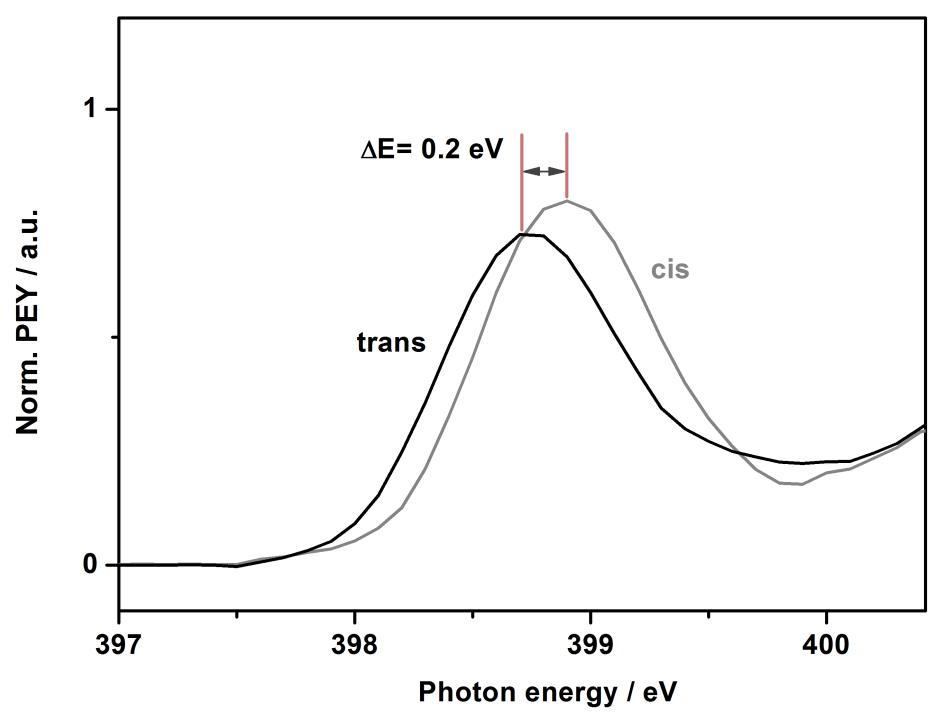

Figure S3: N 1s NEXAFS spectra of the LUMO resonance of the azo moiety after irradiation with light of $365 \mathrm{~nm}$ (grey) and after irradiation with light of $440 \mathrm{~nm}$ (black). 
a

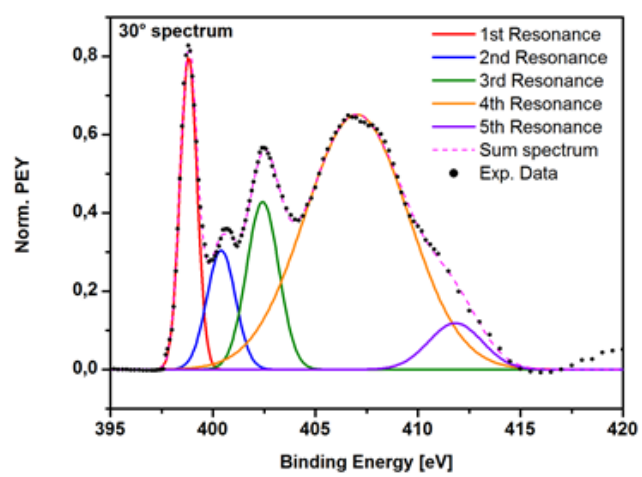

C

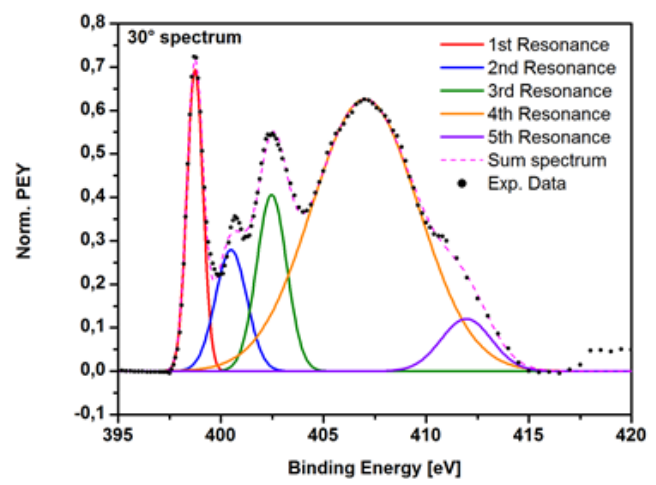

b

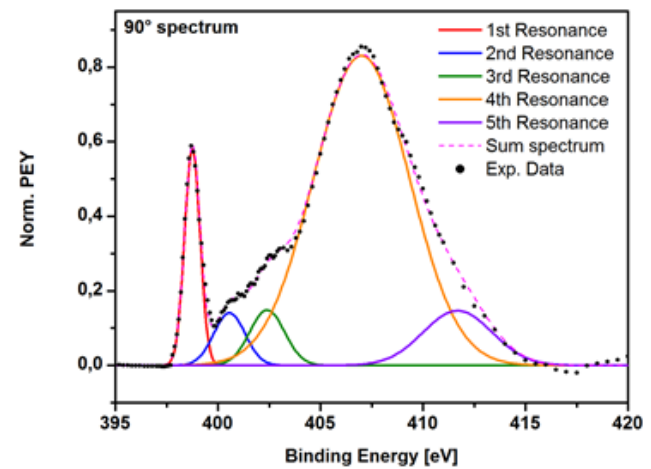

d

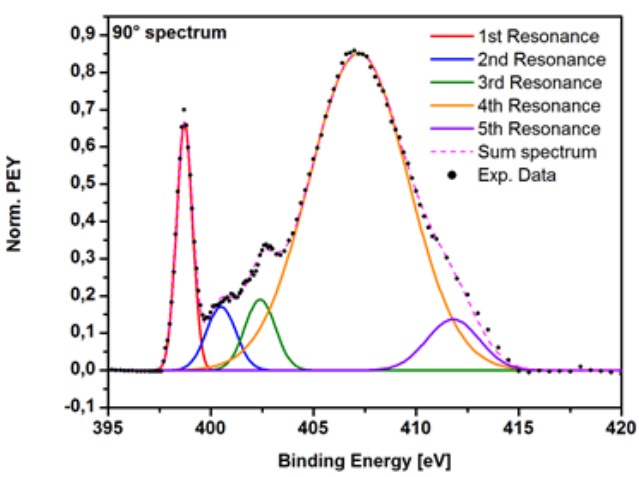

Figure S4: N-NEXAFS spectra ( $\mathrm{a}$ and $\mathrm{b}$ cis, c and d trans) fitted with Gaussians to determine the intensity of the resonances. The spectra were baseline-substracted and afterwards fitted like described in the experimental section. 


\section{Computational Details}

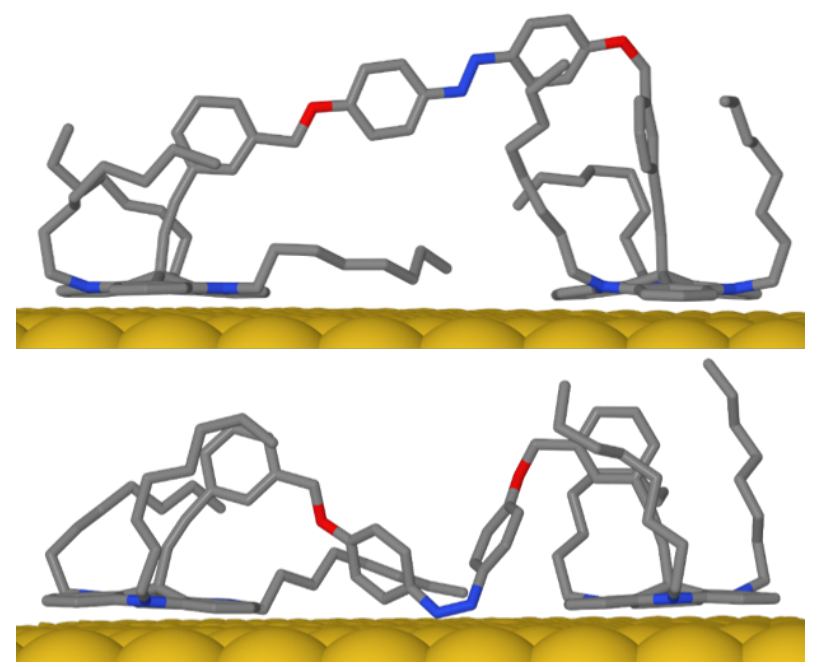

Figure S5: Local energy minima of trans (top) and cis isomer (bottom) conducted with the semiempiric approach. 

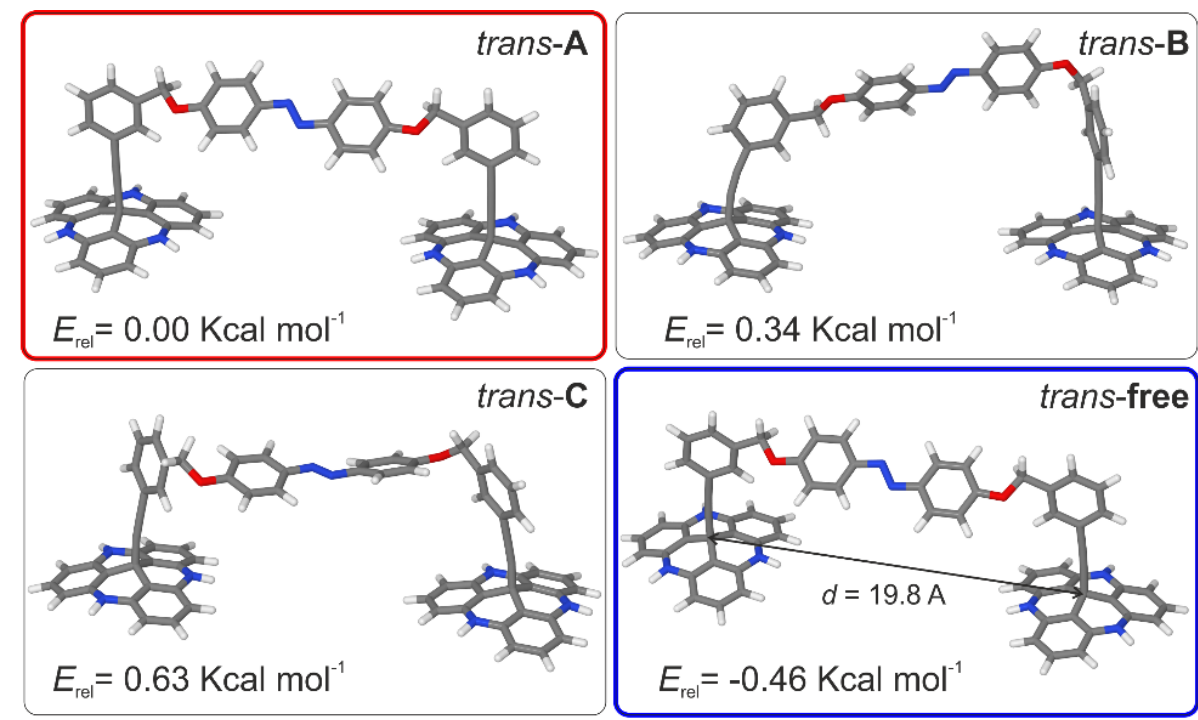

Energies: M06-2X(D3)/def2-TZVPP//B3LYP/6-31G*
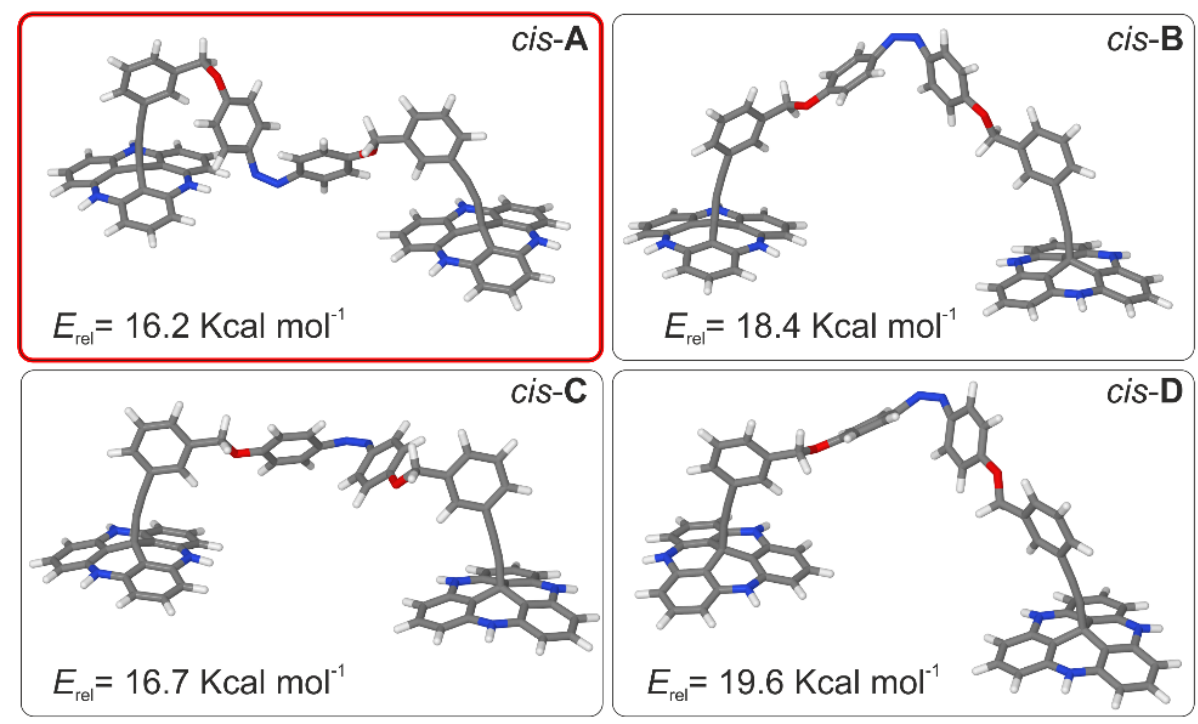

Figure S6: Local energy minima of 3 nearly isoenergetic trans isomers (top) and 4 cis isomers (bottom) with an intramolecular distance of $18.5 \AA$. Each most stable isomer is marked red. Additionally the most stable trans isomer was reoptimized without the constraint of intramolecular distance, yielding an also isoenergetic structure (marked blue) with a distance of $19.8 \AA$. 


\section{XYZ Coordinates $2^{\text {nd }}$ approach}

\section{trans-A}

$\mathrm{E}_{\mathrm{M} 06-2 \mathrm{X}(\mathrm{D} 3) / \mathrm{def} 2-\mathrm{TZVPP}}=-3206.059330528$ Hartree

$\begin{array}{lllll}\text { C } & -9.2754571 & 1.8997519 & -0.3944093\end{array}$

$\begin{array}{llll}\text { C } & -10.4880471 & 2.6169919 & -0.4475393\end{array}$

$\begin{array}{llll}\text { C } & -8.0658671 & 2.6054719 & -0.5048793 \\ \text { C } & -8.0543971 & 3.9939919 & -0.6590493\end{array}$

$\begin{array}{llll}\text { C } & -8.0543971 & 3.9939919 & -0.6590493 \\ \text { C } & -10.4766271 & 3.999411 & -0.6008193\end{array}$

$\begin{array}{llll}\text { C } & -9.2656071 & 4.6897619 & -0.7021693\end{array}$

$\begin{array}{llll}\text { C } & -9.2656071 & 4.6897619 & -0.7021693 \\ \text { C } & -6.7362671 & 4.7127019 & -0.8134993\end{array}$

$\begin{array}{llll}\text { C } & -9.2656071 & 4.6897619 & -0.7021693 \\ \text { O } & -5.8887871 & 4.7400519 & 0.8134993 \\ \text { C } & -4.5517471 & 4.5809619 & 0.1909707\end{array}$

$\begin{array}{llll}\text { C } & -5.7362671 & 4.7127019 & -0.8134993 \\ \text { C } & -4.5517471 & 4.5809619 & 0.2773607 \\ \text { C } & -3.9350671 & 5.3371019 & 0.809707\end{array}$

$\begin{array}{llll}\text { C } & -4.5517471 & 4.5809619 & 0.1909707 \\ \text { C } & -3.9350671 & 5.3371019 & -0.8137093\end{array}$

$\begin{array}{llll}\text { C } & -3.5350671 & 5.3371019 & -0.8137093 \\ \text { C } & -25463971 & 5.4696919 & -0.8115893\end{array}$

$\begin{array}{llll}\text { C } & -2.5463971 & 5.4696919 & -0.8115893 \\ \text { C } & -1.7621571 & 4.8691219 & 0.1786907\end{array}$

$\begin{array}{llll}\text { C } & -2.5463971 & 5.4696919 & -0.8115893 \\ \text { C } & -2.3974371 & 4.8691219 & 0.1786907\end{array}$

$\begin{array}{llll}\text { C } & -1.2621571 & 4.8691219 & 0.1786907 \\ \text { C } & -3.7715971 & 4.1384619 & 1.2042207 \\ N & 3.9985519 & 1.2093807\end{array}$

$\begin{array}{llll}\mathrm{C} & -2.3974371 & 4.1384619 & 1.2042207 \\ \mathrm{~N} & -0.7650771 & 3.9985519 & 1.2093807\end{array}$

$\begin{array}{llll}\mathrm{N} & -0.3650771 & 5.0187219 & 0.0417707 \\ \mathrm{H} & -11.4262071 & 2.0771519 & -0.3653193\end{array}$

$\begin{array}{llll}\text { H } & -7.1291871 & 2.0593219 & -0.4582693\end{array}$

$\begin{array}{llll}\text { H } & -11.4150371 & 4.5462219 & -0.6350593\end{array}$

\begin{tabular}{llll}
$\mathrm{H}$ & -9.2641871 & 5.7716319 & -0.8124393 \\
\hline
\end{tabular}

\begin{tabular}{llll}
$\mathrm{H}$ & -6.8804971 & 5.8016719 & -0.8264593 \\
\hline
\end{tabular}

\begin{tabular}{llll}
$\mathrm{H}$ & -6.2540671 & 4.4250119 & -1.7583493 \\
\hline & -4.583971 & 5.8160619 & -1.591793
\end{tabular}

$\begin{array}{lllll}\text { H } & -4.5183971 & 5.8160619 & -1.5917793\end{array}$

$\begin{array}{llll}\mathrm{H} & -2.0446171 & 6.0366319 & -1.5901093\end{array}$

$\begin{array}{llll}\mathrm{H} & -1.7853271 & 3.6781419 & 1.9715307\end{array}$

$\begin{array}{llll}\text { H } & -4.2798071 & 3.4265519 & 1.9797207\end{array}$

$\begin{array}{llll}\text { C } & 9.2317729 & 1.9440919 & -0.4420193\end{array}$

$\begin{array}{llll}\text { C } & 10.4152429 & 2.6921019 & -0.6071393\end{array}$

$\begin{array}{llll}\text { C } & 7.9996929 & 2.6187019 & -0.4360493\end{array}$

$\begin{array}{llll}\text { C } & 7.9377529 & 4.0062719 & -0.5850593\end{array}$

$\begin{array}{lllll}\text { C } & 10.3537529 & 4.0738219 & -0.7554293\end{array}$

$\begin{array}{lllll}\text { C } & 9.1211729 & 4.7329619 & -0.7408593\end{array}$

$\begin{array}{llll}\text { C } & 6.5911629 & 4.6878919 & -0.6110293\end{array}$

$\begin{array}{lllll}\text { O } & 5.8658129 & 4.2957019 & 0.5588607\end{array}$

$\begin{array}{llll}\text { C } & 4.5114829 & 4.4357619 & 0.5839207\end{array}$

$\begin{array}{llll}\text { C } & 3.7617229 & 5.1469719 & -0.3691193\end{array}$

$\begin{array}{llll}\text { C } & 2.3749129 & 5.1831519 & -0.2715693\end{array}$

$\begin{array}{llll}\text { C } & 1.7149029 & 4.5237119 & 0.7772107\end{array}$

$\begin{array}{llll}\text { C } & 2.4784429 & 3.8494019 & 1.7450607\end{array}$

$\begin{array}{lllll}\text { C } & 3.8600829 & 3.8034119 & 1.6545107\end{array}$

$\begin{array}{llll}\mathrm{N} & 0.3156929 & 4.4409019 & 0.9371107\end{array}$

$\begin{array}{ccccc}\mathrm{N} & 0.3156929 & & \\ \mathrm{H} & 11.3706429 & 2.1767919 & -0.6147593\end{array}$
$\begin{array}{cccc}\mathrm{H} & -7.0099071 & -2.9102381 & 4.1217507 \\ \mathrm{H} & -5.9427171 & -2.7965281 & 1.9588507\end{array}$ $\mathrm{H} \quad-5.9427171-2.7965281 \quad 1.9588507$ \begin{tabular}{llll} 
C & -9.2419771 & -0.7266181 & -0.1090893 \\
\hline
\end{tabular} \begin{tabular}{llll} 
C & -9.2674271 & 0.4799619 & -0.2378093 \\
\hline
\end{tabular} $\begin{array}{llll}\text { C } & 8.4108129 & -2.8646181 & 4.1505807\end{array}$ $\begin{array}{llll}\text { C } & 9.7393629 & -2.7670081 & 3.7400407\end{array}$ $\begin{array}{llll}\text { C } & 10.0224129 & -2.5964381 & 2.3767707\end{array}$ $\begin{array}{llll}\text { C } 8.9763129 & -2.5094181 & 1.4492407\end{array}$ $\begin{array}{llll}\text { C } 7.6489329 & -2.6576381 & 1.8718007\end{array}$ $\begin{array}{llll}\text { C } & 7.6489329 & -2.6576381 & 1.8718907 \\ \text { C } 7.3610429 & -2.8280281 & 3.2342207\end{array}$ $\begin{array}{llll}\mathrm{C} & 7.3610429 & -2.8280281 & 3.2342207 \\ \mathrm{H} & 8.1895229 & -2.9933081 & 5.2066607\end{array}$ $\begin{array}{llll}\mathrm{C} & 7.3610429 & -2.8280281 & 3.2342207 \\ \mathrm{H} & 10.5488129 & -2.833081 & 5.2066607\end{array}$ $\begin{array}{llll}\mathrm{H} & 10.5488129 & -2.8235781 & 4.4633507 \\ \mathrm{~N} & 11.3368029 & -2.5153581 & 1.9095407\end{array}$ $\begin{array}{cccc}\mathrm{N} & 11.3368029 & -2.5153581 & 1.9095407 \\ \mathrm{C} & 9.2757029 & -2.1604581 & -0.0009693\end{array}$ $\begin{array}{llll}\mathrm{C} & 11.3368029 & -2.5153581 & 1.9095407 \\ \mathrm{~N} & 6.6362729 & -2.604581 & -0.0009693 \\ \mathrm{H} & 6.33781 & 0.9092407\end{array}$ $\begin{array}{llll}\mathrm{N} & 6.6362729 & -2.6375781 & 0.9092407 \\ \mathrm{H} & 6.3312329 & -2.9319781 & 3.5661907\end{array}$ $\begin{array}{llll}\mathrm{H} & 6.6362729 & -2.6375781 & 0.9092407 \\ \mathrm{C} & 8.2312329 & -2.9319781 & 3.5661907\end{array}$ $\begin{array}{llll}\text { C } & 8.2117629 & -2.7670181 & -0.9031293 \\ \text { C } & 6.8991529 & -2.9115581 & -0.435393\end{array}$ $\begin{array}{llll}\text { C } & 6.8991529 & -2.9115581 & -0.4353993 \\ \text { C } & 5.8847129 & -3.3299081 & -1.3095093\end{array}$ $\begin{array}{llll}\text { C } & 5.8847129 & -3.3295081 & -1.3095093 \\ \text { C } & 6.2061129 & -3.6147481 & -2.6356493\end{array}$ $\begin{array}{llll}\text { C } & 6.2061129 & -3.6147481 & -2.6356493 \\ \text { C } & 7.5159329 & -3.5222881 & -3.1035393\end{array}$ $\begin{array}{llll}\text { C } & 7.5159329 & -3.5224881 & -3.1035393 \\ \text { C } & 8.5269329 & -3.1031081 & -2.2260493\end{array}$ $\begin{array}{llll}\text { C } & 8.5269329 & -3.1031081 & -2.2260493 \\ \text { C } & 10.6436329 & -2.703481 & -0.3857293\end{array}$ $\begin{array}{llll}\text { C } & 10.6436329 & -2.7034481 & -0.3857293\end{array}$ $\begin{array}{llll}\text { C } & 11.6580929 & -2.7853781 & 0.5769607\end{array}$ $\begin{array}{llll}\text { C } 12.9612429 & -3.1378381 & 0.1949907\end{array}$ $\begin{array}{llll}\text { C } & 13.2229329 & -3.4205581 & -1.1446593\end{array}$ $\begin{array}{llll}\text { C } & 12.2137329 & -3.3915281 & -2.1057493 \\ \text { C } & 0.921229 & -3.038378 & -1.7192093\end{array}$ $\begin{array}{llll}\text { C } & 10.9121229 & -3.0383781 & -1.7192093\end{array}$ $\begin{array}{llll}\mathrm{N} & 9.8594229 & -3.0163981 & -2.6373493\end{array}$ $\begin{array}{lllll}\text { H } & 12.0650529 & -2.6853681 & 2.5894007\end{array}$ $\begin{array}{llll}\text { H } & 5.7033929 & -2.8487481 & 1.2357807\end{array}$ H $\quad 4.8632829 \quad-3.4322281 \quad-0.9520493$ $\begin{array}{llll}\mathrm{H} & 5.4211229 & -3.9363781 & -3.3147893\end{array}$ H $\quad 7.7558729 \quad-3.7740181 \quad-4.1334593$ $\begin{array}{llll}\mathrm{H} & 13.7527729 & -3.1916781 & 0.9380707\end{array}$

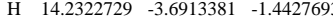
$\begin{array}{lllll}\mathrm{H} & 12.4273029 & -3.6412681 & -3.1418893\end{array}$ $\begin{array}{lllll}\mathrm{H} & 10.0657529 & -3.3623181 & -3.5642893\end{array}$ $\begin{array}{lrrr}\text { H } & 10.065129 & -3.3623781 & -3.5642893 \\ \text { C } & 9.2727129 & -0.6823781 & -0.1601793\end{array}$

$\begin{array}{lllll}\text { C } & 9.2698929 & 0.5244519 & -0.2888393\end{array}$

\section{trans-B}

$\mathrm{E}_{\mathrm{M} 06-2 \mathrm{X}(\mathrm{D} 3) / \mathrm{def2}-\mathrm{TZVPP}}=-3206.058788119$ Hartree

$\begin{array}{llll}\text { C } & -8.6701775 & 2.1760263 & 0.3540248\end{array}$

C -9.3478

$\begin{array}{llll}\text { C } & -7.3263675 & 2.2916963 & -0.0515452 \\ \text { C } & -6.6702275 & 3.5207363 & -0.0547952\end{array}$

$\begin{array}{llll}\text { C } & -6.6263675 & 2.2916063 & -0.0515452 \\ \text { C } & -8.6877675 & 3.5207363 & -0.054795\end{array}$

$\begin{array}{lllll}\text { C } & -8.6877675 & 4.5608763 & 0.7848348\end{array}$

$\begin{array}{lrrrr}\text { C } & -7.3593575 & 4.6642963 & 0.3681248 \\ \text { C } & -5.2537975 & 3.5740863 & -0.5737752\end{array}$

$\begin{array}{llll}\text { C } & -5.2537975 & 3.5740863 & -0.5737752\end{array}$

$\begin{array}{lllll}\text { O } & -4.4864275 & 4.5168463 & 0.1755548\end{array}$

$\begin{array}{llll}\text { C } & -3.1432075 & 4.5683663 & -0.0532552\end{array}$

$\begin{array}{llll}\text { C } & -2.4628575 & 3.7633463 & -0.976995\end{array}$

$\begin{array}{llll}\text { C } & -1.0778175 & 3.8694363 & -1.0861652\end{array}$

$\begin{array}{llll}\text { C } & -0.3549675 & 4.7816563 & -0.310915\end{array}$

$\begin{array}{llll}\text { C } & -1.0503775 & 5.6039363 & 0.5992048\end{array}$

$\begin{array}{llll}\text { C } & -2.4237275 & 5.4943363 & 0.7276548\end{array}$

$\begin{array}{llll}\mathrm{N} & 1.0430925 & 4.7692763 & -0.5004252\end{array}$

H $\quad-10.3816975 \quad 3.2580063 \quad 1.0993448$

$\begin{array}{llll}\text { H } & -6.8031075 & 1.3927563 & -0.3654752\end{array}$

$\begin{array}{llll}\text { H } & -9.2161375 & 5.4499463 & 1.1186448\end{array}$

$\begin{array}{llll}\text { H } & -6.8513675 & 5.6235363 & 0.3819648\end{array}$

$\begin{array}{llll}\mathrm{H} & -5.2370475 & 3.8645063 & -1.6358452\end{array}$

$\begin{array}{llll}\mathrm{H} & -4.8007575 & 2.5774163 & -0.4973652\end{array}$

H $-2.9912075 \quad 3.0542363-1.6023852$

$\begin{array}{llll}\mathrm{H} & -2.9512075 & 3.0542363 & -1.6023852 \\ \mathrm{H} & -0.5297575 & 3.2425563 & -1.7832052\end{array}$

$\begin{array}{llll}\mathrm{H} & -0.5297575 & 3.2425563 & -1.7832052 \\ \mathrm{H} & -0.4881275 & 6.3092563 & 1.2013948\end{array}$

$\begin{array}{llll}\mathrm{H} & -0.4881275 & 6.302563 & 1.2013948 \\ \mathrm{H} & -2.9738875 & 6.1052363 & 1.4369948\end{array}$

$\begin{array}{lllll}\text { C } & -2.673875 & 6.1052363 & 1.4369948\end{array}$

$\begin{array}{llll}\text { C } & -2.9738875 & 6.1052363 & 1.436948 \\ \text { C } & 8.6164125 & 1.3241863 & 0.7810048 \\ \text { C } & 8.831625 & 1.7071763 & 2.1184848\end{array}$

$\begin{array}{llll}\text { C } & 8.6164125 & 1.3241863 & 0.7810048 \\ \text { C } 8.831625 & 1.7071763 & 2.1184848\end{array}$

$\begin{array}{llll}\text { C } & 8.3371025 & 2.3220763 & 0.1730652 \\ \text { C } 8.2734825 & 3.6674663 & 0.1922648\end{array}$

$\begin{array}{llll}\text { C } & 8.2734825 & 3.6674663 & 0.1922648 \\ \text { C } & 8.7632125 & 3.0494563 & 2.4827148\end{array}$

$\begin{array}{lllll}\text { C } & 8.7632125 & 3.0694563 & 2.4827148 \\ \text { C } & 8.4878525 & 4.0282163 & 1.5285548\end{array}$

$\begin{array}{llll}\text { C } & 8.4878525 & 4.0282163 & 1.5285548\end{array}$

$\begin{array}{llll}C & 8.0315225 & 4.7388063 & -0.8536652\end{array}$

$\begin{array}{llll}C & 7.2331125 & 5.8275163 & -0.3828852\end{array}$

$\begin{array}{llll}\text { C } & 5.8768125 & 5.6858663 & -0.2939352 \\ \text { C } & 5.1646125 & 4.5296163 & -0.5530652\end{array}$

$\begin{array}{llll}\text { C } & 5.1646125 & 4.5296163 & -0.6530652 \\ \text { C } & 3.7781325 & 4.5145963 & -0.5542052\end{array}$

$\begin{array}{llll}\text { C } & 3.7781325 & 4.5145963 & -0.5542052 \\ \text { C } & 3.0790425 & 5.6358963 & -0.0804452\end{array}$ $\begin{array}{lllll}\text { C } 3.8042925 & 6.7743163 & 0.3067848\end{array}$ $\begin{array}{llll}\text { C } & 5.1860125 & 6.8074063 & 0.1906448\end{array}$ $\begin{array}{llll}\mathrm{N} & 1.6754625 & 5.7022763 & 0.0722048 \\ \mathrm{H} & 9.0412625 & 0.9420663 & 2.8592248\end{array}$ $\begin{array}{llll}\mathrm{H} & 9.0412625 & 0.9420663 & 2.8592248 \\ \mathrm{H} & 8.1650425 & 2.025963 & -1.204954\end{array}$ \begin{tabular}{llll} 
H & 8.1650425 & 2.0259363 & -1.204915 \\
\hline & 8.9247125 & 3.3349363 & 3.518748
\end{tabular} $\begin{array}{lllll}\text { H } & 8.9247125 & 3.3349363 & 3.5187748\end{array}$ $\begin{array}{llll}\text { H } & 8.4267225 & 5.0738463 & 1.8149148\end{array}$ $\begin{array}{llll}\text { H } & 7.6007425 & 4.3095863 & -1.7668452\end{array}$ $\begin{array}{llll}\text { H } & 8.9774325 & 5.2160263 & -1.131495\end{array}$ $\begin{array}{llll}\mathrm{H} & 5.6822325 & 3.6375963 & -0.9850752\end{array}$ $\begin{array}{llll}\text { H } & 3.2162425 & 3.6291563 & -0.830065\end{array}$ $\begin{array}{lllll}\mathrm{H} & 3.2559625 & 7.6313263 & 0.6864048\end{array}$ $\begin{array}{llll}\text { H } & 5.7563225 & 7.6876063 & 0.4701248\end{array}$ $\begin{array}{llll}\text { C } & -14.0418475 & -2.6105637 & -0.330115\end{array}$ $\begin{array}{llll}\text { C } & -13.4532975 & -2.6524937 & 0.9326748\end{array}$ $\begin{array}{llll}\text { C } & -12.0770675 & -2.4087137 & 1.0545448\end{array}$ $\begin{array}{llll}\text { C } & -11.3145275 & -2.1039037 & -0.0807452\end{array}$ $\begin{array}{llll}\text { C } & -11.9136775 & -2.1070737 & -1.3477552\end{array}$ $\begin{array}{llll}\text { C } & -13.2894575 & -2.3510937 & -1.4743352\end{array}$ $\begin{array}{llll}\mathrm{H} & -15.1073875 & -2.8007637 & -0.4264952\end{array}$ $\begin{array}{llll}\mathrm{H} & -14.0470875 & -2.8819637 & 1.8137548\end{array}$ $\begin{array}{llll}\mathrm{N} & -11.4328475 & -2.4785937 & 2.29 \\ \mathrm{C} & -9.8470775 & -1.7393137 & 0.064\end{array}$ $\begin{array}{lllll}\mathrm{N} & -11.4328475 & -2.4785937 & 2.2931348 \\ \mathrm{C} & -9.8470775 & -1.7393137 & 0.0640648\end{array}$ \begin{tabular}{llll}
$\mathrm{C}$ & -9.8470775 & -1.7393137 & 0.0640648 \\
$\mathrm{~N}$ & -11.1097375 & -1.8795037 & -2.4679552 \\
\hline
\end{tabular} $\begin{array}{llll}\mathrm{N} & -1.1 .107675 & -1.8795037 & -2.4679552 \\ \mathrm{H} & -13.7564775 & -2.3472137 & -2.4558752\end{array}$ C $-9.0908375-2.1478037-1.1921$ $\begin{array}{llll}\text { C } & -9.0908375 & -2.1478037 & -1.1921352 \\ \text { C }-9.7312875 & -2.1036337 & -2.4366752\end{array}$ $\begin{array}{llll}\text { C } & -9.7312875 & -2.1036337 & -2.4366752 \\ \text { C } & -8.9889975 & -2.2803737 & -3.6139852\end{array}$ $\begin{array}{llll}\text { C }-8.6179075 & -2.5143637 & -3.5225552\end{array}$ $\begin{array}{llll}\text { C } & -7.6179075 & -2.5143637 & -3.5225552 \\ \text { C } & -6.9761275 & -2.6163437 & -2.2889952\end{array}$ $\begin{array}{llll}\text { C } & -6.9761275 & -2.6163437 & -2.2889952 \\ \text { C } & -7.7221575 & -2.4368537 & -1.1146252\end{array}$ $\begin{array}{llll}\text { C } & -7.7221575 & -2.4368537 & -1.1146252\end{array}$ $\begin{array}{lllll}\text { C } & -9.2569575 & -2.4539237 & 1.2706148\end{array}$ $\begin{array}{lll}\text { C }-10.059645 & -2.7226937 & 2.3862248\end{array}$ $\begin{array}{llll}\text { C } & -9.4828775 & -3.2305037 & 3.5597048 \\ \text { C } & -8.114075 & -3.4778037 & 3.589348\end{array}$ $\begin{array}{llll}\text { C } & -8.1114075 & -3.4778037 & 3.5898348 \\ C & -7.3076675 & -3.2627937 & 2.4712948\end{array}$ $\begin{array}{llll}\text { C } & -7.3076675 & -3.2627937 & 2.4712948 \\ \text { C } & -7.8884575 & -2.7528937 & 1.3008948\end{array}$
$\begin{array}{lllll}\mathrm{N} & -7.1308975 & -2.5311537 & 0.1476748\end{array}$ $\begin{array}{llll}\text { H } & -11.9953875 & -2.7945537 & 3.0712348\end{array}$ $\begin{array}{llll}\mathrm{H} & -11.5587175 & -1.9727437 & -3.3686152 \\ \mathrm{H} & -9.4799975 & -2.2312837 & -4.5825052\end{array}$ \begin{tabular}{llll}
$\mathrm{H}$ & -9.4799975 & -2.2312837 & -4.5825052 \\
\hline & -7.0405275 & -2.646837 & -4.4336152
\end{tabular} $\begin{array}{llll}\mathrm{H} & -7.0405275 & -2.6468937 & -4.4336152\end{array}$ $\begin{array}{llll}\mathrm{H} & -5.9115775 & -2.8294137 & -2.2336352\end{array}$ $\begin{array}{llll}\mathrm{H} & -10.1013375 & -3.4284137 & 4.4313948\end{array}$ $\begin{array}{lllll}\text { H } & -7.6622175 & -3.8680237 & 4.4991048\end{array}$ $\begin{array}{llll}\mathrm{H} & -6.2441175 & -3.4852737 & 2.5019348\end{array}$ $\begin{array}{llll}\mathrm{H} & -6.1735275 & -2.8542537 & 0.1716548\end{array}$ $\begin{array}{llll}\text { C } & -9.6327875 & -0.2760137 & 0.2329648\end{array}$ $\begin{array}{llll}\text { C } & -9.2686975 & 0.8791363 & 0.3213448\end{array}$ $\begin{array}{llll}\text { C } & 8.9597425 & -4.4386837 & 3.8437748\end{array}$ $\begin{array}{llll}\text { C } & 10.1137025 & -4.2487737 & 3.0851948\end{array}$ $\begin{array}{llll}\text { C } & 9.9983525 & -3.7442737 & 1.7812448\end{array}$ $\begin{array}{llll}\text { C } & 8.7375525 & -3.4219937 & 1.2630748\end{array}$ $\begin{array}{llll}\text { C } & 7.5840125 & -3.6662537 & 2.0197448\end{array}$ $\begin{array}{llll}\text { C } & 7.6943725 & -4.1705037 & 3.3242148\end{array}$ H $\quad 9.0469825 \quad-4.8262237 \quad 4.8552548$ $\begin{array}{llll}\mathrm{H} & 11.0919725 & -4.4889437 & 3.4936448\end{array}$ $\begin{array}{lllll}\mathrm{N} & 11.1206825 & -3.5555337 & 0.9703648\end{array}$ $\begin{array}{llll}\text { C } & 8.6268425 & -2.7109737 & -0.0778652\end{array}$ $\begin{array}{llll}\mathrm{C} & 8.6268425 & -3.7101957 & -0.0778652 \\ \mathrm{~N} & 6.3396925 & -3.4019537 & 1.4431948\end{array}$ $\begin{array}{lllll}\mathrm{N} & 6.3301825 & -3.4019537 & 1.4431948 \\ \mathrm{H} & 6.8018125 & -4.3501237 & 3.9180548\end{array}$ $\begin{array}{llll}\mathrm{H} & 6.8018125 & -4.3501237 & 3.9180548 \\ \mathrm{C} & 7.3009725 & -3.0654837 & -0.7352852\end{array}$ $\begin{array}{llll}\text { C } \quad 6.1751825 & -3.3215837 & 0.0585948\end{array}$ $\begin{array}{lllll}\text { C } & 6.1751825 & -3.3215837 & 0.0585948 \\ \text { C } & 4.9191725 & -3.4984537 & 0.5407052\end{array}$ $\begin{array}{llll}\text { C } & 4.9191725 & -3.4984537 & -0.5407052 \\ \text { C } & 4.8138725 & -3.4328237 & -1.9289652\end{array}$ $\begin{array}{llll}\text { C } & 4.8138725 & -3.4328237 & -1.9289652 \\ \text { C } 5.9324425 & -3.2265337 & -2.7348752\end{array}$ $\begin{array}{llll}\text { C } & 5.9324425 & -3.2265337 & -2.7348752 \\ \text { C } & 7.1863225 & -3.0505337 & -2.1311252\end{array}$ $\begin{array}{llll}\text { C } & 7.1863225 & -3.0505337 & -2.1311252\end{array}$ $\begin{array}{llll}\text { C } 11.0125725 & -3.4835037 & -0.420852\end{array}$ $\begin{array}{llll}\text { C } & 11.0125725 & -3.4835037 & -0.4208852 \\ \text { C } 12.1072425 & -3.7588937 & -1.2539552\end{array}$ $\begin{array}{llll}\text { C } 12.1072425 & -3.758837 & -1.2539552\end{array}$ $\begin{array}{llll}\text { C } & 11.9394025 & -3.7052437 & -2.6365652 \\ \text { C } & 10.7028425 & -3.4025737 & -3.2078552\end{array}$ $\begin{array}{llll}\text { C } & 10.7028425 & -3.4095737 & -3.2078852 \\ \text { C } & 9.6110225 & -3.1350737 & -2.3709352\end{array}$ $\begin{array}{llll}\mathrm{C} & 9.6110225 & -3.1350737 & -2.3709352 \\ \mathrm{~N} & 8.3431525 & -2.8639137 & -2.8936052\end{array}$ 
H $\quad 11.9980025 \quad-3.9021837 \quad 1.3333048$ $\begin{array}{llll}\text { H } & 5.5284725 & -3.6824437 & 1.976654\end{array}$ $\begin{array}{rrrr}\mathrm{H} & 4.0424025 & -3.6861637 & 0.0737448 \\ \mathrm{H} & 3.8412225 & -3.5666637 & -2.3946952\end{array}$
H $\quad 5.8395125-3.2048637 \quad-3.8177052$ $\begin{array}{lll}4 & 13.0706825 & -4.017\end{array}$ $\begin{array}{llll}\mathrm{H} & 12.7864425 & -3.9175437 & -3.2833152 \\ \mathrm{H} & 10.5795125 & -3.3977937 & -4.2878352\end{array}$
H $\quad 8.2404925 \quad-2.9759637 \quad-3.8929652$ $\begin{array}{llll}\text { C } & 8.6703125 & -1.2439337 & 0.1632448\end{array}$ $\begin{array}{llll}\text { C } & 8.6529025 & -0.0573137 & 0.4191148\end{array}$

\section{trans-C}

$\mathrm{E}_{\mathrm{M} 06-2 \mathrm{X}(\mathrm{D} 3) / \mathrm{def} 2-\mathrm{TZVPP}}=-3206.058325100$ Hartree

$\begin{array}{lllll}\text { C } & -8.6943899 & 2.0823093 & -0.2561625\end{array}$

$\begin{array}{llll}\text { C } & -9.63420899 & 2.8559293 & -1.2392525\end{array}$

$\begin{array}{llll}\text { C } & -9.3420899 & 2.8559293 & -1.2392525 \\ \text { C } & -7.7758699 & 2.7066193 & 0.6094975\end{array}$

$\begin{array}{llll}\text { C } & -7.7758699 & 2.7066193 & 0.6094975 \\ \text { C } & -7.5004699 & 4.0702593 & 0.4946675\end{array}$

$\begin{array}{llll}\text { C } & -7.77586969 & 4.0702593 & 0.4946675 \\ \text { C } & -9.0652699 & 4.2145293 & -1.3541225\end{array}$

$\begin{array}{llll}\text { C } & -9.0652699 & 4.2145293 & -1.3541225 \\ \text { C } & -8.1458599 & 4.8206593 & -0.4963225\end{array}$

$\begin{array}{llll}\text { C } & -8.1458599 & 4.8206593 & -0.4963225 \\ \text { C } & -6.5853399 & 4.7734793 & 1.4791575\end{array}$

$\begin{array}{llll}\text { C } & -6.5853399 & 4.7734793 & 1.4791575 \\ \text { O } & -5.532599 & 3.9679193 & 2.0139675\end{array}$

$\begin{array}{llll}\text { C } & -5.5325499 & 3.9679193 & 2.0139675 \\ \text { C } & -4.3266899 & 3.9365193 & 1.3689775\end{array}$

$\begin{array}{llll}\text { C } & -4.3266899 & 3.9365193 & 1.3689775 \\ \text { C } & -3.2206599 & 3.5922393 & 2.1673475\end{array}$

$\begin{array}{llll}\text { C } & -3.2206599 & 3.5922393 & 2.1673475 \\ \text { C } & -1.947279 & 3.5607793 & 1.6248675\end{array}$

$\begin{array}{llll}\text { C } & -1.9472799 & 3.5607793 & 1.6248675 \\ \text { C } & -1.7509799 & 3.8583693 & 0.2622775\end{array}$

$\begin{array}{lllll}\text { C } & -1.7509799 & 3.8583693 & 0.2622775 \\ \text { C } & -2.8628699 & 4.1603293 & -0.5336125\end{array}$

$\begin{array}{llll}\text { C } & -1.75097699 & 3.8583693 & 0.2622775 \\ \text { C } & -4.146499 & 4.1603293 & -0.5336125\end{array}$

$\begin{array}{llll}\mathrm{C} & -4.1464699 & 4.2138293 & 0.0081475 \\ \mathrm{~N} & -0.496699 & 3.8713893 & -0.3896325\end{array}$

$\begin{array}{llll}\mathrm{N} & -0.4966699 & 3.8713893 & -0.3896325 \\ \mathrm{H} & -10.0506499 & 2.3764593 & -1.9072025\end{array}$

$\begin{array}{llll}\mathrm{H} & -10.0506499 & 2.3764593 & -1.9072025 \\ \mathrm{H} & -7.2718299 & 2.1166593 & 1.360075\end{array}$

$\begin{array}{cccc}\mathrm{H} & -7.2718299 & 2.1166593 & 1.368007 \\ \mathrm{H} & -9.5611599 & 4.8044193 & -2.1593425\end{array}$

$\begin{array}{llll}\mathrm{H} & -9.5611599 & 4.8044193 & -2.1203425 \\ \mathrm{H} & -7.9317899 & 5.8829193 & -0.595325\end{array}$

\begin{tabular}{llll} 
H & -7.9317899 & 5.8829193 & -0.5954325 \\
\hline & -7.1616199 & 5.074743 & 2.3619575
\end{tabular}

\begin{tabular}{llll} 
H & -7.1616199 & 5.0747493 & 2.3619575 \\
\hline & -6.1671899 & 5.6838493 & 1.030975
\end{tabular}

$\begin{array}{ccccc}\text { H } & -6.1671899 & 5.6838493 & 1.030957\end{array}$

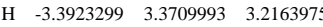

\begin{tabular}{llll}
$\mathrm{H}$ & -1.0853899 & 3.3174793 & 2.236427 \\
\hline
\end{tabular}

$\begin{array}{llll}\text { H } & -2.6996299 & 4.3659593 & -1.5873525\end{array}$

$\begin{array}{llll}\text { H } & -4.9943199 & 4.4441693 & -0.6272325\end{array}$

$\begin{array}{llll}\text { C } & 8.6961001 & 2.0800293 & 0.2530975\end{array}$

$\begin{array}{llll}\text { C } & 9.3446701 & 2.8507193 & 1.2379675\end{array}$

$\begin{array}{llll}\text { C } & 7.7792101 & 2.7075493 & -0.6119225\end{array}$

$\begin{array}{llll}\text { C } & 7.5063601 & 4.0715293 & -0.495002 \\ \text { C } & 9.0699001 & 4.2095293 & 1.3553575\end{array}$

$\begin{array}{llll}\text { C } & 9.0699001 & 4.2095293 & 1.3553575\end{array}$

$\begin{array}{llll}\text { C } & 8.1523001 & 4.8189093 & 0.4979075 \\ \text { C } & 6.5928601 & 4.7783193 & -1.4784825\end{array}$

$\begin{array}{lllll}\text { C } & 6.5928601 & 4.7783193 & -1.4784825\end{array}$

$\begin{array}{llll}\text { O } & 5.5399101 & 3.9753393 & -2.0167625\end{array}$

$\begin{array}{lllll}\text { C } & 4.3335901 & 3.9424293 & -1.3724325\end{array}$

C $3.2277901 \quad 3.6016093-2.1725225$

$\begin{array}{llll}\text { C } & 1.2279542301 & 3.5682593 & -1.6306625\end{array}$

$\begin{array}{llll}\text { C } & 1.954501 & 3.5682593 & -1.6306625 \\ \text { C } & 2.869101 & 3.8606593 & -0.2670425\end{array}$

$\begin{array}{llll}\text { C } & 1.7545201 & 3.8606593 & -0.2670425 \\ \text { C } & 28691101 & 4.1598693 & 0.5302775\end{array}$

$\begin{array}{llll}\text { C } & 1.7575201 & 3.8606593 & 0.2670425 \\ \text { C } & 4.869101 & 4.1598693 & 0.5302775 \\ \text { N } & 0.529101 & 4.2151293 & 0.0107725\end{array}$

$\begin{array}{llll}\mathrm{C} & 4.1529101 & 4.2151293 & -0.0107725 \\ \mathrm{~N} & 0.5031201 & 3.8709393 & 0.3846575\end{array}$

H $\quad 0.5031201 \quad 3.8709393 \quad 0.3846575$

\section{trans-free}

$\mathrm{E}_{\mathrm{M} 06-2 \mathrm{X}(\mathrm{D} 3) / \mathrm{def} 2-\mathrm{TZVPP}}=-3206.060070494$ Hartree

$\begin{array}{llll}\text { C } & 9.6620019 & 2.0175336 & 0.1324547\end{array}$

$\begin{array}{lllll}\text { C } & 10.7881719 & 2.8593136 & 0.0371647\end{array}$

$\begin{array}{llll}\text { C } & 8.3924919 & 2.5987336 & 0.2934847\end{array}$

$\begin{array}{llll}\text { C } & 8.2378819 & 3.9855636 & 0.3530147\end{array}$

$\begin{array}{llll}\text { C } & 10.6344119 & 4.2406836 & 0.096934\end{array}$

$\begin{array}{llll}\text { C } & 9.3652719 & 4.8056236 & 0.2498647\end{array}$

$\begin{array}{llll}\text { C } & 6.8641419 & 4.5744336 & 0.5645047\end{array}$

$\begin{array}{lllll}\text { O } & 5.9795719 & 4.0235736 & -0.415755\end{array}$

$\begin{array}{llll}\text { C } \quad 4.6385519 & 4.2140436 & -0.2795453 \\ \text { C } & 4.03545 & 5.020856 & 0.693684\end{array}$

$\begin{array}{lllll}\text { C } & 4.0354519 & 5.0208136 & 0.6936847\end{array}$

$\begin{array}{llll}\text { C } & 2.6437419 & 5.1070036 & 0.7410947\end{array}$

$\begin{array}{llll}\text { C } & 1.8415619 & 4.4094136 & -0.168035\end{array}$

$\begin{array}{llll}\text { C } & 2.4610719 & 3.6178636 & -1.157585 \\ \text { C } & .838819 & 3.523096 & -1.211053\end{array}$

$\begin{array}{llll}\text { C } & 3.8381819 & 3.5230936 & -1.211105\end{array}$

$\begin{array}{llll}\mathrm{N} & 0.4462419 & 4.5457136 & 0.0008047\end{array}$

$\begin{array}{lllll}\mathrm{H} & 11.7719319 & 2.4168636 & -0.0848353\end{array}$

$\begin{array}{llll}\text { H } & 7.5220119 & 1.9541936 & 0.3606447\end{array}$

$\begin{array}{lllll}\mathrm{H} & 11.5061719 & 4.8844336 & 0.0171147\end{array}$

$\begin{array}{llll}\text { H } & 9.2527119 & 5.88666636 & 0.2859647\end{array}$

$\begin{array}{llll}\text { H } & 6.8894219 & 5.6692936 & 0.4782347\end{array}$

$\begin{array}{lllll}\text { H } & 6.4903019 & 4.3239736 & 1.5676847\end{array}$

$\begin{array}{llll}\mathrm{H} & 4.6312219 & 5.5768736 & 1.4083747\end{array}$

$\begin{array}{llll}\mathrm{H} & 4.6312219 & 5.5768736 & 1.4083747 \\ \mathrm{H} & 2.1541219 & 5.7181836 & 1.4934847\end{array}$

$\begin{array}{llll}\mathrm{H} & 1.8357319 & 3.0818836 & -1.8626253\end{array}$

$\begin{array}{llll}\mathrm{H} & 4.8349119 & 2.0112736 & -1.9580153\end{array}$

\begin{tabular}{llll} 
H & 4.3349119 & 2.9182736 & -1.9580153 \\
\hline
\end{tabular}

$\begin{array}{lllll}\text { C }-10.5849581 & 2.9741636 & 0.6039347\end{array}$

$\begin{array}{llll}C & -10.5849581 & 2.9741636 & 0.6039347 \\ C & -8.1986081 & 2.5719236 & 0.4710447\end{array}$

$\begin{array}{lllll}\text { C } & -8.198681 & 2.5719236 & 0.4710447\end{array}$

$\begin{array}{lllll}\text { C } & -10.3366181 & 4.3344936 & 0.7576747\end{array}$

$\begin{array}{lllll}\text { C } & -10.3366181 & 4.3344936 & 0.7576747 \\ \text { C } & -9.0257781 & 4.8187836 & 0.7638047\end{array}$

$\begin{array}{llll}\text { C } & -9.0257781 & 4.8187836 & 0.7638047 \\ \text { C } & -6.5255281 & 4.4371336 & 0.686747\end{array}$

$\begin{array}{llll}\text { C } & -6.5255281 & 4.4371336 & 0.6806747 \\ \text { O } & -5.8036381 & 3.8703036 & -0.4159453\end{array}$ $\begin{array}{llll}7.2738901 & 2.1196593 & -1.3711325\end{array}$ \begin{tabular}{llll}
$\mathrm{H}$ & 9.5662801 & 4.7971093 & 2.1230375 \\
\hline & 7.940001 & 5.8813593 & 0.588275
\end{tabular} \begin{tabular}{llll} 
H & 7.9400401 & 5.8813593 & 0.5988275 \\
\hline
\end{tabular}

\begin{tabular}{lllll} 
H & 7.1703901 & 5.0817093 & -2.3597725 \\
\hline & 6.175601 & 5.687693 & -1.028025
\end{tabular}

$\begin{array}{llll}\mathrm{H} & 6.1750601 & 5.6877693 & -1.0280925\end{array}$

$\begin{array}{lllll}\text { H } & 3.3997401 & 3.3843093 & -3.2223425\end{array}$

$\begin{array}{llll}\text { H } & 1.0925501 & 3.3272193 & -2.2434125\end{array}$

$\begin{array}{llll}\text { H } & 2.7054901 & 4.3616093 & 1.5847075\end{array}$

\begin{tabular}{lllll} 
H & 5.0005601 & 4.4428693 & 0.6257875 \\
\hline
\end{tabular}

$\begin{array}{llll}\text { C } & -7.6596399 & -3.1548207 & -3.8853225 \\ \text { C } & -9.0383499 & -3.0052307 & -3.724925\end{array}$

$\begin{array}{llll}\text { C } & -9.0383499 & -3.0052307 & -3.7424925\end{array}$

$\begin{array}{llll}\text { C } & -9.5637199 & -2.6946007 & -2.4795725\end{array}$

$\begin{array}{llll}\text { C } & -8.7057099 & -2.5238407 & -1.3862025\end{array}$

$\begin{array}{llll}\text { C } & -7.3273999 & -2.7283907 & -1.5351225\end{array}$

\begin{tabular}{llll} 
C & -6.7973399 & -3.0389207 & -2.7963225 \\
\hline
\end{tabular}

$\begin{array}{llll}\text { C } & -6.79798399 & -3.33004907 & -4.8637925\end{array}$

\begin{tabular}{llll}
$\mathrm{H}$ & -9.7008999 & -3.1259007 & -4.5957725 \\
\hline & -10.9392599 & -2.584607 & -2.2766225
\end{tabular}

$\begin{array}{llll}\mathrm{N} & -10.9392599 & -2.5484607 & -2.276622 \\ \mathrm{C} & -9.2524899 & -1.9985807 & -0.0666325\end{array}$

$\begin{array}{llll}\text { C } & -9.2524899 & -1.9985807 & -0.0666325\end{array}$

\begin{tabular}{llll} 
N & -6.5117999 & -2.6175007 & -0.4077325 \\
\hline & -5.727 & -3.1849007 & -2.9183725
\end{tabular}

$\begin{array}{llll}\mathrm{H} & -5.7271699 & -3.1849007 & -2.918372 \\ \mathrm{C} & -8.39569 & -2.5127507 & 1.081275\end{array}$

$\begin{array}{llll}\text { C } & -8.3965699 & -2.5127507 & 1.0812775\end{array}$

$\begin{array}{llll}\text { C } & -7.0245899 & -2.7207007 & 0.886707\end{array}$

$\begin{array}{llll}\text { C } & -6.2001599 & -3.0273707 & 1.9795675\end{array}$

$\begin{array}{llll}\text { C } & -6.7674599 & -3.1362607 & 3.2481375\end{array}$

$\begin{array}{llll}\text { C } & -8.1382599 & -2.9819907 & 3.4492975\end{array}$

$\begin{array}{llll}\text { C } & -8.9585599 & -2.6755407 & 2.3534475\end{array}$

$\begin{array}{llll}\text { C } & -10.6875099 & -2.4659607 & 0.1150775\end{array}$

$\begin{array}{llll}\text { C } & -11.5055099 & -2.6688207 & -1.0044525\end{array}$

\begin{tabular}{llll} 
C & -12.8588999 & -2.9978507 & -0.8358225 \\
\hline
\end{tabular}

$\begin{array}{llll}\text { C } & -13.3681599 & -3.1399507 & 0.4538675\end{array}$

$\begin{array}{llll}\text { C } & -12.5572099 & -2.9850307 & 1.5767875\end{array}$

$\begin{array}{llll}\text { C } & -11.2040999 & -2.6569207 & 1.4036075\end{array}$ \begin{tabular}{llll}
$\mathrm{N}$ & -10.3413899 & -2.5279607 & 2.4951175 \\
\hline & -1.5335699 & -2.7991207 & -3.0548725
\end{tabular} $\begin{array}{llll}\mathrm{H} & -11.5335699 & -2.7991207 & -3.0548725\end{array}$ $\begin{array}{llll}\mathrm{H} & -5.5372599 & -2.8555407 & -0.5289125\end{array}$ $\begin{array}{llll}H & -5.5372599 & -2.8555407 & -0.5289125 \\ \mathrm{H} & -5.1332599 & -3.1760707 & 1.8344375\end{array}$ \begin{tabular}{llll}
\hline & -6.1293799 & -3.3688907 & 4.0964475
\end{tabular} \begin{tabular}{llll}
4 & -5.1332599 & -3.1760707 & 1.8344375 \\
\hline & -8.5698299 & -3.368800707 & 4.096447 \\
\hline
\end{tabular} $\begin{array}{lllll}H & -8.5698299 & -3.0960707 & 4.4403775 \\ \mathrm{H} & -13.4964199 & -3.1483307 & -1.7033225\end{array}$

$\begin{array}{llll}H & -13.4964199 & -3.1483307 & -1.7033225 \\ \mathrm{H} & -14.4161799 & -3.3948907 & 0.5863375\end{array}$
$\begin{array}{llll}\mathrm{H} & -12.9612799 & -3.1254107 & 2.5760975\end{array}$ H $-10.7257099 \quad-2.7664407 \quad 3.3990075$ $\begin{array}{llll}\text { C } & -9.1580599 & -0.5139907 & -0.0941625 \\ \text { C } & -8.9529799 & 0.6810793 & -0.552725\end{array}$ $\begin{array}{llll}\text { C } & -8.9529799 & 0.6810793 & -0.1552725 \\ \text { C } & 1.763250 & -3.132607 & -3.2306525\end{array}$

$\begin{array}{llll}\text { C } & 11.7632501 & -3.1432607 & -3.2306525 \\ \text { C } & 10.396201 & -3.0132207 & -3.434625\end{array}$

$\begin{array}{llll}\text { C } & 10.3906201 & -3.0132207 & -3.4347625 \\ \text { C } & 9.5652001 & -2.687407 & -2.3480625\end{array}$

$\begin{array}{llll}\text { C } & 9.5652001 & -2.6874907 & -2.3480625\end{array}$

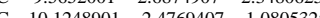
$\begin{array}{lllll}\text { C } & 10.1248511 & -2.4769407 & -1.0805325 \\ \text { C } 11.5003101 & -2.6554507 & -0.8833825\end{array}$ $\begin{array}{llll}\text { C } 1 & 1.5234101 & -2.9806607 & -1.9673125\end{array}$ \begin{tabular}{llll} 
C 12.3294101 & -2.9806607 & -1.5673125 \\
\hline & 12.4039101 & -3.3949107 & -4.0715625
\end{tabular} \begin{tabular}{llll} 
C & 12.4039101 & -3.3949107 & -4.0715625 \\
\hline & 9.9595701 & -3.1683307 & -4.4205025
\end{tabular} \begin{tabular}{llll}
4 & 9.959501 & -3.1683307 & -4.4205025 \\
\hline
\end{tabular} $\begin{array}{llll}\mathrm{N} & 8.1804101 & -2.5761607 & -2.4935725 \\ \mathrm{C} & 9.2470301 & -2.0021707 & 0.0664875\end{array}$ $\begin{array}{lllll}\mathrm{C} & 9.2470301 & -2.0021707 & 0.0664875 \\ \mathrm{~N} & 12.0134801 & -2.5152507 & 0.4095175\end{array}$ \begin{tabular}{llll}
$\mathrm{N}$ & 12.0134801 & -2.5152507 & 0.4095175 \\
\hline
\end{tabular}

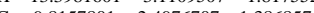
$\begin{array}{llll}\text { C } & 9.8157801 & -2.4976707 & 1.3868575\end{array}$ $\begin{array}{llll}\text { C } & 11.1984901 & -2.6637207 & 1.5356575 \\ \text { C } & 11.7370301 & -2.9798407 & 2.791575\end{array}$ $\begin{array}{llll}\text { C } & 11.1984901 & -2.6637207 & 1.5356575 \\ \text { C } & 11.7370301 & -2.9798407 & 2.7919575\end{array}$ $\begin{array}{llll}\text { C } & 10.8775001 & -3.1447307 & 3.8769775\end{array}$ $\begin{array}{llll}\text { C } & 9.4956101 & -3.0312407 & 3.7347275 \\ \text { C } & 8.9614301 & -2.7142407 & 2.4765975\end{array}$ $\begin{array}{llll}\text { C } & 8.9614301 & -2.7142407 & 2.4765975 \\ \text { C } & 7.8339701 & -2.5388107 & -0.148325\end{array}$ $\begin{array}{llll}\text { C } & 7.8339701 & -2.5388107 & -0.1148325 \\ \text { C } & 7.3159401 & -2.7135607 & -1.404025\end{array}$ $\begin{array}{llll}\text { C } & 7.3159401 & -2.7135607 & -1.4041025\end{array}$ $\begin{array}{llll}\text { C } & 5.9578901 & -3.0173407 & -1.5789525 \\ \text { C } & 5.1437501 & -3.1552207 & -0.4557925\end{array}$ $\begin{array}{llll}\text { C } & 5.1437501 & -3.1552207 & -0.4557925 \\ \text { C } & 5.656401 & -3.0378607 & 0.8351275\end{array}$ $\begin{array}{llll}\text { C } & 5.6564101 & -3.0378607 & 0.8351275 \\ \text { C } & 7.0149501 & -2.7329807 & 1.004575\end{array}$ $\begin{array}{llll}\text { C } & 7.0149501 & -2.7329807 & 1.0047575 \\ \text { N } & 7.5837901 & -2.6135107 & 2.2747975\end{array}$ \begin{tabular}{llll}
$\mathrm{N}$ & 7.5837901 & -2.6135107 & 2.2747975 \\
\hline
\end{tabular} H $\quad 7.8031901 \quad-2.8213907 \quad-3.3985625$ $\begin{array}{lllll}\mathrm{H} & 12.9875101 & -2.7570107 & 0.5302975 \\ \mathrm{H} & 12.810880 & -3.094607 & 2.9119175\end{array}$ $\begin{array}{llll}\mathrm{H} & 12.8108801 & -3.0984607 & 2.9119175 \\ \mathrm{H} & 1.2928401 & -3.3880707 & 4.8512575\end{array}$ $\begin{array}{llll}\mathrm{H} & 11.2928401 & -3.3880707 & 4.8512575\end{array}$ $\begin{array}{lllll}\mathrm{H} & 8.8358101 & -3.1896207 & 4.5839275\end{array}$ $\begin{array}{llll}H & 5.5487901 & -3.1384907 & -2.5787025\end{array}$ \begin{tabular}{llll}
$H$ & 4.8387901 & -3.1384907 & -2.5787025 \\
\hline
\end{tabular} $\begin{array}{llll}H & 4.0897401 & -3.3832907 & -0.5893325 \\ \mathrm{H} & 5.0142501 & -3.1744207 & 1.7014075\end{array}$ $\begin{array}{llll}4 & 5.0938601 & -2.8582307 & 3.0579075\end{array}$ $\begin{array}{llll}\text { H } & 6.9938601 & -2.8582307 & 3.0579075 \\ \text { C } 9.1521701 & -0.5175307 & 0.0897375\end{array}$

$\begin{array}{lrrrr}\text { C } & 9.1521601 & -0.5175307 & 0.0897375 \\ \text { C } 8.9516901 & 0.6783093 & 0.1508075\end{array}$ $\begin{array}{llll}\text { C } & -4.4455681 & 3.9665736 & -0.4416953\end{array}$ $\begin{array}{llll}\text { C } & -3.6772881 & 4.7182036 & 0.4643447\end{array}$ $\begin{array}{llll}\text { C } & -3.6772881 & 4.7182036 & 0.464347 \\ \text { C } & -2.2903081 & 4.7237436 & 0.357924\end{array}$ $\begin{array}{llll}\text { C } & -1.6473081 & 3.9897536 & -0.651135 \\ \text { C } & -2.428141 & 3.260326 & -1.5639053\end{array}$ $\begin{array}{llll}\text { C } & -2.4281481 & 3.2603236 & -1.5639053 \\ \text { C } & -3.8099281 & 3.2461936 & -1.465353\end{array}$ $\begin{array}{llll}\text { C } & -3.8099281 & 3.2461936 & -1.465375 \\ \text { N } & -0.250681 & 3.8553036 & -0.830053\end{array}$ $\begin{array}{lllll}\mathrm{N} & -0.2506881 & 3.8953036 & -0.8300653\end{array}$ $\begin{array}{lllll}\mathrm{H} & -11.6020681 & 2.5949836 & 0.5943547\end{array}$ $\begin{array}{ccccc}\mathrm{H} & -7.3701981 & 1.8820236 & 0.3486047\end{array}$ $\begin{array}{llll}\mathrm{H} & -11.1681181 & 5.0256936 & 0.865634\end{array}$ $\begin{array}{lllll}\mathrm{H} & -8.8414981 & 5.8849236 & 0.8737847\end{array}$ $\begin{array}{llll}\mathrm{H} & -6.0488281 & 4.1307536 & 1.623054\end{array}$ $\begin{array}{llll}\text { H } & -6.4939781 & 5.5340936 & 0.6294047\end{array}$ $\begin{array}{llll}\mathrm{H} & -4.1532581 & 5.2971036 & 1.2479747\end{array}$ $\begin{array}{llll}\mathrm{H} & -1.6845181 & 5.2911536 & 1.0560047\end{array}$ $\begin{array}{llll}\text { H } & -1.9178381 & 2.7002236 & -2.3417253\end{array}$ $\begin{array}{llll}\text { H } & -4.4239181 & 2.6790136 & -2.1576153\end{array}$ $\begin{array}{llll}\text { C } & 13.9153619 & -3.3817764 & 0.5130647 \\ \text { C } & 13.4158019 & -3.1983564 & -0.7752253\end{array}$ $\begin{array}{llll}\text { C } & 13.4158019 & -3.1983564 & -0.7752253 \\ \text { C } 12.0712519 & -2.8336364 & -0.9416553\end{array}$ $\begin{array}{llll}\text { C } & 12.0712519 & -2.8336364 & -0.9416553\end{array}$ $\begin{array}{llll}\text { C } & 11.2535819 & -2.6390364 & 0.1792447\end{array}$ $\begin{array}{llll}\text { C } & 11.7582019 & -2.8744564 & 1.4649047\end{array}$ $\begin{array}{llll}\text { C } 13.1022319 & -3.2387264 & 1.6361047\end{array}$ $\begin{array}{lllll}C & 14.056919 & -3.2387264 & 1.6361\end{array}$ $\begin{array}{lllll}\mathrm{H} & 14.9569419 & -3.6627264 & 0.6437947 \\ \mathrm{H} & 14.0546819 & -3.3405464 & -1.6431053\end{array}$

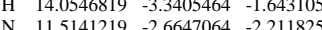
\begin{tabular}{llll} 
C & $9.8415619-2.1024264$ & -2.2118253 \\
\hline & 0.0052047
\end{tabular} $\begin{array}{lllll}\mathrm{C} & 11.5141219 & -2.6647064 & -2.2118253 \\ \mathrm{~N} & 10.8937819 & -2.747264 & 0.0052047\end{array}$ \begin{tabular}{llll}
$\mathrm{C}$ & 10.8937819 & -2.7471864 & 2.5551147 \\
\hline & 13.4984319 & -3.4120064 & 2.6333947
\end{tabular} $\begin{array}{llll}\text { C } & 8.9579619 & -2.6095964 & 1.6353447\end{array}$ $\begin{array}{lllll}\text { C } \quad 8.9579619 & -2.6095964 & 1.1353447\end{array}$ $\begin{array}{llll}\text { C } & 9.5073819 & -2.8341064 & 2.4040147\end{array}$ $\begin{array}{llll}\text { C } & 7.672954719 & -3.2352664 & 3.2764547\end{array}$
$\begin{array}{llll}C & 6.7387219 & -3.0632264 & 2.0101247\end{array}$ $\begin{array}{llll}\text { C } & 7.5798019 & -2.7562464 & 0.9301647\end{array}$

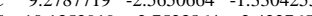
\begin{tabular}{llll} 
C & 10.1352919 & -2.7523864 & -2.422765 \\
\hline
\end{tabular} $\begin{array}{llll}\text { C } & 9.6047419 & -3.0269464 & -3.6919353\end{array}$ $\begin{array}{llll}\text { C } 8.2225319 & -3.1263664 & -3.842685 \\ \text { C } & 7.3598919 & -2.916664 & -2.75653\end{array}$ $\begin{array}{llll}\text { C } & 7.3598919 & -2.9909664 & -2.7561653\end{array}$ $\begin{array}{llll}\text { C } & 7.8949919 & -2.7165164 & -1.4888553 \\ \text { N } & 7.0770519 & -2.5930064 & -0.3629353\end{array}$ $\begin{array}{lllll}\mathrm{N} & 7.0770519 & -2.5930064 & -0.3629353 \\ \mathrm{H} & 12.0283 & -2.9120264 & -2.952753\end{array}$ $\begin{array}{llll}\mathrm{H} & 12.1028319 & -2.9120264 & -2.9952753\end{array}$ $\begin{array}{llll}H & 11.2642919 & -3.0205164 & 3.4548247\end{array}$ $\begin{array}{lllll}\text { H } & 9.0925719 & -3.3045964 & 4.4751047\end{array}$ $\begin{array}{llll}\mathrm{H} & 6.6449119 & -3.4693864 & 4.1148147\end{array}$ $\begin{array}{lllll}\mathrm{H} & 5.6674719 & -3.1653064 & 1.8567247\end{array}$ $\begin{array}{llll}\text { H } & 10.2666719 & -3.1614464 & -4.5435953\end{array}$ $\begin{array}{llll}\mathrm{H} & 7.8093019 & -3.3353764 & -4.8257453\end{array}$ $\begin{array}{lllll}\mathrm{H} & 6.2857319 & -3.0972164 & -2.8844253\end{array}$ $\begin{array}{llll}\mathrm{H} & 6.0978219 & -2.8060164 & -0.4940453\end{array}$ $\begin{array}{llll}\text { C } & 9.8452119 & -0.6160064 & 0.0395547\end{array}$ $\begin{array}{llll}\text { C } & 9.7877119 & 0.5958036 & 0.0765747\end{array}$ $\begin{array}{llll}\text { C } & -13.9404081 & -3.1676064 & 1.1267447\end{array}$ $\begin{array}{llll}\text { C } & -12.9269181 & -3.1751364 & 2.0835947\end{array}$ $\begin{array}{llll}C & -11.6191381 & -2.8458164 & 1.6967747\end{array}$ $\begin{array}{llll}C & -11.3480081 & -2.4957664 & 0.3675047\end{array}$ $\begin{array}{llll}\text { C } & -11.6191381 & -2.8458164 & 1.697747 \\ \text { C }-123686781 & -2.5387964 & 0.3675047 \\ \text { C }-13.679981 & -2.567164 & -0.20853\end{array}$ $\begin{array}{llll}\mathrm{C} & -11.36806781 & -2.5387964 & -0.5912953 \\ \mathrm{C} & -13.6779981 & -2.8673164 & -0.2089053\end{array}$ \begin{tabular}{lllll}
$C$ & -12.3686781 & -2.5387964 & -0.5912953 \\
\hline & -14.9541581 & -3.4213564 & -0.2089053
\end{tabular} \begin{tabular}{llll}
$\mathrm{C}$ & -13.6779981 & -2.8673164 & -0.208953 \\
$\mathrm{H}-13.141581$ & -3.4213564 & 1.424814 \\
\hline & -3.4377964 & 3.1163747
\end{tabular} $\begin{array}{llll}H & -13.1413181 & -3.4377964 & 3.116374\end{array}$ $\begin{array}{llll} & -13.1413181 & -3.4377964 & 3.1163747 \\ C & -10.5623181 & -2.8667864 & 2.6103347\end{array}$ $\begin{array}{llll}\mathrm{C} & -9.9631181 & -2.0010564 & -0.0195253 \\ \mathrm{~N} & -12.0468981 & -2.2591264 & -1.9219953\end{array}$ $\begin{array}{llll}\mathrm{N} & -12.0468981 & -2.2591264 & -1.9219953 \\ \mathrm{H} & -14.4733081 & -2.8922164 & -0.9494853\end{array}$ $\begin{array}{llll}\text { C } & -9.6853381 & -2.3439364 & -1.4756253\end{array}$ 
\begin{tabular}{llll} 
C & -10.7385281 & -2.3800164 & -2.398225 \\
\hline & -3.7553
\end{tabular}

$\begin{array}{llll}\text { C } & -10.4689281 & -2.5400764 & -3.7654553\end{array}$

$\begin{array}{llll}\text { C } & -9.1468281 & -2.6786264 & -4.184965 \\ \text { C } & -8.09178 & -2.6938964 & -3.274453\end{array}$

$\begin{array}{llll}\text { C } & -8.0917081 & -2.6938964 & -3.274145 \\ \text { C } & -8.366128 & -2.5332264 & -1.908853\end{array}$

\begin{tabular}{llll} 
C & -8.3661281 & -2.5332264 & -1.907885 \\
\hline
\end{tabular}

$\begin{array}{llll}\text { C } & -8.9174281 & -2.6590664 & 0.8686047\end{array}$

$\begin{array}{llll}\text { C } & -9.2353481 & -2.9930464 & 2.1911547\end{array}$

$\begin{array}{llll}\text { C } & -8.2325181 & -3.4469064 & 3.0607247\end{array}$
C $\quad-6.9284181 \quad-3.5740764 \quad 2.5850647$ $\begin{array}{llll}\text { C } & -6.6060381 & -3.2927964 & 1.2583647\end{array}$ $\begin{array}{llll}\text { C } & -7.6123281 & -2.8394664 & 0.3923747\end{array}$ $\begin{array}{llll}\text { N } & -7.3484581 & -2.5619464 & -0.9510953\end{array}$ \begin{tabular}{llll}
\hline & -7.3484581 & -2.5619464 & -0.9510953 \\
\hline & -12.784281 & -3.2183864 & 3.5336147
\end{tabular} \begin{tabular}{llll}
\hline & -12.7837581 & -2.3998264 & -2.5993353 \\
\hline
\end{tabular} $\begin{array}{llll}\mathrm{H} & -11.2836281 & -2.5566564 & -4.4848953\end{array}$ $\begin{array}{llll}\text { H } & -8.9357081 & -2.7991064 & -5.2440853\end{array}$
$\begin{array}{llll}\mathrm{H} & -7.0680481 & -2.8296664 & -3.6136053\end{array}$ $\begin{array}{llll}\text { H } & -8.4738481 & -3.6960864 & 4.0908847\end{array}$ $\begin{array}{llll}H & -6.1494281 & -3.9218364 & 3.2582147\end{array}$ $\begin{array}{llll}H & -5.5898281 & -3.4225764 & 0.8949647\end{array}$ H $\quad-6.4243981 \quad-2.7980264 \quad-1.285475$ $\begin{array}{llll}\text { C } & -9.8716481 & -0.5273964 & 0.1554247\end{array}$ $\begin{array}{llll}\text { C } & -9.7341481 & 0.6707236 & 0.2928047\end{array}$

\section{cis-A}

$\mathrm{E}_{\mathrm{M} 06-2 \mathrm{X}(\mathrm{D} 3) / \mathrm{def} 2-\mathrm{TZVPP}}=-3206.033596869$ Hartree

$\begin{array}{lllll}\text { C } & 7.9566994 & 2.7018908 & 0.0412637\end{array}$

$\begin{array}{llll}\text { C } & 7.956394 & 2.7018908 & 0.041263 \\ \text { C } & 6.3923094 & 4.0337408 & -0.0736963\end{array}$

$\begin{array}{lrrr}\text { C } & 8.3923094 & 4.0337408 & -0.0736963 \\ \text { C } & 6.5773894 & 2.4437408 & 0.1785237\end{array}$

$\begin{array}{llll}\text { C } & 8.3923094 & 4.0337408 & -0.0736963 \\ \text { C } & 5.6472394 & 3.4437408 & 0.178523 \\ \text { C } & 7.4634594 & 5.0719108 & 0.1900337\end{array}$

$\begin{array}{lrrr}\text { C } & 5.6472394 & 3.4836108 & 0.1900337 \\ \text { C } & 7.4634594 & 5.0719108 & -0.0608763\end{array}$

$\begin{array}{lrrr}\text { C } & 5.642394 & 3.4836108 & 0.1900337 \\ \text { C } & 6.0985394 & 4.0719108 & -0.0608763 \\ \text { C } & 4.1756394 & 3.1956908 & 0.0636937\end{array}$

$\begin{array}{llll}\text { C } & 6.0985394 & 4.8029408 & 0.0636937 \\ \text { C } & 4.1756394 & 3.1956908 & 0.3964137\end{array}$

$\begin{array}{llll}\text { C } & 4.1756394 & 3.1956908 & 0.3964137 \\ \text { O } & 3.8240294 & 2.0147408 & 0.329476\end{array}$

$\begin{array}{llll}\text { O } & 3.8240294 & 2.0147408 & -0.3294763 \\ C & 2.5946894 & 1.4585208 & -0.1548363\end{array}$

$\begin{array}{llll}\text { C } & 2.5946894 & 1.4585208 & -0.154836 \\ \text { C } & 2.4000694 & 0.216608 & -0.7840863\end{array}$

$\begin{array}{llll}\text { C } & 2.4000694 & 0.2166908 & -0.7840863 \\ \text { C } & 1.1930894 & 0.4482992 & -0.6471763\end{array}$

$\begin{array}{lllll}\text { C } & 1.1930894 & 0.4182992 & 0.6471763\end{array}$

$\begin{array}{llll}\text { C } & 0.1220194 & 0.1273508 & 0.0614837\end{array}$

$\begin{array}{llll}\text { C } & 0.3247094 & 1.3631208 & 0.6942837 \\ \text { C } & 1.5520194 & 2.0214408 & 0.5964637\end{array}$

$\begin{array}{llll}C & 1.5520194 & 2.0214408 & 0.5964637\end{array}$

\begin{tabular}{lrrr}
$\mathrm{N}$ & -1.0142706 & -0.7364392 & 0.207033 \\
\hline
\end{tabular}

$\begin{array}{llll}\mathrm{H} & 9.4526494 & 4.2418308 & -0.177936 \\ \mathrm{H} & 6.2403994 & 1.4159508 & 0.200237\end{array}$

\begin{tabular}{cccc}
$\mathrm{H}$ & 6.2403994 & 1.4159508 & 0.260023 \\
\hline
\end{tabular}

$\begin{array}{lllll}\text { H } & 7.8028594 & 6.0995508 & -0.1585163 \\ \text { H } & 5.3834294 & 5.6225808 & 0.0601437\end{array}$

$\begin{array}{llll}\mathrm{H} & 5.3834294 & 5.6225808 & 0.0601437\end{array}$

$\begin{array}{lllll}\mathrm{H} & 3.5655894 & 4.0439308 & 0.0564437\end{array}$

$\begin{array}{llll}\mathrm{H} & 3.9616994 & 3.0373108 & 1.4640037\end{array}$

$\begin{array}{llll}\mathrm{H} & 3.2266694 & -0.2153392 & -1.3390463\end{array}$

$\begin{array}{llll}\text { H } & 1.0484394 & -1.4304592 & -1.087326\end{array}$

$\begin{array}{llll}\mathrm{H} & -0.4643106 & 1.8101508 & 1.2873637\end{array}$

$\begin{array}{llll}\mathrm{H} & 1.6822594 & 2.9698808 & 1.1053537\end{array}$

$\begin{array}{llll}\text { C } & -8.3380306 & 2.5296908 & 0.0387937\end{array}$

$\begin{array}{llll}\text { C } & -9.23829206 & 3.4282408 & 0.6910037\end{array}$

$\begin{array}{llll}\text { C } & -7.1691306 & 3.0317308 & -0.5647963\end{array}$

$\begin{array}{llll}\text { C } & -6.8435406 & 4.3884008 & -0.4955263\end{array}$

$\begin{array}{llll}\text { C } & -8.8904606 & 4.7846508 & 0.7468737\end{array}$

$\begin{array}{lllll}\text { C } & -7.7145506 & 5.2633608 & 0.1672037\end{array}$

$\begin{array}{llll}\text { C } & -5.5438406 & 4.8917908 & -1.0799263\end{array}$

$\begin{array}{lllll}\text { O } & -4.4319406 & 4.7582708 & -0.1616863\end{array}$

$\begin{array}{llll}\text { C } & -3.8612806 & 3.5074508 & -0.0762763\end{array}$

$\begin{array}{llll}\text { C } & -3.8612806 & 3.5074508 & -0.0762763 \\ \text { C } & -4.0807306 & 2.7278708 & 1.0635737\end{array}$

$\begin{array}{llll}\text { C } & -4.0807306 & 2.7278708 & 1.0635737 \\ \text { C } & -3.5013506 & 1.4648708 & 1.1654537\end{array}$

$\begin{array}{llll}\text { C } & -3.5013506 & 1.4648708 & 1.1654537\end{array}$

$\begin{array}{llll}C & -2.6522006 & 0.978508 & 0.1564937 \\ C & -2.4298706 & 1.7784808 & -0.9849663\end{array}$

$\begin{array}{llll}C & -2.429806 & 1.7784808 & -0.9849663 \\ C & -3.0375306 & 3.0261108 & -1.1019263\end{array}$

$\begin{array}{lllll}\mathrm{N} & -3.03714506 & 0.026103792 & 0.2489337\end{array}$

$\begin{array}{llrr}\mathrm{C} & -3.0375306 & 3.0261108 & -1.1019263 \\ \mathrm{H} & -10.1101506 & -0.3723792 & 0.2489337\end{array}$ $\begin{array}{llll}\text { H } & -6.5088706 & 2.3384708 & -1.0767463\end{array}$ $\begin{array}{llll}\mathrm{H} & -9.5646006 & 5.4720108 & 1.2509437\end{array}$ $\begin{array}{llll}\mathrm{H} & -7.4697606 & 6.3212408 & 0.2281537\end{array}$ $\begin{array}{lllll}\mathrm{H} & -5.6019806 & 5.9637408 & -1.2863263\end{array}$ $\begin{array}{llll}\mathrm{H} & -5.3068506 & 4.3701808 & -2.0156463\end{array}$ $\begin{array}{llll}\mathrm{H} & -4.7308906 & 3.1092008 & 1.8437937\end{array}$ $\begin{array}{lllll}\mathrm{H} & -3.7082806 & 0.8299608 & 2.0220737\end{array}$ $\begin{array}{llll}\mathrm{H} & -1.7897506 & 1.4069008 & -1.7791863\end{array}$ $\begin{array}{llll}\text { H } & -2.8683606 & 3.6396108 & -1.9823763\end{array}$ $\begin{array}{llll}\text { C } & 12.1690594 & -1.9710092 & 3.4064237\end{array}$ $\begin{array}{llll}\text { C } & 12.7806094 & -1.7458692 & 2.1741537\end{array}$ $\begin{array}{llll}\text { C } 11.9827494 & -1.4539392 & 1.0577837\end{array}$ $\begin{array}{llll}\text { C } 10.5913894 & -1.3663492 & 1.027637\end{array}$ $\begin{array}{llll}\text { C } & 9.9889394 & -1.6369792 & 2.4297637\end{array}$ $\begin{array}{llll}\text { C } 10.7831694 & -1.9313292 & 3.5482737\end{array}$ $\begin{array}{llll}\text { H } & 12.7854894 & -2.1990792 & 4.2717737\end{array}$ $\begin{array}{llll}\mathrm{H} & 12.7854894 & -2.1990792 & 4.2717737 \\ \mathrm{H} & 13.8611594 & -1.8060492 & 2.0721937\end{array}$ $\begin{array}{llll}\mathrm{N} & 12.5442994 & -1.2618492 & -0.208896\end{array}$ $\begin{array}{llll}\text { C } & 9.7339894 & -0.9519892 & 0.0107137\end{array}$ $\begin{array}{llll}\mathrm{N} & 8.5955194 & -1.6179892 & 2.513073\end{array}$ $\begin{array}{llll}\mathrm{H} & 10.3182594 & -2.1347392 & 4.5095437\end{array}$ $\begin{array}{llll}\text { C } & 8.3588894 & -1.5989692 & 0.1232837\end{array}$ $\begin{array}{llll}\text { C } & 7.7842394 & -1.7756492 & 1.3882137\end{array}$ $\begin{array}{llll}\text { C } & 6.4181594 & -2.0740992 & 1.5008337\end{array}$ $\begin{array}{llll}\text { C } & 5.6546094 & -2.2008992 & 0.3405437\end{array}$ $\begin{array}{llll}\text { C } & 6.2282294 & -2.0964692 & -0.9267163\end{array}$ $\begin{array}{llll}\text { C } & 7.5942894 & -1.7943192 & -1.0338163\end{array}$ $\begin{array}{llll}\text { C } & 10.3964494 & -1.3825092 & -1.2857863\end{array}$ $\begin{array}{llll}\text { C } & 11.7920394 & -1.4637892 & -1.3708363 \\ \text { C } & 12.4057294 & -1.7575892 & -2.5976063\end{array}$ $\begin{array}{llll}\text { C } & 12.4057294 & -1.7575892 & -2.5976063 \\ \text { C } & 11.608694 & -1.904392 & -3.7173863\end{array}$ $\begin{array}{llll}\text { C } & 11.6086894 & -1.9904392 & -3.7173863 \\ \text { C } & 1.2175294 & -1.956692 & -3.6390963\end{array}$ $\begin{array}{llll}\text { C } & 1.62175294 & -1.9596692 & -3.6390963 \\ \text { C } & 9.6077594 & -1.6634592 & -2.4107463\end{array}$ $\begin{array}{llll}\text { C } & 9.6077594 & -1.6634592 & -2.4107463\end{array}$ $\begin{array}{llll}\text { N } & 8.2190094 & -1.6518692 & -2.2731763\end{array}$ $\begin{array}{llll}\text { H } & 13.5353794 & -1.4458592 & -0.2859963\end{array}$ $\begin{array}{llll}\mathrm{H} & 8.5357494 & -1.458592 & 0.2859963\end{array}$ $\begin{array}{llll}4 & 5.9608794 & -2.1882792 & 2.4802437\end{array}$ $\begin{array}{lllll}\text { H } & 5.908794 & -2.1882792 & 2.4802437\end{array}$ \begin{tabular}{llll}
$H$ & 5.533494 & -2.4178292 & 0.4263437 \\
\hline
\end{tabular} H $13.4891494-1.8118092-2.6671463$ $\begin{array}{lllll}\mathrm{H} & 13.4891494 & -1.8118092 & -2.6671463 \\ \mathrm{H} & 12.0823094 & -2.2189692 & -4.6683263\end{array}$
H $\quad 9.6082694 \quad-2.1699092 \quad-4.5143663$ $\begin{array}{llll}\text { H } & 7.6786594 & -1.9071392 & -3.0878163\end{array}$ $\begin{array}{llll}\text { C } & 9.4172194 & 0.5079608 & 0.0161137\end{array}$ $\begin{array}{llll}\text { C } & 8.8437894 & 1.5796908 & 0.0207437\end{array}$ $\begin{array}{llll}\text { C } & -12.8362306 & -2.8536592 & -0.1097763\end{array}$ $\begin{array}{llll}\text { C } & -12.2024606 & -2.6954592 & 1.1216237\end{array}$ $\begin{array}{llll}\text { C } & -10.8469206 & -2.3340792 & 1.1512937\end{array}$ $\begin{array}{llll}\text { C } & -10.8469206 & -2.3340792 & 1.1512937\end{array}$ C $-10.7895606-2.3351892-1.2756863$ $\begin{array}{llll}C & -10.7895606 & -2.3351892 & -1.2756863 \\ C & -12.1450806 & -2.6961792 & -1.3099263\end{array}$ \begin{tabular}{llll}
$C$ & -12.1450806 & -2.6961792 & -1.3099263 \\
\hline
\end{tabular} $\begin{array}{lll}-13.886806 & -3.1307092 & -0.1344663 \\ -12.8545692 & 2.0496037\end{array}$ $\begin{array}{llll}H & -12.7457906 & -2.8545692 & 2.0496037\end{array}$

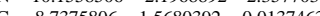
$\begin{array}{llll}\mathrm{C} & -8.7375806 & -1.5680392 & -0.0137463\end{array}$ \begin{tabular}{llll}
\hline & -10.0417006 & -2.2007292 & -2.4477363
\end{tabular} $\begin{array}{llll}H & -12.6439506 & -2.8556192 & -2.2624763\end{array}$ $\begin{array}{lll}\mathrm{C} & -7.9691806-2.0496492 & -1.2364063\end{array}$ $\begin{array}{llll}\text { C } & -8.6453006 & -2.2798892 & -2.4403663\end{array}$ $\begin{array}{llll}C & -7.9223606 & -2.5792592 & -3.6047463 \\ \text { C } & -6.5310706 & -2.6488492 & -3.540263\end{array}$ $\begin{array}{llll}\text { C } & -6.5310706 & -2.6488492 & -3.5402863\end{array}$ $\begin{array}{llll}\text { C } & -5.8449806 & -2.4541692 & -2.3425963\end{array}$ $\begin{array}{llll}\text { C } & -6.5720706 & -2.1612192 & -1.1785163\end{array}$ $\begin{array}{llll}\text { C } & -8.0279606 & -2.0463592 & 1.2459037\end{array}$ $\begin{array}{llll}\text { C } & -8.7604806 & -2.2747592 & 2.4168637\end{array}$ $\begin{array}{llll}\text { C } & -8.0933006 & -2.5709692 & 3.6148137\end{array}$ $\begin{array}{llll}\text { C } & -6.7003706 & -2.6389292 & 3.6170437\end{array}$ $\begin{array}{llll}\text { C } & -5.9578806 & -2.4456192 & 2.4530337\end{array}$ $\begin{array}{llll}\text { C } & -6.6295106 & -2.1566992 & 1.2550637\end{array}$ $\begin{array}{llll}\mathrm{N} & -5.9419506 & -1.9889592 & 0.0536437\end{array}$ $\begin{array}{llll}\mathrm{H} & -10.6544606 & -2.4740592 & 3.1920237\end{array}$ $\begin{array}{llll}\mathrm{H} & -10.5007606 & -2.4755192 & -3.3051763\end{array}$ $\begin{array}{llll}\mathrm{H} & -8.4439006 & -2.7535892 & -4.5425163\end{array}$

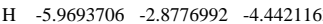
$\begin{array}{llll}\mathrm{H} & -4.7621006 & -2.5345192 & -2.3020363\end{array}$ $\begin{array}{llll}\mathrm{H} & -8.6586206 & -2.7442692 & 4.5270537\end{array}$ $\begin{array}{llll}H & -6.1822206 & -2.8656292 & 4.5450937\end{array}$ $\begin{array}{llll}H & -4.8742506 & -2.5269792 & 2.4631\end{array}$ $\begin{array}{llll}\mathrm{H} & -6.8742506 & -2.5269792 & 2.4631437 \\ \mathrm{H} & -4.9319506 & -2.0512392 & 0.0789837\end{array}$ $\begin{array}{lllll}\text { C } & -8.7287306 & -0.0806692 & -0.0119963\end{array}$

$\begin{array}{llll}\text { C } & -8.7287306 & -0.0806692 & -0.0119963 \\ \text { C } & -8.5959406 & 1.1257908 & 0.0079837\end{array}$

\section{cis-B}

$\mathrm{E}_{\mathrm{M} 06-2 \mathrm{X}(\mathrm{D} 3) / \mathrm{def2}-\mathrm{TZVPP}}=-3206.030037697$ Hartree

$\begin{array}{llll}\text { C } & -8.3541707 & 1.5039358 & -0.6988618\end{array}$

$\begin{array}{llll}\text { C } & -9.2138707 & 2.4982858 & -1.200741\end{array}$

$\begin{array}{llll}\text { C } & -7.0139307 & 1.8406658 & -0.4266218\end{array}$

$\begin{array}{lllll}\text { C } & -6.5377807 & 3.1368958 & -0.629311\end{array}$

$\begin{array}{llll}\text { C } & -8.7343607 & 3.7878358 & -1.413831\end{array}$

$\begin{array}{llll}\text { C } & -7.4073007 & 4.1141158 & -1.126141\end{array}$

$\begin{array}{llll}\text { C } & -5.1116607 & 3.4635358 & -0.2358618\end{array}$

$\begin{array}{lllll}\text { O } & -4.6758907 & 4.6320558 & -0.9257018\end{array}$

$\begin{array}{llll}\text { C } & -3.5922807 & 5.3138758 & -0.4477418\end{array}$

$\begin{array}{llll}\text { C } & -3.4542307 & 6.6330258 & -0.9076018\end{array}$

$\begin{array}{llll}\text { C } & -2.4353307 & 7.4363258 & -0.4207418\end{array}$

$\begin{array}{llll}\text { C } & -1.4849507 & 6.9249658 & 0.4793882\end{array}$

$\begin{array}{lllll}\text { C } & -1.6031307 & 5.5972558 & 0.9063682\end{array}$

$\begin{array}{llll}\text { C } & -2.6552807 & 4.7951358 & 0.4550382\end{array}$

$\begin{array}{llll}\mathrm{N} & -0.6334107 & 7.8961358 & 1.1073282\end{array}$

$\begin{array}{lllll}\text { H } & -10.2468207 & 2.2470558 & -1.4203518\end{array}$

$\begin{array}{llll}\text { H } & -6.3516307 & 1.0660358 & -0.0484518\end{array}$

$\begin{array}{lllll}\mathrm{H} & -9.4015707 & 4.5510158 & -1.8056818\end{array}$

$\begin{array}{llll}\mathrm{H} & -7.0388707 & 5.1200958 & -1.2931618\end{array}$

$\begin{array}{llll}\mathrm{H} & -4.4492207 & 2.6164758 & -0.4653418\end{array}$

$\begin{array}{llll}\mathrm{H} & -4.4492207 & 2.6164758 & -0.4653418 \\ \mathrm{H} & -5.0536207 & 3.6422058 & 0.8483682\end{array}$

$\begin{array}{llll}\mathrm{H} & -4.1905107 & 7.0202058 & -1.6049618\end{array}$

$\begin{array}{lllll}4 & -1.005107 & 7.0202058 & -1.6049618\end{array}$

$\begin{array}{llll}H & -2.3684007 & 8.4801858 & -0.7128818 \\ H & -0.8932707 & 5.1941858 & 1.6219182\end{array}$

$\begin{array}{lllll}H & -0.8932707 & 5.1941858 & 1.6219182\end{array}$

$\begin{array}{llll}\text { C } & -2.7373207 & 3.7758158 & 0.8162182\end{array}$

$\begin{array}{llll}\text { C } & 8.2748193 & 1.4847958 & -0.9169218 \\ \text { C } 8.7692893 & 2.1593258 & -2.0470618\end{array}$

$\begin{array}{llll}\text { C } & 8.7692893 & 2.1593258 & -2.0470618 \\ \text { C } & 7.2599593 & 2.0974158 & -0.1527218\end{array}$

$\begin{array}{llll}\text { C } & 7.2599593 & 2.0974158 & -0.1527218 \\ \text { C } 6.7480693 & 3.3454958 & -0.5033018\end{array}$ $\begin{array}{llll}\text { C } & 8.2536593 & 3.4051958 & -2.4019918\end{array}$ $\begin{array}{llll}\text { C } & 7.2499793 & 3.9981858 & -1.6383518\end{array}$

$\begin{array}{llll}\text { C } & 5.6952293 & 4.0120858 & 0.3472682\end{array}$

$\begin{array}{llll}\text { O } & 4.4949393 & 4.1733758 & -0.4231418\end{array}$

$\begin{array}{llll}\text { C } & 3.5169093 & 4.9869858 & 0.0676682\end{array}$

$\begin{array}{llll}\text { C } & 3.5434693 & 5.5930858 & 1.3317682\end{array}$

$\begin{array}{llll}\text { C } & 2.5329693 & 6.4839858 & 1.6849682\end{array}$

$\begin{array}{llll}\text { C } & 1.4437193 & 6.7273158 & 0.8397782\end{array}$

$\begin{array}{llll}\text { C } & 1.4041093 & 6.0841258 & -0.4125618\end{array}$

$\begin{array}{llll}\text { C } & 2.4337593 & 5.2350358 & -0.7943718\end{array}$

$\begin{array}{llll}\mathrm{N} & 0.6037393 & 7.8111858 & 1.2588182\end{array}$ $\begin{array}{llll}\mathrm{H} & 9.5490693 & 1.6944758 & -2.6422118\end{array}$ $\begin{array}{lllll}\mathrm{H} & 6.8740993 & 1.5748458 & 0.7180882\end{array}$ \begin{tabular}{llll}
$\mathrm{H}$ & 8.6393393 & 3.9166158 & -3.2797618 \\
\hline & 6.886193 & 4.9678358 & -1.9208618
\end{tabular} $\begin{array}{lllll}\mathrm{H} & 6.8486193 & 4.9678358 & -1.9208618\end{array}$ $\begin{array}{llll}\text { H } & 6.0462193 & 5.0013058 & 0.6714182\end{array}$ $\begin{array}{lllll}\text { H } & 5.4846393 & 3.4161158 & 1.2451182\end{array}$ $\begin{array}{llll}\mathrm{H} & 4.3566493 & 5.4119158 & 2.0245582\end{array}$ $\begin{array}{lllll}\mathrm{H} & 2.5799093 & 7.0187558 & 2.6289982\end{array}$ $\begin{array}{llll}\mathrm{H} & 2.57006193 & 6.2816158 & -1.1017918\end{array}$ $\begin{array}{lllll}\text { H } & 2.4352093 & 4.7635058 & -1.7722418\end{array}$ $\begin{array}{llll}\text { C } & 2.435172807 & -3.7407342 & -0.4170918\end{array}$ $\begin{array}{llll}\text { C }-13.3172807 & -3.7407342 & 0.4170918\end{array}$ $\begin{array}{llll}C & -12.8892407 & -3.2959642 & 0.8323782\end{array}$ $\begin{array}{llll}C & -11.5517207 & -2.905992 & 0.9589182\end{array}$ $\begin{array}{llll}\text { C }-1.6681107 & -3.9429742 & -0.0881818\end{array}$ $\begin{array}{llll}\text { C } & -11.1043907 & -3.4326442 & -1.3267918\end{array}$ $\begin{array}{llll}C & -12.4410407 & -3.8233142 & -1.4978018\end{array}$ $\begin{array}{llll}\text { H } & -14.3523207 & -4.0449442 & -0.5472718 \\ \text { H } & -13.5764507 & -3.2608742 & 1.6738582\end{array}$ $\begin{array}{llll}\text { N } & -11.0646707 & -2.4939742 & 2.2425982\end{array}$ $\begin{array}{llll}\text { C } & -9.2448407 & -2.4361842 & 0.0705482\end{array}$ $\begin{array}{llll}\mathrm{N} & -10.1781707 & -3.5375042 & -2.3680818 \\ \mathrm{H} & -12.7813207 & -4.1971942 & -2.4600718\end{array}$ $\begin{array}{llll}\mathrm{H} & -10.1781707 & -3.5375042 & -2.3680818 \\ \mathrm{C} & -8.3237807 & -4.1971942 & -2.4600718\end{array}$ $\begin{array}{llll}\text { C } & -8.3237807 & -3.1900942 & -0.8786818\end{array}$ $\begin{array}{llll}\text { C } & -8.8068107 & -3.6318442 & -2.1166318\end{array}$ $\begin{array}{llll}\text { C } & -7.9204707 & -4.1556742 & -3.0693618\end{array}$ $\begin{array}{llll}\text { C } & -6.5645407 & -4.2432542 & -2.7585118\end{array}$ $\begin{array}{llll}\text { C } & -6.0766207 & -3.8573642 & -1.5108518\end{array}$ $\begin{array}{llll}\text { C } & -6.9663907 & -3.3320242 & -0.5624818\end{array}$ $\begin{array}{llll}\text { C } & -8.7820207 & -2.6486342 & 1.5048682\end{array}$ $\begin{array}{llll}\text { C } & -9.7051907 & -2.5769542 & 2.5554082\end{array}$ $\begin{array}{llll}\text { C } & -9.2582707 & -2.5934642 & 3.8850482\end{array}$ $\begin{array}{llll}\text { C } & -7.8921407 & -2.6996142 & 4.1403582\end{array}$ $\begin{array}{llll}\text { C } & -6.9654007 & -2.8246242 & 3.1063682\end{array}$ $\begin{array}{llll}\text { C } & -7.4168507 & -2.8050442 & 1.7785182\end{array}$ $\begin{array}{llll}\mathrm{N} & -6.5313707 & -2.9351542 & 0.7050982\end{array}$ $\begin{array}{llll}\text { H } & -11.7065707 & -2.5677642 & 3.0199182\end{array}$ $\begin{array}{llll}\mathrm{H} & -10.5078107 & -3.9765642 & -3.2167418\end{array}$

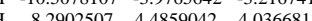
$\begin{array}{llll}\mathrm{H} & -8.2902507 & -3.4859042 & -4.0366818 \\ \mathrm{H} & -5.8756207 & -4.6444142 & -3.4969718\end{array}$ $\begin{array}{llll}H & -5.870205107 & -3.9572042 & -1.2734318\end{array}$ $\begin{array}{llll}H & -9.9715407 & -2.5241342 & 4.7023182 \\ H & -7.5436807 & -2.7090842 & 5.1696182\end{array}$ \begin{tabular}{llll}
-7.5436807 & -2.7090842 & 5.1696182 \\
\hline & -5.9056107 & -2.9345242 & 3.3219782
\end{tabular} $\begin{array}{llll}-5.574107 & -2.9345242 & 3.3219782\end{array}$ \begin{tabular}{llll}
\hline & -5.5741707 & -3.1595842 & 0.9397382 \\
C & -9.1052807 & -0.9868342 & -0.2396618
\end{tabular} $\begin{array}{llll}\text { C } & -9.1052807 & -0.9868342 & -0.2396618 \\ \text { C } & -8.7993107 & 0.1667258 & -0.4644818\end{array}$ $\begin{array}{lrrr}\text { C } & -8.793107 & 0.1667258 & -0.4644818 \\ \text { C } & 13.2378893 & -3.2392242 & 1.4159382\end{array}$ 
$\begin{array}{llll}\text { C } & 12.9284693 & -3.3749342 & 0.0637382\end{array}$ $\begin{array}{llll}\text { C } & 11.6151493 & -3.1321042 & -0.365811\end{array}$ $\begin{array}{llll}\text { C } & 10.6366593 & -2.7343842 & 0.555208\end{array}$ $\begin{array}{llll}\text { C } & 10.9550793 & -2.6421742 & 1.916968\end{array}$ $\begin{array}{llll}\text { C } & 12.2670393 & -2.8843742 & 2.350868\end{array}$ $\begin{array}{llll}\mathrm{H} & 14.2540793 & -3.4293042 & 1.750588\end{array}$ $\begin{array}{llll}\text { H } & 13.6892093 & -3.6775942 & -0.6512818\end{array}$ $\begin{array}{llll}\mathrm{N} & 11.2462893 & -3.2959842 & -1.7042718\end{array}$ $\begin{array}{llll}\text { C } & 9.2369493 & -2.3872742 & 0.0766682\end{array}$ $\begin{array}{llll}\mathrm{N} & 9.9379293 & -2.3244042 & 2.8214882\end{array}$ $\begin{array}{llll}\mathrm{H} & 12.5157593 & -2.8072042 & 3.4062082\end{array}$ $\begin{array}{llll}\text { C } & 8.2286493 & -2.6992142 & 1.1735482\end{array}$ $\begin{array}{llll}\text { C } & 8.5938093 & -2.5573242 & 2.5178082\end{array}$ $\begin{array}{llll}\text { C } & 7.6194493 & -2.6478042 & 3.523108\end{array}$ $\begin{array}{llll}\text { C } & 6.2955293 & -2.8955342 & 3.163628\end{array}$ $\begin{array}{llll}\text { C } 5.9257793 & -3.0937742 & 1.8341782\end{array}$

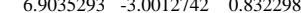
$\begin{array}{lll}8.9046093 & -3.1981842 & -1.1673518\end{array}$ $\begin{array}{llll}\text { C } & 9.9195193 & -3.5476742 & -2.0665118\end{array}$ $\begin{array}{llll}\text { C } & 9.5949793 & -4.1389242 & -3.2964218\end{array}$ $\begin{array}{llll}\text { C } & 8.2566793 & -4.3866942 & -3.597811\end{array}$ $\begin{array}{llll}\text { C } & 7.2392893 & -4.0929442 & -2.6913218\end{array}$ $\begin{array}{llll}7.5685493 & -3.5003642 & -1.4633118\end{array}$

$\begin{array}{llll}\text { N } & 6.5907093 & -3.1997142 & -0.5133218\end{array}$
$\begin{array}{llll}\mathrm{H} & 11.9542993 & -3.6763542 & -2.3173918\end{array}$ $\begin{array}{llll}\mathrm{H} & 10.1860093 & -2.3551442 & 3.8008882\end{array}$ \begin{tabular}{llll}
\hline & 7.8972393 & -2.5239242 & 4.5666682
\end{tabular} $\begin{array}{llll}\text { H } & 5.5383293 & -2.9614142 & 3.9403482\end{array}$ H $4.8941293 \quad-3.3144742 \quad 1.5723582$ $\begin{array}{llll}\text { H } & 10.3798893 & -4.3993042 & -4.0018618\end{array}$ $\begin{array}{llll}\text { H } & 8.0026993 & -4.8409642 & -4.5517318\end{array}$ $\begin{array}{llll}\mathrm{H} & 6.2026993 & -4.3171842 & -2.9294318\end{array}$ $\begin{array}{llll}\text { H } & 5.6503693 & -3.5070242 & -0.7191218\end{array}$ $\begin{array}{llll}\text { C } & 9.0788293 & -0.9450442 & -0.2608518\end{array}$

$\begin{array}{llll}\text { C } & 8.7435193 & 0.1822358 & -0.5642418\end{array}$

\section{cis- $\mathbf{C}$}

$\mathrm{E}_{\mathrm{M} 06-2 \mathrm{X}(\mathrm{D} 3) / \mathrm{def} 2-\mathrm{TZVPP}}=-3206.032771190$ Hartree

C $8.3214377 \quad 2.1146398-1.0841089$

$\begin{array}{llll}\text { C } 9.1050277 & 3.1071298 & -1.7006589\end{array}$

$\begin{array}{llll}\text { C } & 6.9673977 & 2.3875498 & -0.8050289\end{array}$

C $6.4043577 \quad 3.6240998-1.1212889$

$\begin{array}{llll}\text { C } & 8.5410777 & 4.3397698 & -2.0193389\end{array}$

$\begin{array}{llll}\text { C } 7.2012977 & 4.6025298 & -1.728118\end{array}$

$\begin{array}{llll}\text { C } 4.9418677 & 3.9078998 & -0.8532089\end{array}$

$\begin{array}{lrrr}\text { C } & 4.9418677 & 3.9078998 & -0.8532089 \\ \mathrm{O} & 4.5342877 & 3.1922298 & 0.3103811\end{array}$

$\begin{array}{llll}\text { C } 3.2898977 & 3.4049098 & 0.8264911\end{array}$

$\begin{array}{llll}\text { C } & 3.2898977 & 3.4049098 & 0.8264911 \\ \text { C } & 3.0301177 & 2.7593098 & 2.0465711\end{array}$

$\begin{array}{llll}\text { C } & 3.0323177 & 2.7593098 & 2.0465711 \\ \text { C } & 1.8230977 & 2.9593398 & 2.6954211\end{array}$

$\begin{array}{lllll}\text { C } & 0.8142977 & 3.7495498 & 2.116611\end{array}$

$\begin{array}{lllll}\text { C } & 1.0718877 & 4.3795098 & 0.892831\end{array}$

$\begin{array}{llll}\text { C } & 2.3038177 & 4.2182498 & 0.251881\end{array}$

$\begin{array}{llll}\mathrm{N} & -0.2979423 & 4.0414298 & 2.9762811\end{array}$

$\begin{array}{lllll}\text { H } & 10.1484577 & 2.9026798 & -1.919298\end{array}$

$\begin{array}{lllll}\mathrm{H} & 6.3648577 & 1.6259698 & -0.3233889\end{array}$

$\begin{array}{llll}\mathrm{H} & 9.1513577 & 5.1068398 & -2.488388\end{array}$

$\begin{array}{lllll}\mathrm{H} & 6.7764777 & 5.5746298 & -1.9688289\end{array}$

H $\quad 4.3210877 \quad 3.5976398 \quad-1.708478$

$\begin{array}{lllll}\text { H } & 4.7871477 & 4.9859498 & -0.7071489\end{array}$

$\begin{array}{lllll}\mathrm{H} & 3.8114677 & 2.1459898 & 2.4842611\end{array}$

$\begin{array}{lllll}\text { H } & 1.6398677 & 2.5178698 & 3.6705711\end{array}$

$\begin{array}{lllll}\mathrm{H} & 0.3213477 & 5.0238698 & 0.446571\end{array}$

$\begin{array}{lllll}\text { H } & 2.4839477 & 4.7354598 & -0.6839589\end{array}$

$\begin{array}{lllll}\text { C } & -8.2879823 & 1.9824798 & -1.0446289\end{array}$

$\begin{array}{llll}\text { C } & -8.28752623 & 3.0835498 & -0.9316589\end{array}$

$\begin{array}{lllll}\text { C } & -6.1582623 & 3.0835898 & 2.0316589\end{array}$

$\begin{array}{llll}\text { C } & -6.9981723 & 2.1838098 & -1.5737389 \\ \text { C } & -6.5781823 & 3.4523798 & -1.9771189\end{array}$

$\begin{array}{llll}\text { C } & -6.5781823 & 3.4523798 & -1.9771189 \\ \text { C } & -8.7392723 & 4.3484098 & -1.3337189\end{array}$

$\begin{array}{llll}\text { C } & -8.732723 & 4.3484098 & -1.3337189\end{array}$

$\begin{array}{llll}\text { C } & -8.7392723 & 4.3484098 & -1.3337189 \\ \text { C } & -5.4555823 & 4.5363898 & -1.850438 \\ \text { O } & -4.2192823 & 3.6510798 & -2.6241089\end{array}$

\begin{tabular}{llll}
$C$ & -5.2192823 & 3.6310798 & -2.624108 \\
\hline & -4.1791623 & 2.8198098 & -2.1036189
\end{tabular}

$\begin{array}{lllll}C & -4.1791623 & 2.8198098 & -2.1036189\end{array}$

$\begin{array}{llll}\text { C } & -3.5371323 & 3.1839898 & -0.9542189 \\ \text { C } & -3.9312523 & 4.2329298 & -0.113988\end{array}$

$\begin{array}{llll}\text { C } & -3.9312523 & 4.2329298 & -0.1139889\end{array}$

$\begin{array}{llll}\text { C } & -3.2029223 & 4.4870498 & 1.045611 \\ \text { C } & -2.0482223 & 3.7593698 & 1.3606911\end{array}$

$\begin{array}{llll}\text { C } & -3.2029223 & 4.4870498 & 1.045611 \\ \text { C } & -1.6677123 & 3.7593698 & 1.3606911\end{array}$

$\begin{array}{llll}\text { C } & -1.6677123 & 2.6994098 & 0.5162411\end{array}$

$\begin{array}{llll}\mathrm{C} & -2.4101123 & 2.4132998 & -0.6210189 \\ \mathrm{~N} & -1.5072023 & 4.0455298 & 2.657211\end{array}$

$\begin{array}{cccc}\mathrm{N} & -1.5072023 & 4.0455298 & 2.6567211 \\ \mathrm{H} & -10.1532223 & 2.9336498 & -0.5245289\end{array}$ $\begin{array}{llll}\text { H } & 5.2144677 & -3.3926302 & -1.2673589\end{array}$ $\begin{array}{llll}\mathrm{H} & 5.7263477 & -2.4086802 & 0.8827711\end{array}$ $\begin{array}{llll}\text { C } & 9.2165477 & -0.2810102 & -0.4235789\end{array}$ $\begin{array}{llll}\text { C } & 8.8529777 & 0.8337998 & -0.7400589\end{array}$ $\begin{array}{llll}\text { C }-12.8046623 & -3.5364202 & -1.2391489\end{array}$ $\begin{array}{llll}\text { C } & -12.7455023 & -2.9672702 & 0.0318011\end{array}$ $\begin{array}{llll}\text { C }-11.5227123 & -2.4628902 & 0.4996311\end{array}$ $\begin{array}{llll}C & -1.52843823 & -2.4520902 & -0.315998\end{array}$ $\begin{array}{llll}\text { C } & -10.4512423 & -3.1264302 & -1.5740889\end{array}$ $\begin{array}{llll}\text { C } & -11.6719623 & -3.6325402 & -2.0455189\end{array}$ $\begin{array}{llll}\text { H } & -13.7506123 & -3.9290502 & -1.602278\end{array}$ $\begin{array}{llll}\text { H } & -13.6306723 & -2.9229702 & 0.661181\end{array}$ $\begin{array}{llll}\mathrm{N} & -11.4031423 & -1.9195202 & 1.782071\end{array}$ $\begin{array}{llll}\text { C } & -9.0854323 & -1.8755702 & 0.1497211\end{array}$ $\begin{array}{llll}\mathrm{N} & -9.2803423 & -3.2340202 & -2.3286089\end{array}$ H $-11.7262423-4.1029302-3.023968$ $\begin{array}{llll}\text { C } & -7.9040323 & -2.6210502 & -0.4558689\end{array}$ $\begin{array}{llll}\text { C } & -8.0181723 & -3.1889102 & -1.7305689\end{array}$ $\begin{array}{llll}\text { C } & -6.8804123 & -3.6916902 & -2.3790889\end{array}$ $\begin{array}{llll}\text { C } & -5.6475823 & -3.6280902 & -1.7313689\end{array}$ $\begin{array}{llll}\text { C } & -5.5272323 & -3.1155202 & -0.4405589\end{array}$ $\begin{array}{llll}\text { C } & -6.6680023 & -2.6141402 & 0.2040211\end{array}$ $\begin{array}{llll}\text { C } & -9.0008223 & -1.9332802 & 1.667611\end{array}$ $\begin{array}{llll}\text { C } & -10.1686723 & -1.8710102 & 2.4376511\end{array}$ $\begin{array}{llll}\text { C } & -10.0847223 & -1.7697802 & 3.8341011\end{array}$ $\begin{array}{llll}\text { C } & -8.8287923 & -1.7503302 & 4.438821 \\ \text { C } & -7.6583323 & -1.8605502 & 3.6900811\end{array}$ $\begin{array}{llll}\text { C } & -7.6583323 & -1.8605502 & 3.690081\end{array}$ $\begin{array}{llll}C & -7.7471923 & -1.9612202 & 2.6937511\end{array}$ $\begin{array}{llll}\mathrm{C} & -7.6583323 & -1.7605502 & 3.690811 \\ \mathrm{~N} & -6.6076923 & -1.0612202 & 2.2937511 \\ \mathrm{H} & -12.0967402 & 1.4987811\end{array}$ $\begin{array}{llll}\mathrm{N} & -6.6076923 & -2.0967402 & 1.4987811 \\ \mathrm{H} & -12.2179523 & -1.9973302 & 2.3752911\end{array}$ \begin{tabular}{llll}
$\mathrm{H}$ & -6.6076923 & -2.0967402 & 1.4987811 \\
$\mathrm{H}-9.3191523$ & -3.7582802 & -3.3752911 \\
\hline
\end{tabular} \begin{tabular}{llll} 
H & -9.3491523 & -3.7582802 & -3.1899589 \\
\hline
\end{tabular} \begin{tabular}{llll} 
H & -6.9627323 & -4.1196702 & -3.3748789 \\
\hline & -4.7637223 & -4.0109902 & -2.2344989
\end{tabular} $\begin{array}{llll}-4.7637223 & -4.0109902 & -2.234498\end{array}$ $\begin{array}{llll}\text { H } & -4.5636023 & -3.0983402 & 0.0620011 \\ \text { H } & -10.989723 & -1.7600602 & 4.433411\end{array}$ $\begin{array}{llll}\mathrm{H} & -10.9897923 & -1.7100602 & 4.433141 \\ \mathrm{H} & -8.7612723 & -1.6683302 & 5.5202511\end{array}$ $\begin{array}{llll}H & -8.7612723 & -1.6683302 & 5.5202511\end{array}$ \begin{tabular}{llll}
$\mathrm{H}$ & -6.6870223 & -1.8697702 & 4.177771 \\
\hline
\end{tabular}

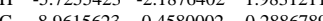
$\begin{array}{llll}\text { C } & -8.9615623 & -0.4580002 & -0.2886789\end{array}$

cis-D

$\mathrm{E}_{\mathrm{M} 06-2 \mathrm{X}(\mathrm{D} 3) / \mathrm{def2}-\mathrm{TZVPP}}=-3206.059330528$ Hartree

-3206.028099474 Basis $=$ def2-TZVPP Functional $=\mathrm{m06}-2 \mathrm{x}$

$\begin{array}{llll}\text { C } & 8.3078827 & 1.4300493 & -1.4437177\end{array}$

$\begin{array}{llll}\text { C } & 9.2088727 & 2.1852893 & -2.2198077\end{array}$

$\begin{array}{llll}\text { C } & 7.0033127 & 1.9204593 & -1.2459477\end{array}$

$\begin{array}{llll}\text { C } & 6.6007427 & 3.1378993 & -1.8012177\end{array}$

$\begin{array}{llll}\text { C } & 8.8082327 & 3.3964993 & -2.7741577\end{array}$

$\begin{array}{llll}\text { C } & 7.5127927 & 3.8750793 & -2.5641377\end{array}$

$\begin{array}{llll}\text { C } & 5.1938127 & 3.6500393 & -1.5945877\end{array}$

$\begin{array}{llll}\text { O } & 4.9173527 & 3.6729793 & -0.1901577\end{array}$

$\begin{array}{llll}\text { C } & 3.8327027 & 4.3620293 & 0.2645323\end{array}$

$\begin{array}{llll}\text { C } & 3.7726327 & 4.5307593 & 1.6581023\end{array}$

$\begin{array}{llll}\text { C } & 2.7653327 & 5.2951793 & 2.2205923\end{array}$

C $\quad \begin{array}{llll}\text { C } & 1.7474627 & 5.8520193 & 1.4247423\end{array}$

$\begin{array}{llll}\text { C } & 1.7915627 & 5.6520193 & 0.0389623\end{array}$

$\begin{array}{llll}\text { C } & 2.8306127 & 4.9194693 & -0.5425477\end{array}$

$\begin{array}{llll}\mathrm{N} & 0.9151227 & 6.8010293 & 2.1060123\end{array}$

$\begin{array}{lllll}\mathrm{H} & 10.2149427 & 1.8097893 & -2.3784177\end{array}$

$\begin{array}{lllll}\text { H } & 6.3091227 & 1.34388893 & -0.6427077\end{array}$

$\begin{array}{lllll}\mathrm{H} & 9.5090227 & 3.9767893 & -3.3681577\end{array}$

$\begin{array}{llll}\mathrm{H} & 7.2119427 & 4.8282493 & -2.9923977\end{array}$

$\begin{array}{lllll}\mathrm{H} & 4.2119427 & 4.8282493 & -2.9923977\end{array}$

$\begin{array}{llll}\mathrm{H} & 5.45757127 & 4.6601793 & -2.0123677\end{array}$

$\begin{array}{llll}4 & 4.5613827 & 4.0990193 & 2.2659223\end{array}$

$\begin{array}{llll}\mathrm{H} & 4.5613827 & 4.0990193 & 2.2659223 \\ \mathrm{H} & 2.7541827 & 5.4972293 & 3.2875223\end{array}$

$\begin{array}{llll}\text { H } & 1.0358627 & 6.0986293 & -0.5988177\end{array}$

$\begin{array}{llll}\text { H } & 2.8540327 & 4.8010393 & -1.6202577\end{array}$

$\begin{array}{llll}\text { C } & -8.1631973 & 1.5258193 & -1.2922977\end{array}$

$\begin{array}{llll}\text { C } & -8.7979073 & 2.4230393 & -2.169917\end{array}$

$\begin{array}{llll}\text { C } & -6.8537273 & 1.8138993 & -0.859677\end{array}$

$\begin{array}{llll}\text { C } & -6.1797873 & 2.9546293 & -1.2966777\end{array}$

$\begin{array}{llll}\text { C } & -8.1268473 & 3.5654993 & -2.5995677\end{array}$

$\begin{array}{llll}\text { C } & -6.8236573 & 3.8338093 & -2.1749077\end{array}$

$\begin{array}{llll}\text { C } & -4.7573273 & 3.1836393 & -0.8300377\end{array}$

$\begin{array}{lllll}\text { O } & -4.4450073 & 4.5713793 & -0.9178977\end{array}$

$\begin{array}{llll}\text { C } & -3.3342873 & 5.0459393 & -0.2841677\end{array}$

$\begin{array}{llll}\text { C } & -3.2336873 & 6.4450493 & -0.2160277\end{array}$

$\begin{array}{llll}\text { C } & -2.1936573 & 7.0314393 & 0.4846123\end{array}$

$\begin{array}{llll}\text { C } & -1.1852673 & 6.2481193 & 1.0747423\end{array}$

$\begin{array}{llll}\text { C } & -1.2709573 & 4.8537093 & 0.9740723\end{array}$

$\begin{array}{llll}\text { C } & -2.3415473 & 4.2518093 & 0.3064923\end{array}$

$\begin{array}{llll}\mathrm{N} & -0.3143373 & 6.9673393 & 1.9595323\end{array}$

$\begin{array}{llll}\mathrm{H} & -9.8092873 & 2.2153493 & -2.5050877\end{array}$

$\begin{array}{lllll}\mathrm{H} & -9.8072873 & 2.2153493 & -2.5050877\end{array}$

$\begin{array}{lllll}\mathrm{H} & -8.6233873 & 4.2568793 & -3.2752677\end{array}$

$\begin{array}{lllll}\mathrm{H} & -6.623093673 & 4.27283593 & -2.5088877\end{array}$

$\begin{array}{llll}\mathrm{H} & -6.3093673 & 4.7283593 & -2.5088877 \\ \mathrm{H} & -4.0479573 & 2.6097293 & -1.4468477\end{array}$

$\begin{array}{rrrr}\mathrm{H} & -4.0479573 & 2.6097293 & -1.4468477 \\ \mathrm{H} & -4.6457873 & 2.8388993 & 0.2067923\end{array}$
$\begin{array}{llll}\mathrm{H} & -4.0154373 & 7.0443893 & -0.6718077\end{array}$ $\begin{array}{lllll}\mathrm{H} & -2.1497173 & 8.1091993 & 0.6099623\end{array}$ $\begin{array}{llll}\mathrm{H} & -0.5217873 & 4.2280193 & 1.4479223\end{array}$ $\begin{array}{lllll}\mathrm{H} & -2.3959573 & 3.1696993 & 0.2637723\end{array}$ $\begin{array}{llll}\text { C } & 12.2275627 & -2.3186507 & 3.1217223\end{array}$ $\begin{array}{llll}\text { C } & 12.5133927 & -2.6891507 & 1.8087223\end{array}$ $\begin{array}{llll}\text { C } & 11.4769827 & -2.7133707 & 0.8635523\end{array}$ $\begin{array}{llll}\text { C } & 10.1773727 & -2.3463607 & 1.2363823\end{array}$ $\begin{array}{llll}\text { C } & 9.8988127 & -2.0172407 & 2.5701023\end{array}$ $\begin{array}{llll}\text { C } & 10.9321827 & -1.9918607 & 3.5186623\end{array}$ $\begin{array}{llll}\text { H } & 13.0289227 & -2.3004007 & 3.8553823\end{array}$ $\begin{array}{llll}\mathrm{H} & 13.5234027 & -2.9671307 & 1.5185323\end{array}$ $\begin{array}{llll}\text { N } & 11.7052927 & -3.1155407 & -0.4561877\end{array}$ $\begin{array}{llll}\text { C } & 9.0764827 & -2.2711307 & 0.1908623\end{array}$ $\begin{array}{lllll}\mathrm{N} & 8.5779127 & -1.7356307 & 2.9268323\end{array}$ $\begin{array}{llll}\text { H } & 10.7182727 & -1.7299407 & 4.5517023\end{array}$ $\begin{array}{llll}\text { C } & 7.7337427 & -2.5778807 & 0.8404723\end{array}$ $\begin{array}{llll}\text { C } 7.5001627 & -2.1970107 & 2.1676823\end{array}$ $\begin{array}{llll}\text { C } & 6.2062627 & -2.2791907 & 2.7035423\end{array}$ $\begin{array}{llll}\text { C } \quad 5.1699427 & -2.7567607 & 1.9028423\end{array}$ $\begin{array}{llll}\text { C } & 5.1699427 & -2.7567607 & 1.9028423 \\ \text { C } & 6.6929227 & -3.1927307 & 0.5983823\end{array}$ $\begin{array}{llll}\text { C } \quad 6.6929227 & -3.1070307 & 0.0666223\end{array}$

$\begin{array}{llll}\text { C } & 6.6929227 & -3.1070307 & 0.0666223 \\ \text { C } & 9.3498427 & -3.2794807 & -0.9147377\end{array}$ 
$\begin{array}{llll}\text { C } & 10.6681227 & -3.6103507 & -1.2527177\end{array}$

$\begin{array}{llll}\text { C } & 10.9247527 & -4.4295607 & -2.3622477\end{array}$

$\begin{array}{llll}\text { C } & 9.8529527 & -4.9221507 & -3.1049077\end{array}$

$\begin{array}{llll}\text { C } & 8.5337627 & -4.6424607 & -2.7522377\end{array}$

$\begin{array}{llll}\text { C } & 8.2819027 & -3.8219507 & -1.6425577\end{array}$

$\begin{array}{llll}\mathrm{N} & 6.9788327 & -3.5324107 & -1.2324477\end{array}$

$\begin{array}{lllll}\text { H } & 12.6288227 & -3.4741907 & -0.6571377\end{array}$

$\begin{array}{llll}\text { H } & 8.4013827 & -1.5810007 & 3.9098423\end{array}$

$\begin{array}{llll}\mathrm{H} & 6.0178727 & -1.9689007 & 3.7281023\end{array}$

$\begin{array}{llll}\mathrm{H} & 4.1657927 & -2.8152607 & 2.3142323\end{array}$

H $\quad 4.5842927 \quad-3.5891007 \quad-0.0041377$

$\begin{array}{lllll}\mathrm{H} & 11.9477527 & -4.6789407 & -2.6321677\end{array}$

$\begin{array}{llll}\text { H } & 10.0496827 & -5.5556407 & -3.9656377\end{array}$

$\begin{array}{llll}\text { H } & 7.7073427 & -5.0564007 & -3.3243177\end{array}$

$\begin{array}{lllll}\text { H } & 6.2354527 & -4.0079607 & -1.7247977\end{array}$

$\begin{array}{llll}\text { C } & 6.2354527 & -4.0079607 & -1.7247977 \\ \text { C } & 8.9560727 & -0.9070507 & -0.3937877\end{array}$

$\begin{array}{llll}\text { C } & 8.98883927 & 0.1735793 & 0.8786977\end{array}$

$\begin{array}{llll}C & -13.2360973 & -3.7478107 & -0.9179177\end{array}$ $\begin{array}{llll}\text { C } & -13.1031773 & -3.0540507 & 0.2836123\end{array}$ $\begin{array}{llll}\text { C } & -11.8460573 & -2.5474207 & 0.6462223\end{array}$ $\begin{array}{llll}\text { C } & -10.7467473 & -2.7175807 & -0.2061077\end{array}$ $\begin{array}{llll}\text { C } & -10.8891973 & -3.4526307 & -1.3911777\end{array}$ $\begin{array}{llll}\text { C } & -12.1443573 & -3.9613407 & -1.7575177\end{array}$ $\begin{array}{llll}\text { H } & -14.2083673 & -4.1435807 & -1.1986977\end{array}$ $\begin{array}{llll}\mathrm{H} & -13.9571673 & -2.9171007 & 0.9420223\end{array}$ $\begin{array}{llll}\text { N } & -11.6527873 & -1.8858707 & 1.8624223\end{array}$ $\begin{array}{llll}\text { C } & -9.4045573 & -2.1022807 & 0.1488723\end{array}$ $\begin{array}{llll}\mathrm{N} & -9.7566373 & -3.6795107 & -2.1776377\end{array}$ H $\quad-12.2560573 \quad-4.5270407 \quad-2.6789577$ $\begin{array}{llll}\text { C } & -8.2816273 & -2.9570707 & -0.4236577 \\ \text { C } & -8.4700273 & -3.6334007 & -1.6352077\end{array}$ $\begin{array}{llll}\text { C } & -8.4700273 & -3.6334007 & -1.6352077\end{array}$ $\begin{array}{llll}\text { C } & -8.473799573 & -4.2400707 & -2.2765777 \\ \text { C } & -6.1202173 & -4.1702007 & -1.6841177\end{array}$ $\begin{array}{llll}\text { C } & -6.1202173 & -4.1702007 & -1.6841177\end{array}$ $\begin{array}{llll}\text { C } & -5.9276373 & -3.5492907 & -0.4506677\end{array}$ $\begin{array}{llll}\text { C } & -7.0200873 & -2.9416607 & 0.1851523\end{array}$

$\begin{array}{llll}\text { C } & -9.2608673 & -2.0199507 & 1.6610223\end{array}$ $\begin{array}{llll}\text { C } & -10.3920973 & -1.8249207 & 2.4630523\end{array}$ $\begin{array}{llll}\text { C } & -10.2455773 & -1.5818107 & 3.8367923\end{array}$ $\begin{array}{llll}\text { C } & -8.9660073 & -1.5571807 & 4.3889423\end{array}$ $\begin{array}{llll}\text { C } & -7.8334973 & -1.8012007 & 3.6134723\end{array}$ $\begin{array}{llll}\text { C } & -7.83848973 & -2.0407207 & 2.2398923 \\ \text { N } & -6.8831073 & -2.3003307 & 1.4195523\end{array}$ $\begin{array}{llll}\text { N } & -6.8831073 & -2.3003307 & 1.4195523\end{array}$ H $-12.4457773 \quad-1.8643807 \quad 2.4889223$ $\begin{array}{llll}\mathrm{H} & -9.8823873 & -4.2798407 & -2.9809777\end{array}$

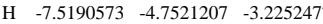
$\begin{array}{llll}\mathrm{H} & -5.2733773 & -4.6346807 & -2.1822077\end{array}$ $\begin{array}{llll}\mathrm{H} & -4.9441473 & -3.5281707 & 0.0120923\end{array}$ $\begin{array}{llll}\mathrm{H} & -11.1213473 & -1.4166207 & 4.4590423\end{array}$ $\begin{array}{llll}\mathrm{H} & -8.8501673 & -1.3659607 & 5.4523423\end{array}$ $\begin{array}{llll}\text { H } & -6.8439673 & -1.8054507 & 4.0634223\end{array}$ \begin{tabular}{llll}
\hline & -5.8439673 & -2.40540007 & 1.0634223
\end{tabular} $\begin{array}{llll}\text { H } & -5.9450873 & -2.4169007 & 1.8881423 \\ \text { C } & -9.2013273 & -0.7375507 & -0.4145877\end{array}$

$\begin{array}{llll}\text { C } & -8.7856873 & 0.3235493 & -0.8355677\end{array}$

trans-Au(111)-A Optimierung

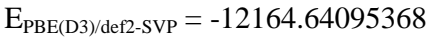

Single Point w/o Au(111) surface

\section{$\mathrm{E}_{\mathrm{M} 06-2 \mathrm{X}(\mathrm{D} 3) / \mathrm{def} 2-\mathrm{TZVPP}}=-3206.028039363$ Hartree}

Au -10.6570346 $4.5805559 \quad 3.9306543$

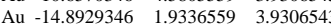
$\begin{array}{lll}\mathrm{Au}-12.0109346 & 2.0343559 & 3.9306543\end{array}$ $\begin{array}{lll}\mathrm{Au}-13.3647346 & -0.5118441 & 3.9306543\end{array}$ $\begin{array}{llll}\mathrm{Au} & -13.5391346 & 4.4798559 & 3.9306543\end{array}$ $\mathrm{Au}-17.6006346-3.15874413 .9306543$ Au $-14.7186346-3.05804413 .9306543$ $\mathrm{Au}-16.0724346 \quad-5.6042441 \quad 3.9306543$ Au - $-16.2467346 \quad-0.6125441 \quad 3.9306543$ Au $-4.8930346 \quad 4.7818559 \quad 3.9306543$ Au $-9.1289346 \quad 2.1349559 \quad 3.9306543$ Au $-6.2469346 \quad 2.2356559 \quad 3.9306543$ $\begin{array}{llll}\mathrm{Au} & -7.6007346 & -0.3106441 & 3.9306543\end{array}$ $\mathrm{Au}-7.7750346 \quad 4.6811559 \quad 3.9306543$ Au $-11.8366346 \quad-2.9574441 \quad 3.9306543$ $\begin{array}{llll}\mathrm{Au} & -8.9546346 & -2.8567441 & 3.9306543\end{array}$ Au $-10.3084346 \quad-5.4029441 \quad 3.9306543$ Au -10.4827346 $-0.4112441 \quad 3.9306543$ Au -14.5442346 -8.04984413 .9306543$ Au -11.6622346 $-7.9492441 \quad 3.9306543$ Au -13.1904346 $\quad-5.5036441 \quad 3.9306543$ Au $\quad 0.8709654 \quad 4.9830559 \quad 3.9306543$ $\begin{array}{llll}\mathrm{Au} & -3.3649346 & 2.3362559 & 3.9306543\end{array}$ $\begin{array}{llll}\mathrm{Au} & -0.4829346 & 2.4368559 & 3.9306543\end{array}$ $\begin{array}{llll}\mathrm{Au} & -1.8367346 & -0.1093441 & 3.9306543\end{array}$ $\begin{array}{llll}\mathrm{Au} & -2.0110346 & 4.8824559 & 3.9306543\end{array}$ $\begin{array}{llll}\text { Au } & -6.0726346 & -2.7561441 & 3.9306543\end{array}$ $\begin{array}{llll}\mathrm{Au} & -3.1906346 & -2.6555441 & 3.9306543\end{array}$ $\begin{array}{llll}\text { Au } & -4.5444346 & -5.2017441 & 3.9306543\end{array}$ $\begin{array}{lllll}\text { Au } & -4.7187346 & -0.2099441 & 3.9305\end{array}$ $\begin{array}{llll}\text { Au } & -4.7187346 & -0.2099441 & 3.9306543 \\ \text { Au } & -8.7802346 & -7.8485441 & 3.9306543\end{array}$ $\begin{array}{lllll}\text { Au } & -8.7802346 & -7.8485441 & 3.9306543 \\ \text { Au } & -5.8982346 & -7.7479441 & 3.9306543\end{array}$ \begin{tabular}{llll} 
& -7.8982346 & -7.7479411 & 3.930653 \\
\hline
\end{tabular} \begin{tabular}{lrrr} 
Au & -7.4264346 & -5.3023441 & 3.9306543 \\
\hline
\end{tabular} Av $7.9887654 \quad 7.7305559 \quad 3.9306543$ $\begin{array}{llll}\text { Au } & 7.9887654 & 7.7305559 & 3.9306543 \\ \text { Au } & 6.6349654 & 5.1843559 & 3.9306543\end{array}$ Au $6.6340654 \quad 5.1843559 \quad 3.9306543$ Au $5.2810654 \quad 2.6381559 \quad 3.9306543$ $\begin{array}{llll}\text { Au } & 5.2810654 & 2.6381559 & 3.9306543 \\ \text { Aun } & 3.9272654 & 0.0919559 & 3.9306543\end{array}$ $\begin{array}{llll}\text { Au } & 3.9272654 & 0.0919559 & 3.9306543\end{array}$ Au 3.75296545 .08375593 .9306543 $\begin{array}{llll}\text { Au } & -0.3086346 & -2.5548441 & 3.9306543\end{array}$ \begin{tabular}{llll} 
Au & 2.5733654 & -2.4542441 & 3.9306543 \\
\hline
\end{tabular} $\begin{array}{llll}\mathrm{Au} & 1.2195654 & -5.0004441 & 3.9306543\end{array}$ Au $1.0452654 \quad-0.0086441 \quad 3.930654$ Au $-1.6624346 \quad-5.1010441 \quad 3.9306543$ Au $10.8707654 \quad 7.8312559 \quad 3.9306543$ Au $\quad 13.7527654 \quad 7.9318559 \quad 3.9306543$ $\begin{array}{llll}\text { Au } & 12.3989654 & 5.3856559 & 3.9306543\end{array}$ $\begin{array}{llll}\text { Au } & 8.1630654 & 2.7388559 & 3.9306543\end{array}$ Au $11.0450654 \quad 2.8394559 \quad 3.9306543$ $\begin{array}{llll}\text { Au } & 9.6912654 & 0.2932559 & 3.9306543\end{array}$ Au $9.5169654 \quad 5.2850559 \quad 3.930654$ $\begin{array}{lllll}\mathrm{Au} & 5.4554654 & -2.3536441 & 3.9306543\end{array}$ $\begin{array}{lllll}\text { Au } & 8.3374654 & -2.2529441 & 3.9306543\end{array}$ $\begin{array}{llll}\mathrm{Au} & 6.9835654 & -4.7991441 & 3.9306543\end{array}$ $\begin{array}{llll}\text { Au } & 6.8092654 & 0.1926559 & 3.9306543\end{array}$ $\begin{array}{llll}\mathrm{Au} & 4.1015654 & -4.8997441 & 3.9306543\end{array}$ Au $\quad 13.9270654 \quad 2.9400559 \quad 3.9306543$ $\begin{array}{llll}\mathrm{Au} & 16.8090654 & 3.0407559 & 3.9306543\end{array}$ $\begin{array}{llll}\mathrm{Au} & 15.4552654 & 0.4945559 & 3.9306543\end{array}$ $\begin{array}{llll}\text { Au } & 15.2809654 & 5.4862559 & 3.9306543\end{array}$ $\begin{array}{lllll}\mathrm{Au} & 11.2194654 & -2.1523441 & 3.9306543\end{array}$ $\begin{array}{llll}\text { Au } & 14.1014654 & -2.0516441 & 3.9306543\end{array}$ $\begin{array}{llll}\mathrm{Au} & 12.7475654 & -4.5978441 & 3.9306543\end{array}$ $\begin{array}{llll}\text { Au } & 12.5732654 & 0.3938559 & 3.9306543\end{array}$ $\begin{array}{lllll}\mathrm{Au} & 9.8655654 & -4.6985441 & 3.9306543\end{array}$ C $-9.0850419-1.2413496-4.1402599$ $\begin{array}{llll}\text { C }-10.2643082 & -1.2941496 & -4.925236\end{array}$ $\begin{array}{llll}\text { C }-7.8271125 & -1.2118525 & -4.7898583\end{array}$ $\begin{array}{llll}\text { C } & -7.7383391 & -1.2383236 & -6.1895503\end{array}$ C $-10.1720809-1.3228255-6.321819$ $\begin{array}{llll}\text { C } & -8.9189350 & -1.3002102 & -6.954984\end{array}$ C $-6.3885279-1.1464557-6.8649048$ $\begin{array}{lllll}\text { O } & -5.4061781 & -1.7263496 & -6.015527\end{array}$ $\begin{array}{llll}\text { C } & -4.0875153 & -1.5169496 & -6.2605790\end{array}$ $\begin{array}{llll}\text { C } & -3.5725286 & -0.8553426 & -7.3963298\end{array}$ $\begin{array}{llll}\text { C } & -2.1890848 & -0.6674461 & -7.5108072\end{array}$ $\begin{array}{llll}\text { C } & -1.3044299 & -1.1347781 & -6.516835\end{array}$ $\begin{array}{llll}\text { C } & -1.8331127 & -1.8237747 & -5.3923018\end{array}$ $\begin{array}{llll}\text { C } & -3.2023204 & -2.0118397 & -5.2685275\end{array}$ $\begin{array}{llll}\mathrm{N} & 0.0593322 & -0.8535078 & -6.7015259\end{array}$ H $-11.2437709-1.3172670 \quad-4.426059$ H $\quad-6.9089422-1.1783508-4.1877331$ $\begin{array}{llll}\mathrm{H} & -11.0893624 & -1.3725317 & -6.9279640\end{array}$ $\begin{array}{llll}\text { H } & -8.8589182 & -1.3348238 & -8.0545937\end{array}$ \begin{tabular}{lllll} 
H & -6.1391762 & -0.0747211 & -7.0553195 \\
\hline
\end{tabular} \begin{tabular}{llll} 
H & -6.4054742 & -1.6598017 & -7.8543295 \\
\hline
\end{tabular} $\begin{array}{llll}\mathrm{H} & -4.2375174 & -0.4848818 & -8.1880402\end{array}$ $\begin{array}{llll}\text { H } & -1.7590947 & -0.1434390 & -8.377458\end{array}$ $\begin{array}{lllll}\mathrm{H} & -1.1295410 & -2.1844203 & -4.6285665\end{array}$ $\begin{array}{lllll}\mathrm{H} & -1.1295410 & -2.1844203 & -4.628566 \\ \mathrm{H} & -3.6375472 & -2.5313998 & -4.4018017\end{array}$ C 9.5401564 $\begin{array}{llll}\text { C } & 9.5401564 & 1.8939679 & -4.1299498 \\ \text { C } & 10.6057797 & 2.2874161 & -4.9780376\end{array}$ $\begin{array}{lllll}\text { C } & 8.3339870 & 1.2874161 & -4.9780376\end{array}$ $\begin{array}{llll}\text { C } & 8.1855930 & 1.3598048 & -6.103601 \\ \text { C } 10.4558346 & 2.2102342 & -6.3678045\end{array}$ $\begin{array}{llll}\text { C } & 0.458346 & 2.2102342 & -6.3678045\end{array}$ $\begin{array}{llll}\text { C } & 9.25647103 & 0.7454733 & -6.9323705\end{array}$ $\begin{array}{llll}C & 6.8647103 & 0.9236270 & -6.6964692\end{array}$ $\begin{array}{llll}\text { C } \quad 4.26143787 & 0.0264262 & -5.8251052\end{array}$ $\begin{array}{llll}\text { C } & 4.9384187 & -0.3116128 & -5.9344480\end{array}$ $\begin{array}{llll}\text { C } & 4.0969143 & 0.155787 & -6.9736437\end{array}$ $\begin{array}{llll}\text { C } & 2.7374698 & -0.1639823 & -6.961113 \\ \text { C } & 2.1923669 & -0.9582157 & -5.9244975\end{array}$ $\begin{array}{llll}\text { C } & 2.1923669 & -0.9582157 & -5.9244975 \\ \text { C } & 3.0506376 & -1.4459444 & -4.9092508\end{array}$ $\begin{array}{llll}\text { C } & 3.0506376 & -1.4459444 & -4.9092508\end{array}$ $\begin{array}{llll}\text { C } & 4.4061006 & -1.1307355 & -4.9120760\end{array}$ $\begin{array}{llll}\mathrm{N} & 0.8347262 & -1.2886017 & -5.7972886\end{array}$ $\begin{array}{llll}\mathrm{H} & 11.5452706 & 2.6461288 & -4.5332598\end{array}$ $\begin{array}{lllll}\mathrm{H} & 7.5074713 & 1.1188077 & -4.0585669\end{array}$ $\begin{array}{llll}\mathrm{H} & 11.2882745 & 2.5081306 & -7.0232407\end{array}$ $\begin{array}{lllll}\text { H } & 9.1549013 & 1.6788134 & -8.0273981\end{array}$ $\begin{array}{lllll}\text { H } & 7.0087781 & 0.4895670 & -7.7128536\end{array}$ $\begin{array}{lllll}\mathrm{H} & 6.1983735 & 1.8120691 & -6.8088509\end{array}$ $\begin{array}{lllll}\mathrm{H} & 4.5004346 & 0.7692240 & -7.7913704\end{array}$ $\begin{array}{lllll}\text { H } & 2.0590257 & 0.1971208 & -7.7475644\end{array}$ $\begin{array}{llll}\mathrm{H} & 2.6087741 & -2.0660312 & -4.115220 \\ \mathrm{H} & 5.085436 & -1.489584 & -4.1254619\end{array}$ H $\quad 5.0854436-1.4895844 \quad-4.1254619$ $\begin{array}{llll}\text { C } & -8.8392060 & -5.3630735 & 0.8666338\end{array}$ $\begin{array}{llll}\text { C } & -10.1116015 & -4.7708993 & 0.8120060\end{array}$ $\begin{array}{llll}\text { C } & -10.2098330 & -3.3720333 & 0.6243570\end{array}$ $\begin{array}{llll}\text { C } & -9.0319763 & -2.6035364 & 0.4860198\end{array}$ $\begin{array}{llll}\text { C } & -7.7572949 & -3.2013519 & 0.6100482\end{array}$ $\begin{array}{lllll}\text { C } & -7.6614253 & -4.6002637 & 0.799143\end{array}$ $\begin{array}{lllll}\text { H } & -8.7628509 & -6.4519796 & 1.0039258\end{array}$

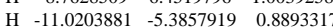

$\begin{array}{llll}\text { N } & -11.4392098 & -2.7209420 & 0.5637275\end{array}$ $\begin{array}{llll}\text { C } & -9.1362557 & -1.1711417 & -0.0014759\end{array}$ $\begin{array}{llll}\mathrm{N} & -6.6302238 & -2.3880237 & 0.5365023\end{array}$ $\begin{array}{llll}\mathrm{H} & -6.6759062 & -5.0833813 & 0.8713872\end{array}$ $\begin{array}{llll}\text { C } & -7.9397764 & -0.3651238 & 0.4654109\end{array}$ $\begin{array}{llll}\text { C } & -6.6870972 & -1.0002252 & 0.6000986\end{array}$ $\begin{array}{llll}\text { C } & -5.5230295 & -0.2133310 & 0.7896065\end{array}$ $\begin{array}{llll}\text { C } & -5.6430664 & 1.1842550 & 0.8477107\end{array}$ $\begin{array}{llll}\text { C } & -6.8933336 & 1.8200122 & 0.7828919\end{array}$ $\begin{array}{llll}\text { C } & -8.0573841 & 1.0345715 & 0.5943986\end{array}$ $\begin{array}{llll}\text { C } & -10.4234482 & -0.5373523 & 0.4873822 \\ \text { C } & -11.5749339 & -1.3397390 & 0.6315751\end{array}$ \begin{tabular}{llll} 
C & -11.5749339 & -1.3397390 & 0.631575 \\
\hline
\end{tabular} $\begin{array}{llll}\text { C } & -12.8359461 & -0.7221101 & 0.833010\end{array}$ $\begin{array}{llll}\text { C } & -12.9075246 & 0.6778960 & 0.8991048\end{array}$ $\begin{array}{llll}\text { C } & -11.7564951 & 1.4820089 & 0.8337252\end{array}$ $\begin{array}{llll}\text { C } & -10.4965183 & 0.8657693 & 0.6205354\end{array}$ $\begin{array}{lllll}\mathrm{N} & -9.3245271 & 1.6069747 & 0.5346491\end{array}$ $\begin{array}{llll}\mathrm{H} & -12.2727537 & -3.2818681 & 0.7517121\end{array}$ $\begin{array}{llll}\mathrm{H} & -5.7255759 & -2.8275796 & 0.7175498\end{array}$ $\begin{array}{llll}\mathrm{H} & -4.5366839 & -0.6943222 & 0.8674980\end{array}$ $\begin{array}{llll}\mathrm{H} & -4.7376055 & 1.7939009 & 0.9857613\end{array}$ $\begin{array}{lllll}\mathrm{H} & -6.9701904 & 2.9139128 & 0.8682734\end{array}$ $\begin{array}{lllll}\mathrm{H} & -13.7465143 & -1.3344380 & 0.9105460\end{array}$ $\begin{array}{llll}\mathrm{H} & -13.8865215 & 1.1576336 & 1.0451314\end{array}$ $\begin{array}{lllll}\mathrm{H} & -11.8335614 & 2.5771314 & 0.9041326\end{array}$ $\begin{array}{lllll}\mathrm{H} & -9.3920490 & 2.6099663 & 0.7189401\end{array}$ $\begin{array}{llll}\text { C } & -9.1465984 & -1.1895773 & -1.4849476\end{array}$ $\begin{array}{llll}\text { C } & -9.1405813 & -1.2163667 & -2.7137515\end{array}$ $\begin{array}{lllll}\text { C } & 13.1506649 & 4.3792694 & 0.8976858\end{array}$ $\begin{array}{lllll}C & 13.2881893 & 2.9838644 & 0.8251436\end{array}$ $\begin{array}{llll}\text { C } & 13.288183 & 2.9838644 & 0.8251436\end{array}$ $\begin{array}{llll}\text { C } 12.1322536 & 2.1860056 & 0.6241182\end{array}$ $\begin{array}{llll}\text { C } 10.8727518 & 2.8094228 & 0.491412\end{array}$

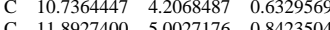

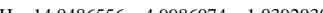
$\begin{array}{llll}\mathrm{C} & 11.8927400 & 5.0027176 & 0.8423504 \\ \mathrm{H} & 14.0486556 & 4.9986074 & 1.0392030 \\ \mathrm{H} & 14.2808140 & 2.5141677 & 0.8905613\end{array}$ $\begin{array}{lllll}\mathrm{H} & 14.0486556 & 4.9986074 & 1.0392030 \\ \mathrm{~N} & 12.20080099 & 2.5141677 & 0.8905613 \\ \mathrm{C} & 0.8013445 & 0.5458981\end{array}$ $\begin{array}{llllll} & \mathrm{N} & 12.2030079 & 0.80134020 & 0.5458981\end{array}$ $\begin{array}{llll}\mathrm{N} & 12.203009 & 0.8013445 & 0.5458981 \\ \mathrm{~N} & 9.4674814 & 1.9938020 & 0.0040111\end{array}$ $\begin{array}{lllll}\mathrm{N} & 9.4674814 & 4.7663641 & 0.5523534 \\ \mathrm{H} & 11.8052509 & 6.0963555 & 0.9211433\end{array}$ $\begin{array}{llllll}\text { H } & 11.8052509 & 6.0963555 & 0.9211433\end{array}$ $\begin{array}{llll}\text { C } & 8.3898774 & 2.6110302 & 0.4766249 \\ \text { C } & 8.2971017 & 4.0135018 & 0.6061791\end{array}$ $\begin{array}{llll}\text { C } & 8.2971017 & 4.0135018 & 0.6061791\end{array}$ $\begin{array}{llll}\text { C } & 7.0288567 & 4.6149957 & 0.7902691\end{array}$ $\begin{array}{llll}\text { C } & 5.8880236 & 3.7977578 & 0.8525965\end{array}$ $\begin{array}{lllll}\text { C } & 5.9771659 & 2.3978637 & 0.7964520\end{array}$ $\begin{array}{llll}\text { C } & 7.2448010 & 1.7950856 & 0.6101821\end{array}$ $\begin{array}{llll}\text { C } & 9.8052682 & 0.5593947 & 0.4831049\end{array}$ $\begin{array}{llll}\text { C } & 11.0840220 & -0.0242181 & 0.6154709\end{array}$ $\begin{array}{llll}\text { C } & 11.1961288 & -1.4211183 & 0.8144383\end{array}$ $\begin{array}{llll}\text { C } & 10.0265418 & -2.1969506 & 0.8812759\end{array}$ $\begin{array}{llll}\text { C } & 8.7486641 & -1.6177552 & 0.8159029\end{array}$ $\begin{array}{llll}\text { C } & 8.6352512 & -0.2200322 & 0.6194748\end{array}$ $\begin{array}{lllll}\text { N } & 7.3992914 & 0.4139111 & 0.5496489\end{array}$ $\begin{array}{llll}\mathrm{H} & 13.1109327 & 0.3699405 & 0.7306953\end{array}$ $\begin{array}{lllll}\mathrm{H} & 9.3858641 & 5.7676536 & 0.7402910\end{array}$ $\begin{array}{llll}\mathrm{H} & 6.9394728 & 5.7087776 & 0.8661192\end{array}$ $\begin{array}{lllll}\mathrm{H} & 4.9015008 & 4.2660081 & 0.9873020\end{array}$ $\begin{array}{llll}\mathrm{H} & 5.0738817 & 1.7752520 & 0.8763372\end{array}$ $\begin{array}{llll}\mathrm{H} & 12.1861896 & -1.8925965 & 0.8986162\end{array}$ $\begin{array}{lllll}\mathrm{H} & 10.1135733 & -3.2843989 & 1.0230678\end{array}$ $\begin{array}{lllll}\mathrm{H} & 7.8460154 & -2.2424416 & 0.8879029\end{array}$

$\begin{array}{llll}\mathrm{H} & 7.8460154 & -2.2424416 & 0.8879029 \\ \mathrm{H} & 6.5723213 & -0.1558477 & 0.7397173\end{array}$ 
cis-Au(111)-A Optimization

$E_{\mathrm{PBE}(\mathrm{D} 3) / \mathrm{def2}-\mathrm{SVP}}=-14609.61438845$ Hartree

Single Point w/o Au(111) surface

\section{$\mathrm{E}_{\mathrm{M} 06-2 \mathrm{X}(\mathrm{D} 3) / \mathrm{def} 2-\mathrm{TZVPP}}=-3205.998121241$ Hartree}

Au $-14.3918437-7.4614089-0.5044600$ $\begin{array}{lll}\mathrm{Au}-11.5081281 & -7.4618861 & -0.4994279\end{array}$ $\begin{array}{llll}\mathrm{Au} & -8.6244125 & -7.4623634 & -0.4943958\end{array}$ $\begin{array}{llll}\text { Au } & -5.7406970 & -7.4628406 & -0.4893637\end{array}$ $\begin{array}{llll}\mathrm{Au} & -2.8569714 & -7.4633178 & -0.4843316\end{array}$ $\begin{array}{llll}\mathrm{Au} & 0.0267442 & -7.4637950 & -0.4792996\end{array}$ $\mathrm{Au} \quad 2.9104597 \quad-7.4642723 \quad-0.4742675$ $\begin{array}{llll}\text { Au } & 5.7941853 & -7.4647495 & -0.4692354\end{array}$ $\begin{array}{llll}\text { Au } & 8.6779009 & -7.4652267 & -0.4642033\end{array}$ $\begin{array}{llll}\mathrm{Au} & 11.5616165 & -7.4657039 & -0.4591712\end{array}$ Au $14.4453420 \quad-7.4661812-0.4541391$ Au $-15.8333509-4.9640591-0.4710266$ $\mathrm{Au}-12.9496354-4.9645363-0.4659945$ Au $-10.0659198 \quad-4.9650135 \quad-0.4609624$ Au $\quad-7.1822042 \quad-4.9654908 \quad-0.4559304$ $\begin{array}{llll}\mathrm{Au} & -4.2984787 & -4.9659680 & -0.4508983\end{array}$ $\begin{array}{llll}\text { Au } & -1.4147631 & -4.9664452 & -0.4458662\end{array}$ $\begin{array}{llll}\mathrm{Au} & 1.4689525 & -4.9669224 & -0.4408341\end{array}$ $\begin{array}{cccc}\mathrm{Au} & 4.3526680 & -4.9673997 & -0.4358020\end{array}$ $\begin{array}{lllll}\mathrm{Au} & 7.2363936 & -4.9678769 & -0.4307699\end{array}$ $\begin{array}{llll}\mathrm{Au} & 10.1201092 & -4.9683541 & -0.4257378\end{array}$ $\begin{array}{llll}\text { Au } & 13.0038248 & -4.9688313 & -0.4207057\end{array}$ $\begin{array}{llll}\text { Au } & 15.8875403 & -4.9693086 & -0.4156736\end{array}$ $\begin{array}{llll}\text { Au } & 15.8875403 & -4.9693086 & -0.4156736 \\ \text { Au } & -17.2748682 & -2.4666992 & -0.4375931\end{array}$ $\begin{array}{llll}\text { Au } & -17.2748682 & -2.466992 & -0.4375931 \\ \text { Au }-14.3911426 & -2.4671765 & -0.4325610\end{array}$ $\begin{array}{lll}\text { Au }-14.3911426 & -2.4671765 & -0.4325610\end{array}$

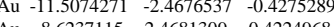
$\begin{array}{llll}\text { Au } & -8.6237115 & -2.4681309 & -0.4224968\end{array}$ $\begin{array}{lll}\text { Au }-5.7399959 & -2.4686082 & -0.4174647\end{array}$ Au $-2.8562704 \quad-2.4690854 \quad-0.4124326$

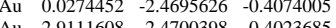
$\begin{array}{llll}\mathrm{Au} & 2.9111608 & -2.4700398 & -0.4023685 \\ \mathrm{Au} & 5.7948863 & -2.4705171 & -0.3973363\end{array}$ $\begin{array}{llll}\text { Au } & 5.7948863 & -2.4705171 & -0.3973363\end{array}$ $\begin{array}{llll}\text { Au } & 8.6786019 & -2.4709943 & -0.3923043\end{array}$ $\begin{array}{llll}\text { Au } & 11.5623175 & -2.4714715 & -0.3872722\end{array}$ $\begin{array}{llll}\text { Au } & 14.4460431 & -2.4719487 & -0.3822401\end{array}$ Au $17.3297586-2.4724260-0.3772080$ $\begin{array}{llll}\mathrm{Au} & -15.8326499 & 0.0301834 & -0.3991275\end{array}$ $\begin{array}{llll}\mathrm{Au} & -12.9489343 & 0.0297061 & -0.3940954\end{array}$ $\begin{array}{llll}\mathrm{Au} & -10.0652188 & 0.0292289 & -0.3890633\end{array}$ $\begin{array}{llll}\mathrm{Au} & -7.1815032 & 0.0287517 & -0.3840312\end{array}$ $\begin{array}{llll}\text { Au } & -4.2977776 & 0.0282745 & -0.3789991\end{array}$ $\begin{array}{llll}\mathrm{Au} & -1.4140621 & 0.0277972 & -0.3739670\end{array}$ $\begin{array}{lllll}\mathrm{Au} & 1.4696535 & 0.0273200 & -0.3689349\end{array}$ $\begin{array}{lllll}\mathrm{Au} & 4.3533691 & 0.0268428 & -0.3639028\end{array}$ $\begin{array}{llll}\mathrm{Au} & 7.2370946 & 0.0263655 & -0.3588707\end{array}$ $\begin{array}{llll}\mathrm{Au} & 10.1208102 & 0.0258883 & -0.3538386\end{array}$ $\begin{array}{llll}\mathrm{Au} & 13.0045258 & 0.0254111 & -0.3488065\end{array}$ $\begin{array}{lllll}\mathrm{Au} & 15.8882414 & 0.0249339 & -0.3437745\end{array}$ $\mathrm{Au}-17.2741672 \quad 2.5275432 \quad-0.3656940$ $\begin{array}{cccc}\mathrm{Au} & -14.3904416 & 2.5270660 & -0.3606619\end{array}$ $\begin{array}{llll}\mathrm{Au} & -11.5067260 & 2.5265887 & -0.3556298\end{array}$ $\begin{array}{lllll}\mathrm{Au} & -8.6230105 & 2.5261115 & -0.3505977\end{array}$ $\begin{array}{llll}\text { Au } & -5.7392949 & 2.5256343 & -0.3455656\end{array}$ $\begin{array}{lllll}\text { Au } & -2.8555693 & 2.5251571 & -0.3405335\end{array}$ $\begin{array}{rrrr}\mathrm{Au} & -2.8555693 & 2.5251571 & -0.3405335 \\ \mathrm{Au} & 0.0281462 & 2.5246798 & -0.3355014\end{array}$ $\begin{array}{llll}\text { Au } & 0.0281462 & 2.5246798 & -0.3355014 \\ \text { Au } & 2.9118618 & 2.5242026 & -0.3304693\end{array}$ $\begin{array}{llll}\text { Au } & 2.9118618 & 2.5242026 & -0.3304693 \\ \text { Au } & 5.7955874 & 2.5237254 & -0.3254372\end{array}$ \begin{tabular}{llll} 
Au & 5.7955874 & 2.5237254 & -0.3254372 \\
\hline & 8.6793029 & 2.5232482 & -0.3204051
\end{tabular} $\begin{array}{llll}\text { Au } & 8.673029 & 2.5232482 & -0.3204051 \\ \text { Aut } & 11.5630185 & 2.5227709 & -0.3153730\end{array}$ Au $11.5630185 \quad 2.5227709-0.3153730$ $\begin{array}{llll}\text { Au } & 14.4467441 & 2.5222937 & -0.3103409 \\ \text { Au } & 17.3304597 & 2.5218165 & -0.3053088\end{array}$

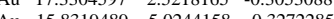

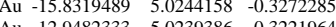
\begin{tabular}{llll} 
Au -12.9482333 & 5.0239386 & -0.3221964 \\
\hline
\end{tabular} $\begin{array}{llll}\text { Au } & -10.0645177 & 5.0234613 & -0.3171643\end{array}$ $\begin{array}{llll}\text { Au } & -7.1808022 & 5.0229841 & -0.3121322\end{array}$ $\begin{array}{llll}\text { Au } & -4.2970766 & 5.0225069 & -0.3071001\end{array}$ $\begin{array}{llll}\text { Au } & -1.4133610 & 5.0220297 & -0.3020680\end{array}$ $\begin{array}{llll}\mathrm{Au} & 1.4703545 & 5.0215524 & -0.2970359 \\ \mathrm{Au} & 4.3540701 & 5.0210752 & -0.2920038\end{array}$

$\begin{array}{llll}\text { Au } & 7.2377957 \quad 5.0205980 & -0.2869717\end{array}$ \begin{tabular}{llll} 
Au & 1.2377957 & 5.0205980 & -0.2869717 \\
\hline
\end{tabular} $\begin{array}{llll}\text { Au } & 1.1215112 & 5.0201208 & -0.2819396 \\ \text { Au } & 13.0052268 & 5.0196435 & -0.2769075\end{array}$ $\begin{array}{llll}\mathrm{Au} & 15.8889424 & 5.0191663 & -0.2718754\end{array}$ $\begin{array}{llll}\mathrm{Au}-14.3897406 & 7.5212984 & -0.2887628\end{array}$ $\begin{array}{llll}\mathrm{Au} & -11.5060250 & 7.5208212 & -0.2837308\end{array}$ $\begin{array}{llll}\mathrm{Au} & -8.6223094 & 7.5203439 & -0.2786987\end{array}$ $\begin{array}{llll}\mathrm{Au} & -5.7385939 & 7.5198667 & -0.2736666\end{array}$ $\begin{array}{llll}\text { Au } & -2.8548683 & 7.5193895 & -0.2686345\end{array}$ $\begin{array}{llll}\mathrm{Au} & 0.0288473 & 7.5189123 & -0.2636024\end{array}$ $\begin{array}{llll}\mathrm{Au} & 2.9125628 & 7.5184350 & -0.2585703\end{array}$ $\begin{array}{lllll}\mathrm{Au} & 5.7962884 & 7.5179578 & -0.2535382\end{array}$ $\begin{array}{lllll}\mathrm{Au} & 8.6800040 & 7.5174806 & -0.2485061\end{array}$ $\begin{array}{lllll}\mathrm{Au} & 11.5637195 & 7.5170034 & -0.2434740\end{array}$ $\begin{array}{lllll}\mathrm{Au} & 14.4474451 & 7.5165261 & -0.2384419\end{array}$ $\begin{array}{llll}\text { C } & -9.0067559 & -1.7996246 & 7.5236496\end{array}$ $\begin{array}{llll}\text { C } & -9.8155023 & -1.4264994 & 8.6260537\end{array}$ $\begin{array}{llll}\text { C } & -7.6632509 & -2.1846699 & 7.7598976\end{array}$ $\begin{array}{llll}\text { C } & -7.1285377 & -2.1909474 & 9.0579942\end{array}$ $\begin{array}{llll}\text { C } & -9.2800417 & -1.4399237 & 9.9187724\end{array}$ $\begin{array}{llll}\text { C } & -7.9447799 & -1.8159360 & 10.1415858\end{array}$ $\begin{array}{llll}\text { C } & -5.6794799 & -2.5876664 & 9.2450203\end{array}$ $\begin{array}{llll}\text { O } & -5.4195287 & -2.8307670 & 10.6221056\end{array}$ $\begin{array}{llll}\text { C } & -5.679485287 & -2.8307670 & 10.6221056 \\ \text { C } & -4.2344757 & -3.3659613 & 11.0028856\end{array}$ $\begin{array}{llll}\text { C } & -5.2344757 & -3.3659613 & 11.0028856 \\ \text { C } & -4.1268042 & -3.6988862 & 12.3752480\end{array}$ $\begin{array}{llll}\text { C } & -4.2344757 & -3.3659613 & 11.0028856 \\ \text { C }-2.9822520 & -4.324852527 & 12.3752480\end{array}$ $\begin{array}{llll}\text { C } & -2.9822520 & -4.3242527 & 12.8537320 \\ \text { C } & -1.8786464 & -4.5771241 & 11.9972097\end{array}$ $\begin{array}{llll}\text { C } & -1.8786464 & -4.5771241 & 11.9972097\end{array}$ $\begin{array}{llll}C & -1.9797449 & -4.2163129 & 10.6308819\end{array}$ $\begin{array}{llll}C & -3.1487176 & -3.6294888 & 10.1334689 \\ \mathrm{~N} & -0.8509500 & -5.3789116 & 12.5338036\end{array}$ $\begin{array}{llll}\mathrm{N} & -0.8509500 & -5.3789116 & 10.5338036 \\ \mathrm{H} & -10.8597819 & -1.1299542 & 8.4517245\end{array}$ $\begin{array}{llll}\mathrm{H} & -10.8597819 & -1.1299542 & 8.4517245 \\ \mathrm{H} & -7.0427408 & -2.4824836 & 6.8996809\end{array}$ $\begin{array}{llll}\mathrm{H} & -7.0427408 & -2.4824836 & 6.8996809 \\ \mathrm{H} & -9.9124475 & -1.1519582 & 10.7723716\end{array}$ $\begin{array}{llll}\text { H } & -9.9124475 & -1.1519582 & 10.7723716\end{array}$ $\begin{array}{llll}\text { H } & -7.5291646 & -1.8294244 & 11.1584829\end{array}$ $\begin{array}{lllll}H & -5.0071189 & -1.7788697 & 8.8693703\end{array}$ \begin{tabular}{llll}
$\mathrm{H}$ & -5.4594134 & -3.5003259 & 8.6439272 \\
\hline
\end{tabular} $\begin{array}{llll}\text { H } & -4.9848552 & -3.4926896 & 13.0311202\end{array}$ $\begin{array}{llll}\text { H } & -2.9094849 & -4.6468874 & 13.9028012\end{array}$ $\begin{array}{llll}\text { H } & -1.1478731 & -4.4302044 & 9.9442117\end{array}$ $\begin{array}{llll}\text { H } & -3.2105336 & -3.3881932 & 9.0636199\end{array}$ $\begin{array}{llll}\text { C } & 7.3009163 & 0.4902570 & 7.5516977\end{array}$ $\begin{array}{llll}\text { C } & 7.5744328 & 1.3883602 & 8.6113981\end{array}$ $\begin{array}{llll}\text { C } & 6.4293699 & -0.6041527 & 7.7917045\end{array}$ $\begin{array}{llll}\text { C } & 5.8482608 & -0.8046756 & 9.0514589\end{array}$ $\begin{array}{llll}\text { C } & 6.9820150 & 1.1931820 & 9.8666728\end{array}$ $\begin{array}{llll}\text { C } & 6.1251636 & 0.1060789 & 10.0922573\end{array}$ C 4.9797668 -2.0135478 9.2995016 $\begin{array}{llll}\text { O } & 3.7781826 & -1.6143979 & 9.9683120\end{array}$ $\begin{array}{llll}\text { C } & 2.9338658 & -2.5729538 & 10.4215687\end{array}$ $\begin{array}{llll}\text { C } \quad 3.1231308 & -3.9625626 & 10.2372402\end{array}$ C $\quad 2.2262692 \quad-4.8627655 \quad 10.8175966$ $\begin{array}{llll}\text { C } & 1.0880858 & -4.4138170 & 11.5261148\end{array}$ $\begin{array}{llll}\text { C } & 0.8883911 & -3.0138392 & 11.6822990\end{array}$ $\begin{array}{llll}\text { C } & 1.8054623 & -2.1137773 & 11.1490350\end{array}$ $\begin{array}{lllll}\mathrm{N} & 0.3535746 & -5.4078327 & 12.2039319\end{array}$ $\begin{array}{lllll}\mathrm{H} & 8.2449838 & 2.2415510 & 8.4339195\end{array}$ $\begin{array}{lllll} & 8.244838 & 2.2415510 & 8.4339195 \\ \mathrm{H} & 6.2075455 & -1.2939445 & 6.9625976\end{array}$ $\begin{array}{rrrr}H & 8.2449838 & 2.2415510 & 8.4339195 \\ \mathrm{H} & 7.1932181 & -1.2939445 & 6.9625976 \\ \mathrm{H} & 5.6505955 & 10.6830072\end{array}$ \begin{tabular}{llll}
\hline & 6.2075455 & -1.2939445 & 6.9625976 \\
\hline & 5.6577105 & -0.0005955 & 10.6830072
\end{tabular} $\begin{array}{llll}H & 5.6577105 & -0.0391608 & 11.0778207 \\ \mathrm{H} & 5.5284814 & -2.7462253 & 9.9375770\end{array}$ \begin{tabular}{llll}
$H$ & 5.5284814 & -2.7462253 & 9.9375770 \\
\hline & 4.7350254 & -2.5236198 & 8.3405155
\end{tabular} $\begin{array}{lllll}H & 4.7350254 & -2.5236198 & 8.3405155\end{array}$ $\begin{array}{llll}\mathrm{H} & 3.9813793 & -4.3506313 & 9.6734445 \\ \mathrm{H} & 2.3901055 & -5.9476259 & 10.7375700\end{array}$ $\begin{array}{lllll}H & 2.390105 & -5.9476259 & 10.7375700\end{array}$ $\begin{array}{llll}\mathrm{H} & 0.0277515 & -2.6415546 & 12.2564620\end{array}$ $\begin{array}{llll}H & 1.6877132 & -1.0292952 & 11.2898705\end{array}$ $\begin{array}{llll}\text { C } & -1.68377992 & -3.7763026 & 2.6159599\end{array}$ $\begin{array}{llll}C & -12.4544388 & -4.5291974 & 2.6789702\end{array}$ $\begin{array}{llll}\text { C } & -11.2242588 & -3.8591750 & 2.8872179 \\ \text { C }-11.2119054 & -2.4551543 & 3.0472107\end{array}$

\section{cis-Au(111)-B Optimization}

$\mathrm{E}_{\mathrm{PBE}(\mathrm{D} 3) / \mathrm{def2}-\mathrm{SVP}}=-14609.64759805$

Single Point w/o Au(111) surface

$\mathrm{E}_{\mathrm{M} 06-2 \mathrm{X}(\mathrm{D} 3) / \mathrm{def2}-\mathrm{TZVPP}}=-3205.994729367$ Hartree

Au $-14.3918209-7.4965826 \quad 0.3034598$

Au $-11.5081038 \quad-7.4965179 \quad 0.2993902$ $\begin{array}{llll}\text { C } & -12.3987964 & -1.7015663 & 2.9114363\end{array}$ $\begin{array}{llll}\text { C } & -13.6279931 & -2.3734169 & 2.6953403\end{array}$ $\begin{array}{llll}\mathrm{H} & -14.5953344 & -4.2958585 & 2.4631314 \\ \mathrm{H} & -12.4804468 & -5.6247834 & 2.5842273\end{array}$ $\begin{array}{llll}\mathrm{H} & -12.4804468 & -5.6247834 & 2.5842273 \\ \mathrm{~N} & -10.0157966 & -4.5462541 & 2.9367727\end{array}$ $\begin{array}{llll}\text { C } & -9.9424865 & -1.7744361 & 3.5131721\end{array}$ $\begin{array}{llll}\mathrm{N} & -12.3247940 & -0.3159553 & 2.9965979\end{array}$ $\begin{array}{llll}\mathrm{H} & -14.5648468 & -1.8018073 & 2.6193530\end{array}$ $\begin{array}{llll}\text { C } & -9.9133133 & -0.3276970 & 3.0595209\end{array}$ $\begin{array}{llll}\text { C } & -11.1235938 & 0.3879380 & 2.9393856\end{array}$ $\begin{array}{llll}\text { C } & -11.0878751 & 1.7926908 & 2.7667381\end{array}$ $\begin{array}{llll}\text { C } & -9.8444569 & 2.4432661 & 2.7153735\end{array}$ $\begin{array}{llll}\text { C } & -8.6342696 & 1.7319890 & 2.7688186\end{array}$ $\begin{array}{llll}\text { C } & -8.6688350 & 0.3281339 & 2.9336983\end{array}$ $\begin{array}{llll}\text { C } & -8.7227374 & -2.5149123 & 2.9941512\end{array}$ $\begin{array}{llll}\text { C } & -8.7773141 & -3.9190807 & 2.8610466\end{array}$ $\begin{array}{llll}\text { C } & -7.5788144 & -4.6507398 & 2.6683842\end{array}$ $\begin{array}{llll}\text { C } & -6.3598784 & -3.9575860 & 2.6113960\end{array}$ $\begin{array}{llll}\text { C } & -6.3011937 & -2.5545515 & 2.6787260\end{array}$ $\begin{array}{lllll}\text { C } & -7.4985812 & -1.8217331 & 2.8764761\end{array}$ $\begin{array}{llll}\mathrm{N} & -7.5041404 & -0.4359355 & 2.9768561\end{array}$ $\begin{array}{llll}\mathrm{H} & -10.0425483 & -5.5503738 & 2.7485429\end{array}$ $\begin{array}{lllll}\mathrm{H} & -13.1816687 & 0.2095111 & 2.8122835\end{array}$ $\begin{array}{llll}\mathrm{H} & -13.1816867 & 0.205111 & 2.8122835 \\ \mathrm{H}-12.0238685 & 2.3663014 & 2.6961003\end{array}$ $\begin{array}{llll}\mathrm{H} & -12.0238685 & 2.3663014 & 2.6961003 \\ \mathrm{H} & -9.8179967 & 3.5364560 & 2.5929081\end{array}$ \begin{tabular}{llll}
$H$ & -9.81786857 & 2.3663014 & 2.6961003 \\
\hline$H$ & -7.6716837 & 2.258560 & 2.5929081
\end{tabular} $\begin{array}{cccc}\mathrm{H} & -7.6716837 & 2.2588226 & 2.6927110 \\ \mathrm{H} & -7.6050717 & -5.7471886 & 2.5868994\end{array}$ $\begin{array}{cccc}\mathrm{H} & -7.6050717 & -5.7471886 & 2.5868994 \\ \mathrm{H} & -5.4275294 & -4.5248720 & 2.4710258\end{array}$ $\begin{array}{llll}\mathrm{H} & -5.4275294 & -4.5248720 & 2.4710258 \\ \mathrm{H} & -5.3356415 & -2.0310444 & 2.6167028\end{array}$ $\begin{array}{llll}\mathrm{H} & -5.3356415 & -2.0310444 & 2.6167028 \\ \mathrm{H} & -6.6228105 & 0.0493327 & 2.7988109\end{array}$ $\begin{array}{cccc}H & -5.6356415 & -2.031044 & 2.6167028 \\ \mathrm{C} & -6.8167126 & 0.0493327 & 2.7988109 \\ \mathrm{C} & -9.7970958 & 4.9845679\end{array}$ $\begin{array}{llll}\text { C } & -9.8167126 & -1.7970958 & 4.9945679 \\ \text { C } & -9.4949111 & -1.7903702 & 6.1815906\end{array}$ $\begin{array}{llll}\text { C } & -9.4949111 & -1.7903702 & 6.1815906\end{array}$ $\begin{array}{llll}\text { C } & 11.9026511 & -1.2660726 & 2.7265036\end{array}$ $\begin{array}{llll}\text { C } & 11.0282016 & 0.1339680 & 2.8243087 \\ \text { C } & 10.8196804 & 0.847974 & 3.0265256\end{array}$ $\begin{array}{llll}\text { C } & 10.8196804 & 0.8417974 & 3.0265225 \\ \text { C } & 9.606611 & 0.1281674 & 3.1414056\end{array}$ $\begin{array}{llll}\text { C } & 9.6066411 & 0.1281674 & 3.1414056\end{array}$ $\begin{array}{llll}\text { C } & 9.5741124 & -1.2710231 & 2.9613419\end{array}$ \begin{tabular}{llll} 
C & 10.7833648 & -1.9784622 & 2.7637205 \\
\hline$H$ & 12.933656 & -1.8158371 & 2.57429
\end{tabular} $\begin{array}{llll}\mathrm{H} & 12.9334656 & -1.8158901 & 2.574029\end{array}$ $\begin{array}{ccccc}\mathrm{H} & 12.9824647 & 0.6763718 & 2.7521258\end{array}$ $\begin{array}{llll}\mathrm{N} & 10.7891283 & 2.2322370 & 3.1079186\end{array}$ $\begin{array}{llll}\text { C } & 8.3521902 & 0.8481345 & 3.5901031\end{array}$ $\begin{array}{llll}\mathrm{N} & 8.3394190 & -1.9201883 & 2.9748145\end{array}$ $\begin{array}{llll}\mathrm{H} & 10.7733656 & -3.0719295 & 2.6442035\end{array}$ C $7.1171520 \quad 0.1551385 \quad 3.0396002$ C $7.1265173 \quad-1.2494560 \quad 2.8900813$ C $\quad 5.9009111 \quad-1.9349692 \quad 2.6872216$ $\begin{array}{llll}\text { C } & 4.7029629 & -1.1995086 & 2.6543974\end{array}$ $\begin{array}{llll}\text { C } & 4.6902191 & 0.2014092 & 2.7461026\end{array}$ $\begin{array}{llll}\text { C } & 5.9141979 & 0.8890395 & 2.9376673\end{array}$ $\begin{array}{lllll}\text { C } & 8.3793321 & 2.2971794 & 3.1474492\end{array}$ $\begin{array}{lllll}\text { C } & 9.6136586 & 2.9705221 & 3.0320842\end{array}$ $\begin{array}{llll}\text { C } & 9.6246732 & 4.3762061 & 2.8460817\end{array}$ $\begin{array}{lllll}\text { C } & 8.4040851 & 5.0692420 & 2.7833301\end{array}$ $\begin{array}{llll}\text { C } & 7.1712743 & 4.3998828 & 2.8342670\end{array}$ $\begin{array}{llll}\text { C } \quad 7.1591148 & 2.9944017 & 3.0093881\end{array}$ $\begin{array}{llll}\mathrm{C} & 7.1591148 & 2.994017 & 3.0093881 \\ \mathrm{~N} & 5.9702761 & 2.2729186 & 3.0476737\end{array}$ $\begin{array}{llll}\mathrm{N} & 5.9702761 & 2.2729186 & 3.0476737 \\ \mathrm{H} & 11.6649607 & 2.7287748 & 2.9335415\end{array}$ $\begin{array}{lllll}\text { H } & 11.6649607 & 2.7287748 & 2.9335415 \\ \text { H } & 8.3366844 & -2.9204040 & 2.7645956\end{array}$ \begin{tabular}{llll}
$\mathrm{H}$ & 11.6649607 & 2.7287748 & 2.933545 \\
$\mathrm{H}$ & 5.8864933 & -2.9204040 & 2.7645956 \\
\hline
\end{tabular} \begin{tabular}{llll}
$H$ & 5.8864933 & -3.0319143 & 2.6063729 \\
\hline & 3.7517077 & -1.7351947 & 2.5169075
\end{tabular} \begin{tabular}{llll}
$\mathrm{H}$ & 3.8864933 & -3.0319143 & 2.6063729 \\
$\mathrm{H}$ & 3.7433707 & 0.7551947 & 2.5169075 \\
\hline
\end{tabular} $\begin{array}{cccc}\mathrm{H} & 3.751733707 & 0.7583367 & 2.6922255 \\ \mathrm{H} & 10.5798906 & 4.9184905 & 2.7842029\end{array}$ $\begin{array}{lllll}\mathrm{H} & 10.57980112 & 4.9184905 & 2.7842029\end{array}$ \begin{tabular}{lllll}
$H$ & 8.4159112 & 6.1614449 & 2.6530118 \\
\hline$H$ & 6.2267487 & 4.9571086 & 2.7493183
\end{tabular} H $5.22674874 .9571086 \quad 2.7493183$ \begin{tabular}{ccccc} 
H & 5.1044403 & 2.7904088 & 2.8832291 \\
\hline C & 8.1908286 & 0.7794064 & 5.0670820
\end{tabular} $\begin{array}{llll}\text { C } & 8.1908286 & 0.7794064 & 5.0670820 \\ \text { C } & 7.8293110 & 0.6758198 & 6.2382920\end{array}$ 
$\begin{array}{llll}\text { Au } & -5.7406695 & -7.4963886 & 0.2912509\end{array}$ $\begin{array}{llll}\mathrm{Au} & -2.8569424 & -7.4963240 & 0.287181\end{array}$ $\begin{array}{lllll}\mathrm{Au} & 0.0267747 & -7.4962594 & 0.283111\end{array}$ $\begin{array}{lllll}\mathrm{Au} & 2.9104919 & -7.4961947 & 0.2790419\end{array}$ $\begin{array}{llll}\mathrm{Au} & 5.7942190 & -7.4961301 & 0.2749722\end{array}$ $\begin{array}{lllll}\text { Au } & 8.6779361 & -7.4960654 & 0.2709026\end{array}$ $\begin{array}{llll}\text { Au } & 11.5616532 & -7.4960008 & 0.2668329\end{array}$ Au $\quad 14.4453804 \quad-7.4959362 \quad 0.2627633$ $\begin{array}{llll}\mathrm{Au} & -15.8337197 & -4.9992699 & 0.3166762\end{array}$ Au $-12.9500025 \quad-4.9992053 \quad 0.3126065$ Au $-10.0662854 \quad-4.9991406 \quad 0.3085369$ $\begin{array}{llll}\text { Au } & -7.1825683 & -4.9990760 & 0.3044672\end{array}$ $\begin{array}{llll}\mathrm{Au} & -4.2988412 & -4.9990114 & 0.3003975\end{array}$ $\begin{array}{llll}\text { Au } & -1.4151240 & -4.9989467 & 0.2963279\end{array}$ $\begin{array}{lllll}\text { Au } & 1.4685931 & -4.9988821 & 0.2922582\end{array}$ $\begin{array}{lllll}\text { Au } & 1.46853102 & -4.9988821 & 0.2922582\end{array}$ $\begin{array}{llll}\text { Au } & 7.2360374 & -4.9987528 & 0.2841189\end{array}$ $\begin{array}{llll}\text { Au } & 7.2360374 & 4.9987528 & 0.2841189 \\ \text { Aul } & 10.1197545 & -4.9986882 & 0.2800493\end{array}$ $\begin{array}{llll}\text { Au } & 10.1197545 & -4.9986882 & 0.2800493 \\ \text { Au } & 13.0034716 & -4.9986235 & 0.2759796\end{array}$ $\begin{array}{llll}\text { Au } & 13.0034716 & -4.9986235 & 0.2759796 \\ \text { Au } & 15.8871887 & -4.9985589 & 0.2719100\end{array}$ $\begin{array}{llll}\text { Au } & 15.887887 & -4.9985589 & 0.2719100\end{array}$ \begin{tabular}{llll} 
Au -17.2756284 & -2.5019473 & 0.3298926 \\
\hline
\end{tabular} \begin{tabular}{lll} 
Au -14.3919013 & -2.5018826 & 0.3258229 \\
\hline
\end{tabular} \begin{tabular}{llll} 
Au -11.5081842 & -2.5018180 & 0.3217532 \\
\hline
\end{tabular} $\begin{array}{llll}\text { Au } & -8.6244670 & -2.5017534 & 0.3176836\end{array}$

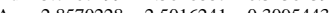
$\begin{array}{llll}\text { Au } & -2.8570228 & -2.5016241 & 0.3136139 \\ & & 0.305443\end{array}$ $\begin{array}{llll}\text { Au } & 0.0266943 & -2.5015594 & 0.3054746\end{array}$ $\begin{array}{llll}\text { Au } & 2.9104115 & -2.5014948 & 0.3014050\end{array}$ $\begin{array}{llll}\text { Au } & 5.7941386 & -2.5014301 & 0.2973353\end{array}$ $\begin{array}{llll}\text { Au } & 8.6778557 & -2.5013655 & 0.2932656\end{array}$ Au $11.5615728-2.5013009 \quad 0.2891960$ Au $14.4453000-2.5012362 \quad 0.2851263$ Au $17.3290171 \quad-2.5011716 \quad 0.2810567$ Au $-15.8338001 \quad-0.0045600 \quad 0.3390393$ $\begin{array}{lll}\mathrm{Au}-12.9500829 & -0.0044953 & 0.3349696\end{array}$ $\begin{array}{llll}\mathrm{Au}-10.0663658 & -0.0044307 & 0.3309000\end{array}$ $\begin{array}{llll}\mathrm{Au} & -7.1826487 & -0.0043661 & 0.3268303\end{array}$ $\begin{array}{llll}\text { Au } & -4.2989216 & -0.0043014 & 0.3227606\end{array}$ $\begin{array}{llll}\mathrm{Au} & -1.4152044 & -0.0042368 & 0.3186910\end{array}$ $\begin{array}{llll}\mathrm{Au} & 1.4685127 & -0.0041721 & 0.3146213\end{array}$ $\begin{array}{llll}\mathrm{Au} & 4.3522298 & -0.0041075 & 0.3105517\end{array}$ $\begin{array}{llll}\mathrm{Au} & 7.2359570 & -0.0040429 & 0.3064820\end{array}$ $\begin{array}{lllll}\mathrm{Au} & 10.1196741 & -0.0039782 & 0.3024124\end{array}$ $\begin{array}{llll}\text { Au } & 13.0033912 & -0.0039136 & 0.2983427\end{array}$ $\begin{array}{lllll}\text { Au } & 15.8871083 & -0.0038489 & 0.2942731\end{array}$ $\begin{array}{llll}\mathrm{Au} & -17.2757088 & 2.4927627 & 0.3522556\end{array}$ $\begin{array}{llll}\mathrm{Au} & -14.3919817 & 2.4928273 & 0.3481860\end{array}$ $\begin{array}{lllll}\text { Aul } & -11.5082646 & 2.4928919 & 0.3441163\end{array}$ $\begin{array}{llll}\text { Au } & -11.5082646 & 2.4928919 & 0.3441163 \\ \text { Au } & -8.6245474 & 2.4929566 & 0.3400467\end{array}$ $\begin{array}{llll}\text { Au } & -8.6240874 & 2.492956 & 0.3400467\end{array}$ $\begin{array}{llll}A & -2.7571032 & 2.4930859 & 0.3319074\end{array}$ \begin{tabular}{llll} 
Au & -2.8571032 & 2.4930859 & 0.3319074 \\
\hline
\end{tabular} \begin{tabular}{llll} 
Au & 0.0266139 & 2.4931505 & 0.3278377 \\
\hline Au & 2.9103311 & 2.4932151 & 0.3237680
\end{tabular} Au $5.7940582 \quad 2.4932798 \quad 0.3196984$ $\begin{array}{llll}\text { Au } & 5.790582 & 2.4932798 & 0.3196984\end{array}$ $\begin{array}{llll}\text { Au } & 8.6777753 & 2.4933444 & 0.3156287\end{array}$ $\begin{array}{llll}\text { Au } & 11.5614924 & 2.4934091 & 0.3115591\end{array}$ $\begin{array}{cccc}\mathrm{Au} & 14.4452196 & 2.4934737 & 0.3074894 \\ \mathrm{Au} & 17.3289367 & 2.4935384 & 0.3034198\end{array}$ \begin{tabular}{llll} 
Au & 17.3289367 & 2.4935384 & 0.3034198 \\
Au & -15.8338805 & 4.9901399 & 0.3614023 \\
\hline
\end{tabular} $\begin{array}{llll}\text { Au } & -15.8338805 & 4.9901399 & 0.3614023 \\ \text { Au }-12.9501633 & 4.9902046 & 0.3573327\end{array}$ $\mathrm{Au}-10.0664462 \quad 4.9902692 \quad 0.3532630$ $\begin{array}{llll}\text { Au } & -7.1827291 & 4.9903339 & 0.3491933\end{array}$ $\begin{array}{llll}\mathrm{Au} & -4.2990020 & 4.9903985 & 0.3451237\end{array}$ $\begin{array}{llll}\text { Au } & -1.4152848 & 4.9904632 & 0.3410540\end{array}$ $\begin{array}{lllll}\text { Au } & 1.4684323 & 4.9905278 & 0.3369844\end{array}$ $\begin{array}{lllll}\mathrm{Au} & 4.3521494 & 4.9905924 & 0.3329147\end{array}$ $\begin{array}{llll}\mathrm{Au} & 7.2358766 & 4.9906571 & 0.3288451\end{array}$ $\begin{array}{lllll}\text { Au } & 10.1195937 & 4.9907217 & 0.3247754\end{array}$ $\begin{array}{llll}\mathrm{Au} & 13.0033108 & 4.9907864 & 0.3207058\end{array}$ $\begin{array}{llll}\mathrm{Au} & 15.8870279 & 4.9908510 & 0.3166361\end{array}$ Au - $14.3920621 \quad 7.4875272 \quad 0.3705490$ $\begin{array}{llll}\mathrm{Au} & -11.5083450 & 7.4875919 & 0.3664794\end{array}$ $\begin{array}{llll}\text { Au } & -8.6246278 & 7.4876565 & 0.3624097\end{array}$ $\begin{array}{lllll}\text { Au } & -5.7409107 & 7.4877212 & 0.3583401\end{array}$ $\begin{array}{lllll}\mathrm{Au} & -2.8571836 & 7.4877858 & 0.3542704\end{array}$ $\begin{array}{llll}\mathrm{Au} & 0.0265335 & 7.4878504 & 0.3502007\end{array}$ $\begin{array}{lllll}\text { Au } & 2.9102507 & 7.4879151 & 0.3461311\end{array}$ $\begin{array}{lllll}\mathrm{Au} & 5.7939778 & 7.4879797 & 0.3420614\end{array}$ $\begin{array}{lllll}\mathrm{Au} & 8.6776949 & 7.4880444 & 0.3379918\end{array}$ $\begin{array}{lllll}\text { Au } & 11.5614120 & 7.4881090 & 0.3339221\end{array}$ $\begin{array}{lllll}\text { Au } & 11.5614120 & 7.4881090 & 0.3339221 \\ \text { Au } & 14.4451392 & 7.4881736 & 0.3298525\end{array}$ $\begin{array}{llll}\text { Au } & 14.555013 & -0.9695342 & -7.1494071\end{array}$ $\begin{array}{llll}\text { C } & 7.5555013 & -0.9695342 & -7.149407 \\ \text { C } & 7.7987720 & -0.9821057 & -8.5422995\end{array}$ $\begin{array}{llll}\text { C } & 7.5558013 & 0.9695342 & -7.1494071 \\ \text { C } & 6.2568014 & -0.6821057 & -8.5422995 \\ \text { C } & 5.221661 & -6.6778771\end{array}$ $\begin{array}{llll}\text { C } & 7.7987720 & 0.9821057 & -8.5422995 \\ \text { C } 5.2216937 & -0.6411661 & -6.677877 \\ \text { C } & 0.3298753 & -7.5673013\end{array}$ $\begin{array}{llll}\text { C } & 5.2216937 & -0.0411661 & -6.6778771 \\ \text { C } & 6.761526 & -0.6651142 & -9.5673013\end{array}$ $\begin{array}{llll}\text { C } & 5.2216937 & 0.3298753 & -7.5673013 \\ \text { C } & 5.4818250 & 0.0651142 & -9.4298734\end{array}$ $\begin{array}{llll}\text { C } & 5.4818250 & -0.3366448 & -8.9530117 \\ \text { C } & 3.8284862 & -0.0518712 & -7.0507341\end{array}$ $\begin{array}{lllll}\text { O } & 3.9022260 & 0.5019942 & -5.7337160\end{array}$ $\begin{array}{llll}\text { C } & 2.7631453 & 0.7534642 & -5.0489976\end{array}$ $\begin{array}{llll}\text { C } & 2.9152483 & 1.3520967 & -3.7750668\end{array}$ $\begin{array}{llll}\text { C } & 1.7935624 & 1.6554031 & -3.0132285\end{array}$ $\begin{array}{llll}\text { C } & 0.4825223 & 1.3326885 & -3.4532440\end{array}$ $\begin{array}{llll}\text { C } & 0.3387758 & 0.7492200 & -4.7406595\end{array}$ $\begin{array}{llll}\text { C } & 1.4597001 & 0.4790531 & -5.5304839\end{array}$ $\begin{array}{lllll}\mathrm{N} & -0.5332616 & 1.7403404 & -2.5535634\end{array}$ $\begin{array}{llll}\text { H } & 8.8009017 & -1.2351165 & -8.9170726\end{array}$

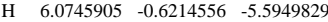
H $\quad 6.9534176-0.6656175-10.5134793$ $\begin{array}{llll}\mathrm{H} & 4.6811964 & -0.0810142 & -9.6654985\end{array}$ $\begin{array}{lllll}\text { H } & 3.2431493 & -1.0016662 & -7.0209879\end{array}$ $\begin{array}{lllll}\text { H } & 3.2907511 & 0.6486102 & -7.7296351\end{array}$ $\begin{array}{llll}\text { H } & 3.9246143 & 1.6041988 & -3.4174240\end{array}$ $\begin{array}{llll}\mathrm{H} & 3.9246143 & 1.6041988 & -3.4174240 \\ \mathrm{H} & 1.9017744 & 2.1568306 & -2.0383120\end{array}$ $\begin{array}{lllll}\mathrm{H} & 1.9017744 & 2.156806 & -2.0383120 \\ \mathrm{H} & -0.6503081 & 0.5254964 & -5.1551079\end{array}$ $\begin{array}{llll}\mathrm{H} & -0.650301 & 0.5254964 & -5.1551079 \\ \mathrm{H} & 1.3077649 & 0.0480638 & -6.5287585\end{array}$ $\begin{array}{llll}\text { C } & -7.4507369 & -1.3015330 & -7.2564353\end{array}$ $\begin{array}{llll}\text { C } & -7.45073693 & -1.3015330 & -7.2564353 \\ \text { C }-7.7145033 & -0.9125084 & -8.5884052\end{array}$ $\begin{array}{llll}C & -7.7145033 & -0.9125084 & -8.5884052 \\ C & -6.1564586 & -1.7765546 & -6.9159610\end{array}$

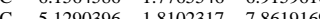
$\begin{array}{llll}\text { C } & -5.1290396 & -1.8102317 & -7.8619169 \\ \text { C } & -6.6890117 & -0.9784229 & -9.5438020\end{array}$ $\begin{array}{lllll}\text { C } & -6.6890117 & -0.9784229 & -9.5438020 \\ \text { C } & -5.4020218 & -1.4091966 & -9.1875003\end{array}$ $\begin{array}{llll}\text { C } & -5.4020218 & -1.4091966 & -9.1875003\end{array}$ $\begin{array}{lllll}\text { C } & -3.7343814 & -2.2644471 & -7.4730109\end{array}$ $\begin{array}{llll}\text { C } & -3.5567355 & -2.5667278 & -6.0904645 \\ \text { C } & -3.2040063 & -1.5671584 & -5.2280032\end{array}$ $\begin{array}{lllll}\text { C } & -3.2040063 & -1.5671584 & -5.2280032\end{array}$ $\begin{array}{llll}\text { C } & -3.5689339 & -0.2113924 & -5.3872939\end{array}$ $\begin{array}{llll}\text { C } & -3.1234893 & 0.7473128 & -4.4628778\end{array}$ $\begin{array}{llll}\text { C } & -2.2612194 & 0.3744023 & -3.413002\end{array}$ $\begin{array}{llll}\text { C } & -1.9647363 & -0.9927406 & -3.2041828\end{array}$ $\begin{array}{llll}\text { C } & -2.4435294 & -1.9522834 & -4.0999459\end{array}$ $\begin{array}{llll}\mathrm{N} & -1.7356750 & 1.3796050 & -2.5518222\end{array}$ \begin{tabular}{llll} 
H & -8.7148410 & -0.5469152 & -8.8610395 \\
\hline
\end{tabular} $\begin{array}{llll}\mathrm{H} & -5.9591558 & -2.0954026 & -5.8824528\end{array}$ H $-6.8925299-0.6726250-10.5813703$ H $\quad-4.6026182-1.4304822 \quad-9.945935$

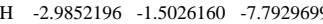
$\begin{array}{llll}\mathrm{H} & -3.4887488 & -3.2078050 & -8.0062992\end{array}$ $\begin{array}{llll}\mathrm{H} & -4.2099059 & 0.0993603 & -6.2239657\end{array}$ $\begin{array}{lllll}\text { H } & -3.3890972 & 1.8074769 & -4.5907540\end{array}$ \begin{tabular}{llll} 
H & -1.3264097 & -1.2906445 & -2.3576135 \\
\hline
\end{tabular} $\begin{array}{llll}\text { H } & -2.2019762 & -3.0170956 & -3.9656582\end{array}$ $\begin{array}{llll}\text { C } & 13.2247513 & -3.3392614 & -2.840068\end{array}$ $\begin{array}{lllll}\text { C } & 12.0952526 & -4.1671185 & -2.9192894\end{array}$ $\begin{array}{llll}\text { C } & 10.8190456 & -3.5781036 & -3.0990719\end{array}$ $\begin{array}{llll}\text { C } & 10.7080431 & -2.1762862 & -3.2270958\end{array}$ $\begin{array}{llll}\text { C } 13.1160108 & -1.9394503 & -2.8775883\end{array}$ $\begin{array}{llll}\mathrm{H} & 14.2162751 & -3.7960547 & -2.7042542\end{array}$ $\begin{array}{llll}\text { H } & 12.1948243 & -5.2599904 & -2.842561\end{array}$ $\begin{array}{llll}\text { N } & 9.6613371 & -4.3482340 & -3.1450403\end{array}$ $\begin{array}{llll}\text { C } & 9.3846571 & -1.5681922 & -3.6279565\end{array}$ \begin{tabular}{llll}
$\mathrm{N}$ & 11.6737518 & 0.0313527 & -3.098164 \\
\hline
\end{tabular} $\begin{array}{llll}\text { H } & 14.0089752 & -1.3060880 & -2.7708533\end{array}$ $\begin{array}{llll}\text { C } & 9.2694689 & -0.1452622 & -3.1174258\end{array}$ $\begin{array}{llll}\text { C } 10.4302119 & 0.6506763 & -3.008246\end{array}$ $\begin{array}{llll}\text { C } & 10.3010926 & 2.0478931 & -2.8168805\end{array}$ $\begin{array}{llll}\text { C } & 9.0167459 & 2.6091080 & -2.7282394\end{array}$ $\begin{array}{lll}\text { C } 7.8571767 & 1.8163625 & -2.7735690\end{array}$ C $7.98512620 .4206350-2.9615769$ $\begin{array}{llll}\text { C } 8.2331979 & -2.4100523 & -3.1100534\end{array}$ $\begin{array}{llll}\text { C } & 8.2331979 & -2.4100523 & -3.1100534 \\ \text { C } & 8.3846475 & -3.8110115 & -3.0273752\end{array}$ $\begin{array}{llll}\text { C } & 8.3846475 & -3.8110115 & -3.0273752 \\ \text { C } 7.2413678 & -4.6272649 & -2.8424899\end{array}$ $\begin{array}{llll}\text { C } & 7.2413678 & -4.6272649 & -2.8424899 \\ \text { C } 5.9790046 & -4.0207786 & -2.7494594\end{array}$ $\begin{array}{llll}\text { C } & 5.9790046 & -4.0207786 & -2.7494594 \\ \text { C } 5.8241323 & -2.6239266 & -2.7643483 \\ \text { C } 6.9668105 & -1.8076829 & -2.9516173\end{array}$ $\begin{array}{llll}\text { C } & 6.9668105 & -1.8076829 & -2.9516173\end{array}$ \begin{tabular}{llll}
$\mathrm{N}$ & 6.8743351 & -0.4206116 & -3.0162878 \\
\hline
\end{tabular} $\begin{array}{llll}\mathrm{H} & 9.7617560 & -5.3524270 & -2.9848342\end{array}$ $\begin{array}{lllll}\text { H } & 12.4964271 & 0.6067637 & -2.9063909\end{array}$ $\begin{array}{lllll}\mathrm{H} & 11.1949046 & 2.6860597 & -2.7553419\end{array}$ $\begin{array}{lllll}\mathrm{H} & 8.9168894 & 3.6967760 & -2.5968343\end{array}$ $\begin{array}{lllll}\mathrm{H} & 6.8629054 & 2.2762220 & -2.6731938\end{array}$ \begin{tabular}{llll}
$\mathrm{H}$ & 7.3408800 & -5.7218711 & -2.8034331 \\
\hline & 5.088080 & -4.6557220 & -2.6255669
\end{tabular}

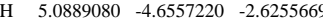
\begin{tabular}{lllll}
$\mathrm{H}$ & 4.8261876 & -2.1690179 & -2.6775885 \\
\hline & 5.966349 & -0.0069141 & -2.7950318
\end{tabular} $\begin{array}{llll}\text { H } & 5.9661349 & -0.0069141 & -2.7950318\end{array}$ $\begin{array}{llll}\text { C } 9.1389306 & -1.4806468 & -5.0980117\end{array}$ $\begin{array}{llll}\text { C } \quad 8.5242171 & -1.2679696 & -6.1442472\end{array}$ $\begin{array}{llll}C & -13.2396319 & -1.8952962 & -2.8019378\end{array}$ $\begin{array}{llll}\text { C }-12.7923416 & -0.5637196 & -28395407\end{array}$ $\begin{array}{llll}\text { C }-11.4116219 & -0.3057698 & -3.0153564\end{array}$ C $-10.5160729-1.3873232-3.1571486$ $\begin{array}{llll}\text { C } & -1.5160729 & -1.3873232 & -3.1571486\end{array}$ C $-12.3476683-2.9759133-28673598$

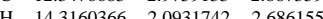
$\begin{array}{llll}\mathrm{H} & -14.3160366 & -2.0931742 & -2.6861559 \\ \mathrm{H}-13.5063644 & 0.2683615 & -2.7509172\end{array}$ $\begin{array}{llll}\mathrm{H} & -13.5063644 & 0.2683615 & -2.7509172 \\ \mathrm{~N} & -10.9058923 & 0.9922991 & -3.0493429\end{array}$ $\begin{array}{llll}\text { C } & -9.0918769 & -1.1263921 & -3.5858258\end{array}$ \begin{tabular}{lllll}
$\mathrm{N}$ & -10.0275750 & -3.7491676 & -3.0738886 \\
\hline & -12.750229 & -4.009686 & -2.75394
\end{tabular} $\begin{array}{lllll}\text { H } & -12.7150229 & -4.0096868 & -2.785394\end{array}$ $\begin{array}{llll}\text { C } & -8.1681042 & -2.2173157 & -3.0761063\end{array}$ $\begin{array}{llll}\text { C } & -8.6567438 & -3.5387421 & -2.9751098\end{array}$ $\begin{array}{llll}\text { C } & -7.7410329 & -4.6056768 & -2.802123 \\ \text { C } & -6.3661931 & -4.3238183 & -2.7389856\end{array}$ $\begin{array}{llll}\text { C } & -6.3661931 & -4.3238183 & -2.7389856\end{array}$ $\begin{array}{llll}\text { C } & -5.8738771 & -3.0084081 & -2.7849090\end{array}$ $\begin{array}{lllll}\text { C } & -6.7869427 & -1.9403996 & -2.9597065\end{array}$ $\begin{array}{llll}\text { C } & -8.6199289 & 0.2299177 & -3.1017444\end{array}$ $\begin{array}{llll}\text { C } & -9.5484403 & 1.2844733 & -2.9738788\end{array}$ $\begin{array}{llll}\text { C } & -9.0756944 & 2.6073102 & -2.7784639\end{array}$ $\begin{array}{lllll}\text { C } & -7.6905833 & 2.8387766 & -2.7234336\end{array}$ $\begin{array}{llll}\text { C } & -6.7617751 & 1.7886808 & -2.7887609\end{array}$ $\begin{array}{llll}C & -7.2330728 & 0.4636291 & -2.9725504\end{array}$ \begin{tabular}{cccc}
$\mathrm{C}$ & -7.2330728 & 0.4636291 & -2.9725504 \\
$\mathrm{~N}$ & -6.3635829 & -0.6183029 & -3.0435125 \\
\hline
\end{tabular} $\begin{array}{llll}\mathrm{H} & -11.5603880 & 1.7543606 & -2.8610656\end{array}$ \begin{tabular}{llll}
$\mathrm{H}$ & -11.5603880 & 1.7543606 & -2.861065 \\
\hline & -10.3681935 & -4.6987959 & -2.9121079
\end{tabular} \begin{tabular}{llll}
$H$ & -1.5683835 & -4.6987959 & -2.9121079 \\
\hline & -8.1027276 & -5.6427018 & -2.7435277
\end{tabular} $\begin{array}{llll}4 & -8.36827276 & -5.6427018 & -2.9121079527\end{array}$ $\begin{array}{lllll}H & -5.6556956 & -5.1556022 & -2.620665 \\ H & -4.7946125 & -28078272 & -2.7209936\end{array}$ \begin{tabular}{llll}
$H$ & -5.6556956 & -5.1556022 & -2.6206651 \\
\hline & -9.7853610 & -2.8078272 & -2.7209936
\end{tabular} \begin{tabular}{llll}
$H$ & -9.7853610 & 3.4430854 & -2.6910531 \\
\hline
\end{tabular} \begin{tabular}{llll}
4 & -7.3263354 & 3.8675160 & -2.5840966 \\
\hline & -5.6816150 & 1.9841302 & -2.7145701
\end{tabular} $\begin{array}{llll}\mathrm{H} & -5.6816150 & 1.9841302 & -2.7145701 \\ \mathrm{H} & -5.3644094 & -0.4312427 & -2.9248323\end{array}$ $\begin{array}{llll}\text { C }-8.9024346 & -1.4338975 & -5.0618801\end{array}$ $\begin{array}{llll}\text { C } & -8.9024346 & -1.1538975 & -5.0618801 \\ \text { C } & -8.3698182 & -1.1971330 & -6.1704635\end{array}$ 